\title{
A Model of China's State Capitalism*
}

\author{
Xi Li Xuewen Liu Yong Wang \\ The Hong Kong University of Science and Technology
}

This version: October 2012

\begin{abstract}
This paper documents a hallmark feature of China's state capitalism as the state controlling the economy in a vertical structure: State-owned enterprises (SOEs) monopolize key industries in the upstream, whereas the downstream industries are largely open to private competition. We develop a general-equilibrium model to show that this unique vertical structure, when combined with openness and labor abundance, is critical in explaining the puzzling fact that China's SOEs outperformed non-SOEs in the past decade while the opposite was true in the 1990s. We show how the upstream SOEs extract rents from the liberalized downstream industries in the process of industrialization and globalization. The unprecendented prosperity of SOEs is shown to be an efficiency-undermining symptom of the incompleteness of market-oriented reforms rather than a proof of SOE superiority. Emergence, sustainability, redistributive effects, and general implications for other countries of this state capitalism are also discussed.
\end{abstract}

Key Words: State Capitalism; China Economy; Partial Reforms; Growth and Development; Structural Change; Labor Income Share; International Trade

JEL Classifications: F63, L16; O14, O53, P23, P31

${ }^{*}$ The paper was presented at Chinese University of Hong Kong, Hong Kong University of Science and Technology, Dallas Fed-SHUFE Conference on International Linkages in a Globalized World, China Economics Summer Institute, and the CCES-SSEM Conference on Institutions, International Trade and Economic Growth. For helpful discussions and comments, we are grateful to Kalok Chan, Sudipto Dasgupta, Steve Davis, Alan Deardorff, Gino Gancia, ChangTai Hsieh, Jennifer Huang, Chad Jones, Tim Kehoe, Joe Kaboski, Justin Yifu Lin, Norman Loayza, Rachel Ngai, Albert Park, Diego Restuccia, Gerard Roland, Kim Ruhl, Katy Russ, Michael Song, Jian Wang, Shang-Jin Wei, Laura Wu, Danyang Xie, Colin Xu, Dennis Yang, Yang Yao, and Xiaodong Zhu. We thank Chong-En Bai for sharing the data with us. We thank Daravadee Panichakarn, Chenlai Shi, Zhiyang Li, and Yiou Zhang for research assistance. Emails: acli@ust.hk; xuewenliu@ust.hk; yongwang@ust.hk. 


\section{Introduction}

Major emerging economies (especially BRIC) all practice some forms of state capitalism, which generally refers to the state controlling an important share of the economy while the private sector largely operates in the free market. ${ }^{1}$ The case in point is China. The market-oriented reform toward a so-called "Socialist Market Economy with Chinese Characteristics" leads to a rapid expansion of the private sector while state-owned enterprises (SOEs hereafter) as a whole are still an important part of the economy. ${ }^{2}$ In fact, SOEs are the main focus of the analysis of China's state capitalism in a recent influential report by the US-China Economic and Security Review Commission under the US Congress (Szamosszegi and Kyle (2011)).

With the backdrop of the economic success of BRIC (especially China) contrasted by the recent deep recession in the developed world, some have touted state capitalism as a legitimate alternative growth model (see, e.g., the special issue on "state capitalism" in the Economist of Jan 21st, 2012.). ${ }^{3}$ In China for instance, from 2001 to 2011, the total GDP rose from world number six to number two with an annual growth rate close to $10 \%$ on average. Most strikingly, SOEs seem to outperform non-SOEs in the last decade. Figure 1 plots the ratio of profit to sales revenue of SOEs versus non-SOEs between 1993 and 2010, together with the export as percentage of GDP.

\section{Insert Figure 1 Here}

The profitability of SOEs has surpassed that of non-SOEs in the last decade while the opposite was true in the 1990s, even though China has recorded stably high GDP growth rates during the whole period. Interestingly, the profitability of SOEs has been co-moving with the export GDP ratio, especially after China entered WTO in 2001, although SOEs' share of export has been decreasing and becoming relatively small (see Table 1). As further corroboration, Figures 2a and

\footnotetext{
${ }^{1}$ The term "state capitalism" has various meanings, but it is usually characterized by the dominance or existence of a significant number of state-owned business enterprises (see, e.g., Binns (1986), Bremmer (2010)).

${ }^{2}$ According to the National Bureau of Statistics (NBS) of China, the SOEs still account for about $40 \%$ of total fixed investments (see Lin, Cai and Li (1999), Naughton (2007)). Note that NBS changes the definition of the state enterprises over time, with some years reporting on state owned enterprises (SOEs) and the other years reporting on state owned and holding enterprises (SOEs and SHEs). SOEs are wholly state-owned firms and SHEs are firms whose majority shares belong to the government or other SOEs. We call all these state enterprises SOEs and the remaining enterprises non-SOEs throughout the paper.

${ }^{3}$ Most developed economies such as the US and many European countries are generally believed to have adopted liberal capitalism, which features absolute dominance of the private enterprise system and a weaker role for the state. In particular, the share of SOEs in liberal capitalism is typically insignificant.
} 
$2 \mathrm{~b}$ present two alternative measures of profitability, namely, the total profit of industrial enterprises scaled by the number of enterprises and by employees, respectively. Again, the profitability of SOEs far outstrips that of non-SOEs in the last decade. In fact, almost all of the 57 Chinese firms on the list of the Fortune Global 500 in 2011 are SOEs (see Table 2).

\section{Insert Figures 2a and 2b Here}

This recent phenomenon may appear puzzling because it seems to contradict the common notion that enhanced competition due to market-oriented reforms (including trade liberalization) would hurt less efficient firms (SOEs). ${ }^{4}$ It also seems at odds with the literature of structural change and resource misallocation, which predicts the incompatibility of fast aggregate growth with less productive firms (SOEs) persistently outperforming more productive ones (private firms). ${ }^{5}$ The main purpose of this paper is to explain this puzzling fact by providing a theory of China's state capitalism, which has important policy implications. ${ }^{6}$

Our theory is based on a crucial feature of China's state capitalism that emerged around 2001. SOEs have monopolized most of the upstream industries (and have also continuously consolidated this power through government-arranged mergers), while the downstream industries are liberalized and mostly open to intensive competition. In other words, the upstream is controlled by the state, whereas the downstream operates under capitalism. For example, the manufacturing sector, one of the downstream industries and also the main source of commodity trade, has in the last decade already become one of the most liberalized sectors with the lowest shares of state investment. In stark contrast, upstream industries such as petroleum and natural gases, electricity and power, banks, transport, storage and post, and information transmission are still highly monopolized by SOEs, which charge a price markup. ${ }^{7}$ This important "vertical structure" seems to have received

\footnotetext{
${ }^{4}$ There exists abundant empirical evidence that productivities and investment efficiency of SOEs are lower than that of non-SOEs; see e.g., Sun and Tong (2003) and Dollar and Wei (2007), Liu and Siu (2011), Brandt, Hsieh, and Zhu (2008), and Cao and Liu (2011). So it is unlikely that superior profitability of SOEs mainly results from higher TFPs of SOEs than non-SOEs. Empirically, it is challenging to accurately differentiate TFPs from monopoly markup. Notice that TFP calculation in standard growth accounting assumes perfect competition. We will propose an explanation without assuming TFP dominance of SOEs over non-SOEs.

${ }^{5}$ See, e.g., Kangsmnut, Rebelo and Xie (2001), Ngai and Pissaridies (2007), Restuccia, Yang, and Zhu (2008), Hsieh and Klenow (2009) and Song, Storesletten and Zilibotti (2011).

${ }^{6}$ In a comprehensive report by the World Bank (2012), further reform of monopolist SOEs is regarded as a top priority. But defenders for SOEs disagree and claim that SOEs are significantly contributing to China's high growth and hence need more support rather than significant reform. See, e.g., various articles on the official website of the State-Owned Assets Supervision and Administration Commission (SASAC hereafter) of the State Council in China.

${ }^{7}$ There exist numerous anecdotal evidences for markup pricing. For instance, in 2011, the monthly service fee
} 
insufficient attention in the literature, and will be documented in detail in Section 2.

Our core argument is as follows: By 2001 or so, low-productivity SOEs have already exited from most downstream industries while the upstream industries are still monopolized by SOEs. The enhanced trade liberalization (especially the accession to WTO in December 2001) results in a rapid expansion of the non-SOEs in the capitalist downstream industries, which in turn leads to more demand for the intermediate goods, factors, and services that are monopolized by the SOEs in those upstream industries. As a consequence, the upstream SOEs flourish disproportionately more than the non-SOEs in the competitive downstream. In addition, the SOEs' profitability closely co-moves with the export GDP ratio even though SOEs' share of export is relatively small and decreasing over time.

Notice that, besides the vertical structure, trade openness and labor abundance are the two other important ingredients of our theory. Without the enlarged external demand due to international trade, downstream non-SOEs would not expand that much, and hence upstream SOEs would not be able to make outsized profit. On the other hand, without abundant labor, wages would rise immediately after the expansion of the downstream industries. Then there would be less room for the monopoly pricing on the intermediate goods charged by upstream SOEs, as international trade imposes a price ceiling on the downstream goods, and thus the upstream SOEs would not be able to maintain persistent and high profitability.

Although the analytical focus of this paper is on the post-2001 period, our framework can also explain why the fortune of SOEs was the opposite during the 1992-2001 period (see Section 5). The initial deregulation reform and trade liberalization in downstream industries in the 1990s led to the entry and expansion of high-productivity non-SOEs, which beat the SOEs in the same industries. Therefore, many SOEs suffered severe losses and gradually exited from downstream industries, which were eventually dominated by the competitive non-SOEs. The aggregate economy grew fast as a result of this improved resource reallocation, and non-SOEs outperformed SOEs as a whole until unprofitable SOEs largely exited from the downstream industries, as reflected in Figure 1. However, once the vertical structure came into its full shape around 2001, the remaining SOEs,

charged by China Mobile for the 20M broadband was 188 Chinese Yuan, while Orange UK only charged 50 Chinese Yuan (excluding line rental). The retail price for 93\# gasoline was 8.33 Yuan per liter in Beijing while the average price in US was 6.52 Yuan per liter in the same year (source: http://cnpolitics.org/2012/04/state-owned-enterprise). The Herfindahl-Hirschman index for market concentration will be provided in Section 2. See Szamosszegi and Kyle (2011) for more comprehensive evidences for SOE monopoly in upstream industries. 
which mainly stayed in the upstream industries, started to outperform non-SOEs as they benefitted from the expansion of downstream industries. SOEs as a whole have changed from being the victims to being the beneficiaries of the market-oriented reform and trade liberalization. Such a reversal of fortune for SOEs crucially depends on the emergence of the vertical structure, without which SOEs would always get hurt whenever non-SOEs expand because of the competition effect, no matter whether they compete in the same industry or in horizontally substituting industries.

Our model of state capitalism also has important distributive implications on factor returns. Figure 3 shows that the share of labor income in China's total GDP has been persistently declining since 1990. It took a dive around 2001, when China joined WTO. This pattern is first systematically documented by Bai and Qian (2009). It contradicts the common belief that this share should be roughly constant, known as one of the Kaldor facts in standard neoclassical growth theory (see, e.g., Acemoglu (2008)). It seems also at odds with the standard Heckerscher-Ohlin trade theory (Feenstra (2004)), which implies that labor income share in GDP should increase after trade liberalization because the price of labor, as the abundant factor, should increase relative to the scarce factor (capital). Why, in a labor-abundant country like China, does the labor income share plunge while the export accelerates after entering the WTO? Besides, the level of this share is also very low by international standards (around $40 \%$ for China and more than $60 \%$ in most other economies).

\section{Insert Figure 3 Here}

This puzzle can be resolved within our framework. One key element of our model is the "excessive" labor supply in the spirit of Lewis (1954). Here the large labor pool in the non-industrial sector ensures the low and constant wage during industrialization, which in turn yields the declining labor income share as GDP increases. Trade liberalization boosts industrialization and GDP growth, and, therefore, lowers the labor income share even further. This is consistent with Figure 3. The major reforms in the industrial sectors and urban areas started after Deng Xiaoping's South Tour in 1992, so the labor income share began to decline with industrialization. This share plunged around 2001 because external demand increased sharply as China entered WTO that year.

Our general-equilibrium benchmark model studies two cases. We start with the case of autarky, which highlights the mechanism through which the SOE in the upstream industry extracts monopoly rents from the non-SOEs in the competitive downstream industries in the industrial- 
ization process. We analytically characterize the profit of the upstream SOE, labor income share in total GDP, aggregate GDP, and their relations to the industrialization. We show how labor abundance enables the SOE to earn a high monopoly rent by keeping wage constantly low as the economy industrializes. The economic distortion caused by the upstream monopoly is demonstrated by comparing this equilibrium with the socially optimal allocation when the upstream monopoly is eliminated.

Then we consider the case with free trade between two large countries. We illustrate how international trade boosts the aggregate demand for the downstream good (such as manufacturing consumption good), which in turn leads to a higher profit of the SOE in the upstream industry of the home country. The comparative advantage of the export sector largely relies on labor abundance, which creates room for the monopoly markup charged by the upstream SOE. As the wage remains constant after trade liberalization while GDP becomes larger, the labor income share in GDP becomes smaller than that in autarky. The key mechanism we highlight here is how international trade facilitates the upstream SOE to extract more rents from the downstream non-SOEs.

We extend the benchmark model to discuss the sustainability (future) and the emergence (past) of China's state capitalism. For sustainability, we show that, when domestic wage starts to rise endogenously after sufficient industrialization, China's downstream private industries would eventually be strangled by the upstream SOE monopoly and lose international competitiveness if the upstream SOE does not sufficiently improve productivity. Also, our model implies that the profit of upstream SOE is more sensitively exposed to external demand volatility (due to the markup price effect) than that of the downstream industries, even though it is downstream industries that directly participate in trade. This is consistent with the 2007-2008 episode in Figure 1. For emergence, we show how the vertical structure (i.e., downstream capitalism plus upstream state monopoly) can be rationalized as an equilibrium outcome of SOE maximizing aggregate profit.

Related literature. We believe that our paper is the first to document and theorize the vertical economic structure featured in China's state capitalism. Our work contributes to several strands of literature in growth and development as well as institutional reforms.

First, our paper sheds new light on structural change (industrialization), both in the closed economy and in a globalized economy (see Matsuyama (2008) and Herrendorf, Rogerson and Valentinyi (2011) for excellent surveys). ${ }^{8}$ One of our key innovations is to introduce the vertical structure into

\footnotetext{
${ }^{8}$ Brandt, Hsieh and Zhu (2010) look at China's structural transformation.
} 
the industrial sector. We show that monopoly in the upstream industries impedes industrialization (i.e., labor reallocation from agriculture to industry), even though the upstream monopolist benefits from the expansion of the downstream industries. In contrast, the standard literature treats the industrial sector either as one homogeneous industry with perfectly competitive firms or as an aggregate of horizontally differentiated sub-industries or firms, and, therefore, competition implies that a productivity increase of a firm or a sub-industry would always hurt the profitability of other firms or sub-industries (see Kangsmnut, Rebelo and Xie (2001), Ngai and Pissaridies (2007), Restuccia, Yang, and Zhu (2008)). ${ }^{9}$ This prediction is inconsistent with China's industrialization experience in the last decade, because the profitability of SOEs has increased relative to non-SOEs even though trade is more liberalized and downstream industries become increasingly competitive. We also show how international trade (and export-promoting policies) facilitates industrialization and, conversely, how industrialization (and pro-industrialization policies such as relaxing restrictions on labor migration) also propels international trade and boosts GDP. ${ }^{10}$

Second, our model contributes to the literature of economic transition and institutional reforms, especially in the context of Chinese economic development (see Roland (2000), Naughton (2007)). While Lau, Qian, and Roland (2000) emphasize how the gradual dual-track reform in China was successful as a Pareto-improving process, Murphy, Shleifer and Vishny (1992) and Young (2000) emphasize more the economic distortions created in this process (see also Bruno (1972), Shleifer and Vishny (1994), and Bai et al. (2004)). We document and theorize a new aspect of incompleteness and gradualism in China's economic reform: the downstream (and typically tradable) industry has been already liberalized but the upstream (and often non-tradable) industry remains monopolized by SOEs. We show how the emergence of this vertical structure, together with trade liberalization, has led to a reversal of fortune for SOEs in the last two decades. We emphasize that the unprecedented prosperity of SOEs may in fact be an undesirable symptom of the gradualism and incompleteness of reform, which can eventually undermine the growth sustainability. It is the downstream capitalist industries, which are liberalized and expand along with industrialization and globalization, that are the true driving force for China's economic growth. ${ }^{11}$

Third, our paper provides the first theoretical model with explicit international trade and

\footnotetext{
${ }^{9}$ Also see Acemoglu and Guerierri (2008), Buera and Kaboski (2012), etc.

${ }^{10}$ See Matsuyama (2009), Yi and Zhang (2010), McMillan and Rodrik (2011) for open-economy settings. Yi (2003) highlights the role of vertical specialization in international trade, but it is not related to the structural change.

${ }^{11}$ Allen, Qian and Qian (2005) find that the private sector in China grew much faster than other sectors and contributed to most of the economy's growth.
} 
structural change that explains the puzzling fact of the declining labor income share in China. ${ }^{12}$ By explicitly introducing the dual economy feature with abundant labor (see Lewis (1954), Dooley, Folkerts-Landau, and Garber (2007), and Vollrath (2009)), our model explains why the labor income share in GDP declines at the early stage of industrialization, deviating from the prediction of standard neoclassical growth models (Acemoglu (2008)). In our model, the decline in labor income share is mainly due to the structural change that reallocates labor from the labor-intensive non-industrial sector to the more capital-intensive industrial sector, which is proven quantitatively important by Bai and Qian (2010). Moreover, we show how international trade may reduce the labor income share even further in a labor-abundant country, contrary to the prediction of standard trade theory (see Ventura (1997), Feenstra (2004), Burstein and Vogel (2011)). This is mainly because the large population in the agriculture sector sustains the wage rate at a constant low level before all those workers are absorbed by the industrial sector, while at the same time the GDP becomes even larger thanks to trade-induced industrialization. However, our model predicts that the wage rate and the labor income share will start to increase when all the rural labor has been absorbed into the industrial sector.

Finally, our paper contributes to the literature of China's SOE reforms. Almost all the early literature focuses on how SOEs improved their governance structure and productivity or how they gradually exited from the downstream sectors in the 1990s (see, e.g., Groves, Hong, McMillan, and Naughton (1994), Qian (1996), Li (1997), Lin, Cai and Li (1998)). Even the most recent literature has largely ignored the vertical structure featured in China's economy (see, e.g., Hsieh and Klenow (2009), Song et al. (2011), and Cao and Liu (2011)). ${ }^{13}$ Our paper emphasizes the vertical and complementary interaction between firms located in the upstream and downstream industries, in which productivity increase in the downstream private firms would benefit rather than hurt the profitability of upstream SOE. In addition, the source of distortion in our paper is different. The existing literature, including Dollar and Wei (2007) and Brandt, Tombe and Zhu (2010), emphasizes factor market distortions (especially capital allocation efficiency), whereas our paper differs from and complements theirs by highlighting the SOE monopoly in the product markets (of upstream

\footnotetext{
${ }^{12}$ Harrison (2002) and Jaumotte and Tytell (2007), Karabarbounis and Neiman (2012) show that this phenomenon also exists in many other countries.

${ }^{13}$ This literature focuses on resource misallocation between horizontally competing firms, SOEs versus non-SOEs, within the (downstream) manufacturing sector; therefore, low-productivity SOEs must lose profit or even have to exit without government subsidy, a story generally consistent with our discussion of the process by which the vertical structure gradually emerged (see Section 5).
} 
industries). We show in general equilibrium that the product market monopoly also indirectly distorts the prices and allocations of production factors even when the factor markets themselves are perfect. Yet another distinctive feature of our paper is that we address these issues in the explicit context of structural change and globalization.

The paper is structured as follows. Section 2 documents the hallmark feature of the vertical structure in China's state capitalism and the institutional background. Section 3 presents the benchmark model. Section 4 and Section 5 study the sustainability and emergence of China's state capitalism, respectively. Section 6 briefly discusses several other relevant issues such as alternative market structures, implications for income distribution, labor market integration, subsidies and taxes, and causes of monopoly. Section 7 explicitly illustrates how this model of China's state capitalism can be useful in helping us think about similar and related issues for other countries. The last section concludes.

\section{Institutional Background and Stylized Facts}

This section first briefly documents the relevant history of China's SOE reforms in the past three decades and highlights the institutional background on how the vertical structure of China's state capitalism came into existence. It then provides detailed quantitative facts about this vertical structure.

\subsection{A Brief History of China's SOE Reforms}

After China's historical decision on "reform and opening up" in 1978, the central government has taken a gradual, experimental, and pragmatic approach of "crossing the river by touching stones" to reform SOEs (see, e.g., Qian (1996), Lin, Cai and Zhou (1999), Sachs and Woo (2000), and Xu (2011)). The central government has been trying to improve SOE performance while maintaining state ownership and control over a large swath of the economy. ${ }^{14}$

Until 1978, virtually all firms were SOEs in both upstream and downstream industries. Inspired

\footnotetext{
${ }^{14}$ Deng Xiaoping proclaimed that "As long as we keep ourselves sober-minded, there is nothing to be feared. We still hold superiority, because we have large and medium state-owned enterprises and township and village enterprises. More importantly, we hold the state power in our hands". In 1995, CCP General Secretary Jiang Zemin argued that the dominant public ownership in the Chinese economy means that the state should concentrate on public entities' control of economic assets and SOEs' leading role in key economic sectors and in the orientation of economic development (see China Daily, March 7, 2000).
} 
by the success of the household responsibility system in the rural reforms in the early 1980s, the central government first focused on increasing enterprise autonomy through a system that requires managers to meet performance targets in return for retained profit. This system initially improved SOEs' performance (see, e.g., Groves et al. (1994), Li (1997)). However, it quickly ran into trouble because managers were rewarded for success but not punished for failure and were able to exploit their effective control over SOE assets at the expense of the state (e.g., Naughton (2007)). Although other types of contracts were tried, SOEs stacked up huge losses, especially because of the increasing competition from non-SOEs, which were mainly foreign enterprises and township and village enterprises (see, e.g., Li, Li, Zhang (2000)). During the 1978-1993 period, the share of SOEs' net industrial output decreased from more than $80 \%$ to about $65 \%$, even though this period witnessed virtually no closing of any SOEs. Table 3 shows a steady rise in the financial loss and leverage of SOEs, along with a steady drop in the economic significance of SOEs. About $40 \%$ of SOEs were loss-makers in 1994 and their debt to equity ratio increased to 200\%. These developments put substantial pressure on government revenue, fiscal burden, and banking stability.

After the historical Southern tour of Deng Xiaoping in 1992, China started the second stage of its SOE reforms. In the 14th CCP Congress in 1992 and its Third Plenum in 1993, the central government endorsed and defined the "socialist market economy" based on public ownership, not necessarily public sole proprietorships, as its goal of reform. In the 15th Party Congress in 1997 SOEs were downgraded to a "pillar of the economy", and private ownership was later incorporated into the new Chinese Constitution in 1999. The state launched a "three-year battle" to ameliorate SOEs' situation between 1998 and 2000.

Privatization of SOEs and layoffs of workers began on a large scale in 1995, when the central government formally set the policy of "nurturing the large and letting the small go" (or zhuada fangxiao). The central government explicitly pursued the strategy of retaining state control of 500-1,000 large SOEs in the strategic sectors and granting them government monopoly, and meanwhile disposing of small and medium-sized SOEs, which were typically located in labor-intensive competitive industries such as textiles, food processing, and electronics (see, e.g., Cao et al. (1999) and Green and Liu (2005)). ${ }^{15}$ Note that the 500 largest SOEs held $37 \%$ of the state's industrial

\footnotetext{
${ }^{15}$ Vice-Premier Wu Bangguo said in 1997 that "Control of the [500] largest firms means we have a control of the largest chunk of the state economy." The 10th Five-Year Plan for National Economic and Social Development (for the 2001-2005 period) called for the government to "hold a controlling stake in strategic enterprises that concern the national economy" and also to "uphold the dominance of the public sector of the economy [and] let the state-
} 
assets, contributed $46 \%$ of all the tax revenues from SOEs, and totaled $63 \%$ of SOEs' profits at the end of 1997. In comparison, small SOEs, generally controlled by local governments, were performing poorly, especially in the aftermath of enormous entry of non-SOEs into the liberalized industries. For example, $72.5 \%$ of local SOEs were unprofitable, whereas $24.3 \%$ of central SOEs were unprofitable in 1995 (see Szamosszegi and Kyle (2011) and World Bank (2012)).

Throughout and after this round of SOE reform, central SOEs consolidated their monopoly position in the upstream industries and reinforced their advantageous position even further through reorganizations such as mergers and groupings. Since the upstream industries are generally in nontradable sectors, central SOEs are more shielded from intensified competition after the WTO entry. By contrast, although the WTO membership led to further expansion of the non-SOEs as a whole in tradable sectors, the non-SOEs nevertheless faced more fierce competitions in the largely liberalized downstream industries. Overall, the monopoly position of SOEs in the upstream is protected and strengthened while the downstream becomes more competitive. ${ }^{16}$

\subsection{Stylized Facts}

This subsection first provides some further evidence on firm profitability of SOEs versus non-SOEs since 1993. It then provides detailed evidence on the development of the vertical structure of China's state capitalism in the last two decades.

Complementing Figures 1 and 2, Figure 4 examines firm profitability from yet another angle. The left two panels show that SOEs' presence in the low and medium profit margin sub-industries in the industrial sector has declined drastically, especially around 2003, whereas the right panel shows that SOEs' presence in the high profit margin sub-industries kept stable at a high level.

Figures 5-6 and Table 2 document the vertical structure. Figure 5 presents SOEs' share in domestically funded fixed asset investment across all urban sectors. ${ }^{17}$ The left part of the figure represents the upstream industries, mainly consisting of energy and other key intermediate goods and services. The middle part illustrates the downstream industries, which are mainly industries owned sector play the leading role." In 2006, SASAC designated defense, electric power and grid, petroleum and petrochemical, telecommunications, coal, civil aviation, and shipping to be strategic industries.

${ }^{16}$ For example, Dean et al. (2010) report that by 2008, total assets of SOEs in China were $\$ 6$ trillion, or $133 \%$ of Chinese GDP, whereas the corresponding numbers for France, a developed country known for its outsized state control in economy, were $\$ 686$ billion and $28 \%$, respectively. In particular, there are fewer than 200 SOEs directly under the SASAC supervision, but their assets account for $62 \%$ of GDP.

${ }^{17}$ Unfortunately, the data for value added are unavailable for urban sectors. 
directly targeting consumption goods and services. Other public sectors, especially those serving non-profit social purposes, are on the right part of the figure. The figure shows that SOEs have a high and stable presence in upstream sectors at well above $50 \%$ by 2009 , whereas their presence in downstream sectors has decreased dramatically. In particular, the manufacturing sector, which is the main source of export goods, is one of the sectors with the least state investment shares.

Figure 6 further examines SOEs' presence in different sub-industries within the industrial sector measured by value-added share from 1995 to 2007. The upstream and downstream industries are on the left and right parts of the figure, respectively. ${ }^{18}$ Figure 6 a shows the shares of SOEs, and Figure 6b shows SOEs' shares normalized by the initial levels in 1995, the starting point of our sample period, which highlights the percentage change relative to the base year. ${ }^{19}$

Figure 6a shows that SOEs continue to dominate the upstream industrial sub-industries but have retreated dramatically from the downstream sub-industries. ${ }^{20}$ This pattern is even more pronounced in Figure $6 \mathrm{~b}$ when we adjust for the lower level of initial presence of SOEs in the downstream sub-industries. The exit of SOEs from the downstream sub-industries seemed to accelerate in the late 1990s, consistent with the aforementioned time line of China's SOE reform and the approach of "nurturing the large and letting the small go." 21

To further examine the vertical structure, Table 2 reports the names, rank, revenues, the headquarter city, and the affiliated industry of the 57 Chinese firms on the list of the Fortune Global 500 in 2011. Three of the largest ten Fortune Global 500 are from China. Interestingly, almost all the Chinese firms on the list are SOEs. Furthermore, these largest Chinese firms are mostly from upstream industries such as power generation, oil and energy, materials, and telecommunications.

\footnotetext{
${ }^{18}$ We corroborate the classifications of upstream and downstream using China's input and output tables reported about every five years from the early 1990s. The results are qualitatively the same across the years (see Antras et al. (2011)).

${ }^{19}$ When decomposing firms in the industrial sector into upstream SOEs, upstream non-SOEs, downstream SOEs and downstream non-SOEs, we find that in the last two decades the average profit sales ratio of upstream SOEs is always higher than that of downstream non-SOEs, which is in turn higher than that of downstream SOEs. We also find that profit margins of upstream SOEs increased sharply in the late 1990s but plunged after 2007, while profit margins of downstream non-SOEs also increased over time but with a much flatter slope. As will be clear later, all these features are consistent with our story.

${ }^{20}$ Using the same dataset, we find that, during the past decade, both the mean and medium values of the HerfindahlHirschman Indices (in terms of profit) across all the upstream indutries have been always above $20 \%$ and always more than ten times higher than the downstream counterpart in the same year, implying a persistently high market concentration (monoply market structure) in the upstream industries and competitive market structures in the downstream industries.

${ }^{21}$ We also investigate SOEs' share in the upstream, downstream, and other subsectors within the industrial sector in terms of revenue, taxes and other charges, total assets, and gross output. These are all the other variables available for the industrial sector. We find patterns similar to Figure 6 .
} 
In fact, these few industries represent 29 of the 47 non-financial firms on the list. All these facts point to the salient feature of the vertical structure with SOEs dominating upstream industries in China's economy. However, this vertical structure is not observed in countries with "liberal capitalism". For example, among the Fortune Global 500 in 2011, far fewer French and American firms are state-owned or in the upstream industries.

\section{Benchmark Model}

In this section, we first study the autarky, which features the "vertical structure" of China's state capitalism. Then we extend it to an open economy to highlight the role of international trade. Labor abundance plays a crucial role in both cases.

\subsection{Autarky}

\subsubsection{Model Environment}

Consider a closed economy $\mathrm{H}$, which is populated by a continuum of agents with measure equal to unity. Agents can be divided into two groups: an elite class with measure equal to $\theta \in(0,1)$ and the grass roots with measure $1-\theta$. Agents are identical within each group.

Preference All the agents have the same utility function

$$
u(c)=c_{n}+\frac{\epsilon}{\epsilon-1} c_{d}^{\frac{\epsilon-1}{\epsilon}}, \epsilon>1
$$

where $c$ is a consumption vector composed of consumption of numeraire good $n$ (denoted by $c_{n}$ ) and a composite consumption good $d$ (denoted by $c_{d}$ ). The parameter $\epsilon$ measures the price elasticity of demand for good $d$. We assume that $u(c)=-\infty$ if $c_{n}<0$, so $c_{n}$ has to be non-negative in equilibrium. In reality, good $d$ can be thought of as an aggregate of the consumption goods produced in the industrial sector while the numeraire good may represent a composite of agriculture goods.

Technologies All the technologies are constant returns to scales. One unit of labor produces one unit of numeraire good $n$. Producing good $d$ requires capital $k$, labor $l$, and intermediate good $m$. The production function is:

$$
F_{d}(k, l, m)=A k^{\alpha} l^{\beta} m^{1-\alpha-\beta},
$$


where $\alpha>0, \beta>0, \alpha+\beta<1$.

The intermediate good $m$ is produced with the following technology

$$
F_{m}(k, l)=A_{m} k^{\gamma} l^{1-\gamma}
$$

where $\gamma \in(0,1)$.

Endowment and Market Structure Each agent, elite or grass root, is endowed with $L$ units of time (labor) and $K$ units of capital. The intermediate good is produced by a monopolist firm, which is owned by the "state" but fully controlled by the elite class as if the elite class owns it. The numeraire good and good $d$ are produced by competitive private firms, which are owned by the grass root. ${ }^{22}$ Only the intermediate good market is a monopoly, whereas all the other markets (goods markets and factor markets) are perfectly competitive with free entry.

Vertical Structure The firm that produces the intermediate good is in the upstream, while all the firms producing good $d$ are in the downstream. So good $d$ is also referred as the "downstream good". From the ownership point of view, the upstream firm is an SOE while all the downstream firms are privately-owned enterprises (POEs hereafter). This feature of ownership distribution is referred as the "vertical structure" in this paper, and it is to capture the main feature of China's reality in the last decade. As documented in Section 2, the downstream industries in China have been dominated by competitive private firms since the massive privatization of SOEs in the late 1990s. However, SOEs have still monopolized key industries in the upstream.

In summary, the economy has two main sectors: an agricultural sector producing the numeraire good $n$ and an industrial sector. Within the industrial sector, there is a vertical structure with the upstream industry producing intermediate good $m$ and the downstream industry producing industrial consumption good $d$.

\subsubsection{Characterizing Equilibrium}

Let $W$ and $R$ denote the wage and the rental price of capital, respectively. Let $p_{n}, p_{d}$, and $p_{m}$ denote the prices of numeraire good $n$, downstream good $d$, and intermediate good $m$, respectively.

Consumer Problem Let $I_{e}$ and $I_{g}$ denote the total income of a representative agent in

\footnotetext{
${ }^{22}$ The composite good $d$ can be decomposed into a continuum of differentiated goods. Such a decomposition becomes useful or even necessary when discussing the downstream reforms with private and state firms coexisting or when some downstream firms earning positive profit through monopolisitc competition (See Section 5).
} 
the elite class and in the grass root, respectively. The total income of the elite class is given by $\theta I_{e}=\theta[W L+R K]+\Pi_{m}$, where $\Pi_{m}$ is the total profit of the SOE (i.e., it produces intermediate good $m)$. The total income of the grass root is $(1-\theta) I_{g}=(1-\theta)[W L+R K]$. An agent with income $I$ maximizes the utility function (1) subject to the following budget constraint: ${ }^{23}$

$$
p_{n} c_{n}+p_{d} c_{d} \leq I,
$$

where $I \in\left\{I_{e}, I_{g}\right\}$. When $I$ is sufficiently large, the optimal consumption demand is given by

$$
c_{n}=\frac{I-p_{n}^{\epsilon} p_{d}^{1-\epsilon}}{p_{n}} ; c_{d}=\left(\frac{p_{n}}{p_{d}}\right)^{\epsilon} .
$$

Therefore, the aggregate demand is as follows:

$$
\begin{aligned}
D_{n} & =\frac{W L+R K+\Pi_{m}}{p_{n}}-\left(\frac{p_{n}}{p_{d}}\right)^{\epsilon-1} ; \\
D_{d} & =\left(\frac{p_{n}}{p_{d}}\right)^{\epsilon} .
\end{aligned}
$$

Firm Decisions Given $R, W$ and $p_{m}$, perfect competition with free entry in the downstream sector implies that the price equals the marginal cost:

$$
p_{d}=\frac{R^{\alpha} W^{\beta} p_{m}^{1-\alpha-\beta}}{A \alpha^{\alpha} \beta^{\beta}(1-\alpha-\beta)^{1-\alpha-\beta}} .
$$

By Shephard Lemma, to produce one unit of good $d$ requires $\frac{\partial p_{d}}{\partial W}$ units of labor, $\frac{\partial p_{d}}{\partial R}$ units of capital, and $\frac{\partial p_{d}}{\partial p_{m}}$ units of intermediate good. Therefore, the aggregate demand for $m$, by revoking (6) and (7), is

$$
D_{m}=D_{d} \frac{\partial p_{d}}{\partial p_{m}}=(1-\alpha-\beta) \cdot p_{n} \cdot\left[\frac{R^{\alpha} W^{\beta}}{A \alpha^{\alpha} \beta^{\beta}(1-\alpha-\beta)^{1-\alpha-\beta}}\right]^{1-\epsilon} \cdot p_{m}^{(1-\alpha-\beta)(1-\epsilon)-1} .
$$

\footnotetext{
${ }^{23}$ We keep $p_{n}$ explicitly in the formula without substituting it with unity because this numeraire good may not be produced in some rare cases, in which $p_{n}$ can be indeterminate; thus it is inappropriate to call this good $n$ numeraire good. However, for most cases, it causes no problem to replace $p_{n}$ with one. Wage may conceptually serve as a better numeraire but it would tremendously complicate the analysis.
} 
The monopolist SOE, which produces good $m$, maximizes its profit:

$$
\Pi_{m}=\max _{p_{m}} D_{m} \cdot\left[p_{m}-\frac{R^{\gamma} W^{1-\gamma}}{A_{m} \gamma^{\gamma}(1-\gamma)^{1-\gamma}}\right]
$$

where $\frac{R^{\gamma} W^{1-\gamma}}{A_{m} \gamma^{\gamma}(1-\gamma)^{1-\gamma}}$ is the unit cost of good $m$. It follows that

$$
p_{m}=\mu \frac{R^{\gamma} W^{1-\gamma}}{A_{m} \gamma^{\gamma}(1-\gamma)^{1-\gamma}}
$$

where the markup $\mu \equiv \frac{(1-\alpha-\beta)(\epsilon-1)+1}{(1-\alpha-\beta)(\epsilon-1)}>1$. Intuitively, $\mu$ is determined by the cost share of the intermediate good in the production of the downstream good $d$ (i.e., the term $(1-\alpha-\beta)$ ) and the price elasticity of demand for good $d$ (reflected by the term $\epsilon-1)$.

Market Clearing Conditions We assume that the labor endowment $L$ is sufficiently large such that $D_{n}>0$. Thus the labor market clearing condition is given by

$$
L=\underbrace{D_{m} \frac{\partial \frac{R^{\gamma} W^{1-\gamma}}{A_{m} \gamma^{\gamma}(1-\gamma)^{1-\gamma}}}{\partial W}}_{\text {by producer of intermediate good } m}+\underbrace{D_{d} \frac{\partial p_{d}}{\partial W}}_{\text {by producers of downstream good } d}+\underbrace{D_{n}}_{\text {by producers of good } n}
$$

To ensure $D_{n}>0$, we must require $L>\bar{L}$, where $\bar{L}$ is the sum of the first two terms in (11), or the total employment in the industrial sector (that is, the non-numeraire part of the economy). Substituting (6), (7), and (8) into (11) yields

$$
\begin{aligned}
\bar{L} \equiv & \frac{1}{\mu}\left\{\frac{\left[\frac{\mu}{\gamma^{\gamma}(1-\gamma)^{1-\gamma}}\right]^{1-\alpha-\beta}}{\alpha^{\alpha} \beta^{\beta}(1-\alpha-\beta)^{1-\alpha-\beta}}\right\}^{1-\epsilon}[(1-\gamma)(1-\alpha-\beta)+\beta \mu] \\
& \cdot\left[A_{m}^{(1-\alpha-\beta)} A\right]^{\epsilon-1}\left(\frac{R}{W}\right)^{-[\alpha(\epsilon-1)+\gamma(1-\alpha-\beta)(\epsilon-1)]}\left(\frac{p_{n}}{W}\right)^{\epsilon} .
\end{aligned}
$$

Whenever the numeraire good is produced in equilibrium (i.e., $L>\bar{L}$ ), wage must be equal to marginal product of labor under perfect competition:

$$
W=p_{n},
$$


which shows that wage is independent of $K, A_{m}, A$, or $L$. Capital market clears:

$$
K=\underbrace{D_{m} \frac{\partial \frac{R^{\gamma} W^{1-\gamma}}{A_{m} \gamma^{\gamma}(1-\gamma)^{1-\gamma}}}{\partial R}}_{\text {by producer of intermediate good } m}+\underbrace{D_{d} \frac{\partial p_{d}}{\partial R}}_{\text {by producers of downstream good } d}
$$

which, by revoking (6), (8) and (10), is reduced to

$$
K=\varkappa\left[A_{m}^{(1-\alpha-\beta)} A\right]^{\epsilon-1}\left(\frac{R}{W}\right)^{-[1+\alpha(\epsilon-1)+\gamma(1-\alpha-\beta)(\epsilon-1)]} \cdot\left(\frac{p_{n}}{W}\right)^{\epsilon}
$$

where

$$
\varkappa \equiv \frac{1}{\mu}\left\{\frac{\left[\frac{\mu}{\gamma^{\gamma}(1-\gamma)^{1-\gamma}}\right]^{1-\alpha-\beta}}{\alpha^{\alpha} \beta^{\beta}(1-\alpha-\beta)^{1-\alpha-\beta}}\right\}^{1-\epsilon}[\gamma(1-\alpha-\beta)+\alpha \mu] .
$$

By combining (14), (7), (10) and (13), we obtain the equilibrium prices as summarized in the following lemma.

Lemma 1 Suppose L is sufficiently large (to be strictly defined in Lemma 2). The autarky model has a unique equilibrium, in which the prices are given by

$$
\begin{aligned}
R & =p_{n} \cdot\left[A_{m}^{(1-\alpha-\beta)} A\right]^{\frac{\epsilon-1}{1+\alpha(\epsilon-1)+\gamma(1-\alpha-\beta)(\epsilon-1)}}\left(\frac{K}{\varkappa}\right)^{\frac{1+\alpha(\epsilon-1)+\gamma(1-\alpha-\beta)(\epsilon-1)}{1+\gamma}} \\
p_{m} & =p_{n} \cdot \frac{\mu}{\gamma^{\gamma}(1-\gamma)^{1-\gamma}} A_{m}^{-1}\left[A_{m}^{(1-\alpha-\beta)} A\right]^{\frac{-1}{1+\alpha(\epsilon-1)+\gamma(1-\alpha-\beta)(\epsilon-1)}}\left(\frac{K}{\varkappa}\right)^{\frac{(1+\alpha(\epsilon-1)+\gamma(1-\alpha-\beta)(\epsilon-1)}{1+(1)}} \\
p_{d} & =p_{n} \cdot\left\{\frac{\left[\frac{\mu}{\gamma^{\gamma}(1-\gamma)^{1-\gamma}}\right]^{1-\alpha-\beta}}{\alpha^{\alpha} \beta^{\beta}(1-\alpha-\beta)^{1-\alpha-\beta}}\right\}\left[A_{m}^{(1-\alpha-\beta)} A\right]^{\frac{-\gamma}{1+\alpha(\epsilon-1)+\gamma(1-\alpha-\beta)(\epsilon-1)}}\left(\frac{K}{\varkappa}\right)^{\frac{-[\alpha+\gamma(1-\alpha-\beta)]}{1+\alpha(\epsilon-1)+\gamma(1-\alpha-\beta)(\epsilon-1)}},
\end{aligned}
$$

where $\varkappa$ is defined in (15) and $W$ is given by (13).

Now we conduct comparative statics based on the above lemma.

First, (16) implies that $\frac{\partial R}{\partial K}<0, \frac{\partial R}{\partial A_{m}}>0, \frac{\partial R}{\partial A}>0, \frac{\partial R}{\partial L}=0$. A larger capital supply $K$ naturally leads to a lower rental price of capital $R$ due to the standard market mechanism. An increase in the Hicks-neutral productivity, either at the upstream $\left(A_{m}\right)$ or downstream $(A)$, leads to a larger marginal productivity of capital and hence a higher capital rental price $R$. There are two reasons that $\frac{\partial R}{\partial L}=0$. First, the quasi-linear utility function implies the absence of income effect for the 
downstream good $\left(\frac{\partial D_{d}}{\partial I}=0\right.$ according to $\left.(6)\right)$, so a larger labor income due to a higher $L$ has no income effect on the demand for the downstream good and hence no effect on the intermediate good either $\left(\frac{\partial D_{m}}{\partial I}=0\right.$ according to $\left.(8)\right)$. This, in turn, implies that $L$ has no income effect on the demand for capital. Second, wage does not change with $L$ (shown by (13)) so there exists no substitution effect on the demand for capital, either. Thus, $R$ does not change with $L$ for any given capital supply $K$.

Second, (17) implies $\frac{\partial p_{m}}{\partial K}<0, \frac{\partial p_{m}}{\partial A_{m}}<0, \frac{\partial p_{m}}{\partial A}>0, \frac{\partial p_{m}}{\partial L}=0$. When the capital stock increases, it drives down the rental price of capital while the wage does not change, and the markup $\mu$ is a constant according to (10); thus $p_{m}$ decreases. An increase in the upstream TFP drives down the factor demand for any given output, leading to a net decrease in the unit cost even though $R$ is increased; therefore, $\frac{\partial p_{m}}{\partial A_{m}}<0$ as the markup is constant. However, an increase in the downstream TFP leads to a higher equilibrium price for the intermediate good $\left(\frac{\partial p_{m}}{\partial A}>0\right)$ because of the general equilibrium effect that $R$ is driven up due to the increase in the marginal productivity of capital; observe that the wage and the markup do not change. In other words, the more productive the private firms, the higher the equilibrium price of the good produced by the SOE. This equilibrium feature results from the vertical structure. As explained earlier, when $L$ is large enough, it has no impact on the demand for the intermediate good or the unit cost of intermediate good; thus it does not affect $p_{m}$.

Third, (18) implies $\frac{\partial p_{d}}{\partial K}<0, \frac{\partial p_{d}}{\partial A_{m}}<0, \frac{\partial p_{d}}{\partial A}<0, \frac{\partial p_{d}}{\partial L}=0$. An increase in capital stock $K$ drives down $R$ and $p_{m}$, hence the unit cost of the downstream good becomes smaller $\left(\frac{\partial p_{d}}{\partial K}<0\right)$. An increase in the upstream TFP lowers $p_{m}$, which dominates the resulting increase in $R$, so $\frac{\partial p_{d}}{\partial A_{m}}<0$ as the unit cost for the downstream good decreases. The factor-saving effect due to the increase in the downstream productivity dominates the resulting increase in both the rental price of capital and the intermediate good price; consequently we obtain $\frac{\partial p_{d}}{\partial A}<0$. Labor endowment does not affect any input prices, so $\frac{\partial p_{d}}{\partial L}=0$.

Next, we characterize several key quantities and values in the equilibrium.

Applying Lemma 1 to (12), we obtain the total employment in the industrial sector as

$\bar{L}\left(A, A_{m}, K\right) \equiv \varkappa \frac{(1-\gamma)(1-\alpha-\beta)+\beta \mu}{\gamma(1-\alpha-\beta)+\alpha \mu}\left[A_{m}^{(1-\alpha-\beta)} A\right]^{\frac{\epsilon-1}{1+\alpha(\epsilon-1)+\gamma(1-\alpha-\beta)(\epsilon-1)}}\left(\frac{K}{\varkappa}\right)^{\frac{\alpha(\epsilon-1)+\gamma(1-\alpha-\beta)(\epsilon-1)}{1+\alpha(\epsilon-1)+\gamma(1-\alpha-\beta)(\epsilon-1)}}$.

This implies that an increase in productivity, $A$ or $A_{m}$, will lead to more industrial employment, or 
more industrialization. This structural change (labor reallocation) also occurs when capital stock $K$ increases $\left(\frac{\partial \bar{L}\left(A, A_{m}, K\right)}{\partial K}>0\right)$, as it tends to increase the marginal product of labor in the industrial sector.

When $L>\bar{L}\left(A, A_{m}, K\right)$ holds, the elite class consumes a positive amount of the numeraire good, but a stronger condition is required to ensure that the grass root class also consumes a positive amount of the numeraire good, considering $I_{e}>I_{g}$. In fact, $D_{n}$ is given by (5) only when the grass root class also consumes numeraire good, that is, $I_{g}>p_{n}^{\epsilon} p_{d}^{1-\epsilon}$, which requires (by applying Lemma 1) that $L>\frac{\mu-\gamma(1-\alpha-\beta)-\alpha \mu}{(1-\gamma)(1-\alpha-\beta)+\beta \mu} \bar{L}\left(A, A_{m}, K\right)$. Observe that $\frac{\mu-\gamma(1-\alpha-\beta)-\alpha \mu}{(1-\gamma)(1-\alpha-\beta)+\beta \mu}>1$.

The following lemma characterizes several key macroeconomic variables in the equilibrium.

Lemma 2 Suppose $L>\frac{\mu-\gamma(1-\alpha-\beta)-\alpha \mu}{(1-\gamma)(1-\alpha-\beta)+\beta \mu} \bar{L}\left(A, A_{m}, K\right)$. In the autarky equilibrium, the profit of the upstream SOE $\Pi_{m}$, the total GDP (per capita) $Y$, and the labor income share in total GDP (denoted by $\theta_{L}$ ) are given by

$$
\begin{aligned}
\Pi_{m} & =\frac{(1-\alpha-\beta)(\mu-1)}{(1-\gamma)(1-\alpha-\beta)+\beta \mu} \bar{L}\left(A, A_{m}, K\right) p_{n}, \\
Y & =W L+R K+\Pi_{m}=\left[L+\frac{\alpha \mu+(1-\alpha-\beta)(\gamma+\mu-1)}{(1-\gamma)(1-\alpha-\beta)+\beta \mu} \bar{L}\left(A, A_{m}, K\right)\right] p_{n}, \\
\theta_{L} & =\frac{W L}{W L+R K+\Pi_{m}}=\frac{L}{L+\frac{\alpha \mu+(1-\alpha-\beta)(\gamma+\mu-1)}{(1-\gamma)(1-\alpha-\beta)+\beta \mu}\left(A, A_{m}, K\right)},
\end{aligned}
$$

where $\bar{L}\left(A, A_{m}, K\right)$ is given by (19).

(20) implies that the upstream SOE profit is proportional to the total employment in the industrial sector $\bar{L}\left(A, A_{m}, K\right)$, reflecting the fact that the upstream extracts more rent as industrialization deepens. (21) indicates that an increase in total GDP is equivalent to an increase in the total industrial employment, revealing that structural change drives up the total output. Also, (21) and (19) imply that the aggregate output is of decreasing returns to scale in the factor inputs, although all the technologies are homogeneous of degree one with respect to labor and capital. This is because the monopoly of the upstream SOE enables it to "steal away" part of the total output by indirectly depressing the rental price of capital in the general equilibrium, even though the capital market itself is perfect. (22) shows that industrialization (an increase in $\bar{L}\left(A, A_{m}, K\right)$ ) lowers the labor income share in total GDP, when labor is sufficiently abundant. 
To highlight the determinants of the upstream SOE profit and the labor income share, we have the following proposition.

Proposition 1 Suppose $L>\frac{\mu-\gamma(1-\alpha-\beta)-\alpha \mu}{(1-\gamma)(1-\alpha-\beta)+\beta \mu} \bar{L}\left(A, A_{m}, K\right)$. In the autarky equilibrium, an increase in the productivity in either the upstream industry or the downstream industry, or an increase in the total capital stock, will raise the monopoly profit of the upstream SOE and decrease the labor income share in GDP (that is, $\frac{\partial \Pi_{m}}{\partial A}>0, \frac{\partial \Pi_{m}}{\partial A_{m}}>0, \frac{\partial \Pi_{m}}{\partial K}>0 ; \frac{\partial \theta_{L}}{\partial A}<0, \frac{\partial \theta_{L}}{\partial A_{m}}<0, \frac{\partial \theta_{L}}{\partial K}<0$ ).

This proposition states that, under the vertical economic structure, an increase in the productivity of private firms in the downstream industry actually benefits the upstream SOE $\left(\frac{\partial \Pi_{m}}{\partial A}>0\right)$. This is in contrast to the result in the existing literature (e.g., Song, Storesletten, and Zilibotti (2011)) that efficient private firms compete and drive out less efficient SOEs in the same industries. The intuition is as follows. First, an increase in the downstream productivity $A$ lowers the price for the downstream final good $\left(\frac{\partial p_{d}}{\partial A}<0\right)$ and hence increases its demand $\left(\frac{\partial D_{d}}{\partial A}>0\right)$, which in turn raises the demand for the upstream intermediate good $\left(\frac{\partial D_{m}}{\partial A}>0\right)$. Second, an increase in the downstream productivity $A$ increases the equilibrium price for the upstream intermediate good $\left(\frac{\partial p_{m}}{\partial A}>0\right.$ as explained earlier) and hence also increases the profit per unit of sale $\left(\frac{\mu-1}{\mu} p_{m}\right)$. These two forces jointly lead to a higher profit for the upstream $\operatorname{SOE}\left(\frac{\partial \Pi_{m}}{\partial A}>0\right)$.

An increase in the upstream TFP also leads to an increase in the upstream profit $\left(\frac{\partial \Pi_{m}}{\partial A_{m}}>0\right)$ because the quantity of demand increases $\left(\frac{\partial D_{m}}{\partial A_{m}}>0\right)$ as the price goes down $\left(\frac{\partial p_{m}}{\partial A_{m}}<0\right)$ and the effect of quantity expansion dominates the effect of profit reduction per unit of sale (the decrease in $\left.\frac{\mu-1}{\mu} p_{m}\right)$. To see why $\frac{\partial \Pi_{m}}{\partial K}>0$, note that when capital stock $K$ increases, $R$ goes down, so the production costs of both the upstream and the downstream industries decrease; the demand for the intermediate good goes up, which dominates the effect that profit per unit of sale $\left(\frac{\mu-1}{\mu} p_{m}\right)$ goes down. Consequently, the total profit increases. ${ }^{24}$

To understand $\frac{\partial \theta_{L}}{\partial A}<0$ and $\frac{\partial \theta_{L}}{\partial A_{m}}<0$, notice that an increase in productivity $A$ or $A_{m}$ causes both capital price $R$ and $\Pi_{m}$ to go up. By definition $\theta_{L}=\frac{W L}{W L+R K+\Pi_{m}}$, so the labor income share must decrease with $A$ or $A_{m}$ as $W$ remains constant. When capital stock $K$ increases, the GDP increases because $\Pi_{m}$ increases (as argued before) and $R K$ also increases $\left(R K=\frac{\alpha \mu+(1-\alpha-\beta) \gamma}{(1-\gamma)(1-\alpha-\beta)+\beta \mu} \bar{L}\left(A, A_{m}, K\right) p_{n}\right)$. However, the total labor income is still fixed because wage remains constant, implying a decrease in the labor income share in total GDP.

\footnotetext{
${ }^{24}$ We provide three alternative measures for profitability in the introduction. Throughout the model we characterize profit per firm.
} 
To further understand the consequence of the upstream monopoly, it is natural to ask what happens when the upstream monopoly is eliminated. When the upstream industry is liberalized (allowing for free entry) and hence becomes perfectly competitive, the new market equilibrium is Pareto efficient according to the first welfare theorem. More specifically, we have

Proposition 2 Suppose $L$ is sufficiently large. In the socially efficient equilibrium where the upstream industry is liberalized, the wage is still equal to the numeraire good price, the rental price of capital becomes larger, both the intermediate good and the downstream good become cheaper, the total industrial employment and the GDP both become larger, and the labor income share becomes smaller.

The proof is straightforward: all the equilibrium prices and the quantities are still given by the same formula in Lemma 1 and Lemma 2 except that $\mu$ is now replaced by one. The intuition for Proposition 2 is the following. Alleviation of the upstream monopoly lowers the price of the intermediate good, which in turn lowers the unit cost of the downstream good and hence its price. Therefore, the aggregate demand on and hence the output of the downstream industry increase, absorbing more labor from the agriculture (numeraire) sector. This, in turn, drives up the marginal product of capital and hence the rental price of capital. The GDP becomes larger primarily because the elimination of the upstream monopoly facilitates the structural change, moving more labor from the relatively low-value-added agriculture sector into the relatively higher value-added industrial sector. From the factor income point of view, the increase in the total rental income of capital $(R K)$ more than compensates for the dissipation of the monopoly profit $\left(\Pi_{m}\right)$. The equilibrium wage remains unchanged as there is still "surplus labor" in the agriculture sector (because $L$ is sufficiently large), so the labor income share in total GDP becomes smaller. ${ }^{25}$

In the past decade, China has witnessed a more rapid increase in the profit of SOEs than private firms, while the aggregate GDP still increases rapidly. Our analysis stresses that the unusual prosperity of SOEs is an undesirable symptom due to the incompleteness of the SOE reform (that is, the downstream industries are largely liberalized but the upstream industries continue to be monopolized by SOEs). This view is diametrically opposite to the claim made by SOE defenders that the existing SOEs need no major reforms as SOEs are doing very well and

\footnotetext{
${ }^{25}$ The SOE monopoly also has important distributive implications. It depresses the rental price of capital and hence the capital income share in total GDP, and it raises the labor income share mainly by reducing GDP.
} 
significantly contributing to China's economic exuberance. Their claim appears to be supported by the profitability data, but our model highlights an opposite view, illustrating the mechanism by which the upstream SOE, as a monopolist, is able to extract the surplus from the private industry in the downstream. In particular, suppose nothing happens to the upstream SOE but the productivity of the downstream private firms increases; by Lemma 2 and Proposition 1, the total GDP will increase and so will the monopoly profit of the upstream SOE. In other words, high profit of the upstream SOE can be merely a consequence of the dynamisms in the private downstream industry; it is the downstream private firms, rather than the SOE, that are the true driving force of GDP expansion. In fact, Proposition 2 makes it clear that the SOE monopoly is an obstacle to reaching the GDP potential of the economy.

Finally, we make one remark regarding competition between SOEs and downstream non-SOEs. In our model, a productivity increase in the downstream private firms raises the upstream SOE profit $\left(\frac{\partial \Pi_{m}}{\partial A}>0\right.$, see Proposition 1), and a productivity increase in the upstream SOE reduces the unit cost of any downstream private firm $\left(\frac{\partial p_{d}}{\partial A_{m}}<0\right.$, see (18) in Lemma 1). This complementarity between the SOE and private firms would disappear without the vertical structure. If private firms and SOEs compete in the same or horizontally substituting industries, then the productivity increase in private firms would hurt rather than boost the profit of SOEs. However, we must emphasize that, despite the vertical structure, competition still exists between the SOE and the private firms on the factor markets even if these factor markets are perfect. The crowding-out effect can be even stronger when there exist market imperfections. For example, if the financial market is plagued by financial contracting frictions with collateral constraints in the spirit of Kiyotaki and Moore (1997) and Bernanke and Gertler (1989), then the more profitable upstream SOEs can have advantages in obtaining loans over the private firms, ceteris paribus. On the labor market, high profitability of SOEs allows them afford to pay a higher wage, which can steal talents away from the downstream private firms and hence undermine the true engine of China's growth. In short, the monopoly of SOEs in the upstream industry can create more distortions via the factor markets, beyond the distortions in the product market itself. The factor market distortion can be the consequence of, rather than the reason for, the high profit of SOEs. 


\subsection{Open Economy}

Now we study how international trade affects economic performance, especially the profit of the upstream SOE and the labor income share in GDP, in a two-country free trade world. This openeconomy setup is particularly important for understanding China's economy given its high degree of trade openness, especially after its accession to WTO in 2001.

Consider a world with two countries, home $(\mathrm{H})$ and foreign $(\mathrm{F})$. The home country is identical to the economy specified in Section 3.1. Country F is populated with a continuum of identical households with measure equal to unity. We use an asterisk to denote the variables for country F. Each household in country $\mathrm{F}$ is endowed with $L^{*}$ units of labor and has the same utility function as in country $\mathrm{H}$ (given by (1)).

All firms in country $\mathrm{F}$ are private and no capital or intermediate good is needed in production. Each foreign firm has free access to the following constant-return-to-scale technologies: One unit of foreign labor can produce either $A^{*}$ units of numeraire good or one unit of good $d .{ }^{26}$ All the markets are perfectly competitive in country F.

The two countries have free trade. To make our analysis relevant for China (country $\mathrm{H}$ in the model), we focus on the case in which country $\mathrm{H}$ has a comparative advantage on good $d$, which may represent a composite of manufacturing goods. Therefore, country $\mathrm{H}$ exports $d$ and imports the numeraire good, which may represent tradable services or high-quality agricultural products. This is a hybrid of Ricardian and Heckscher-Ohlin trade models. ${ }^{27}$

The labor endowment in country $\mathrm{H}$ is assumed to be sufficiently large that in equilibrium country $\mathrm{H}$ produces and consumes both good $d$ and the numeraire good. Country $\mathrm{F}$ also consumes both but only produces the numeraire good. The necessary and sufficient conditions for this equilibrium pattern to occur are the following:

$$
\begin{gathered}
A^{* 1-\epsilon}<\frac{\mu}{2[(1-\gamma)(1-\alpha-\beta)+\beta \mu]} \overline{\bar{L}}\left(A, A_{m}, K\right), \\
\frac{\mu}{2[(1-\gamma)(1-\alpha-\beta)+\beta \mu]} \overline{\bar{L}}\left(A, A_{m}, K\right)<L^{*} A^{*},
\end{gathered}
$$

\footnotetext{
${ }^{26}$ Here foreign labor may be interpreted as a composite of raw labor and the associated human capital or skills.

${ }^{27}$ We choose not to adopt the pure Ricardian trade framework primarily for two reasons. One is that we want to derive non-trivial implications for the labor income share in total GDP for country H. The other is to highlight the role of capital (accumulation) in the industrialization process. We do not use the pure Heckscher-Ohlin trade model mainly to keep the analysis of country $\mathrm{F}$ as simple as possible, because our primary focus is on country $\mathrm{H}$.
} 
and

$$
L>\frac{\frac{\mu}{2}-\gamma(1-\alpha-\beta)-\alpha \mu}{(1-\gamma)(1-\alpha-\beta)+\beta \mu} \overline{\bar{L}}\left(A, A_{m}, K\right)
$$

where $\overline{\bar{L}}\left(A, A_{m}, K\right)$ is the total industrial employment in country $\mathrm{H}$ and given by

$$
\overline{\bar{L}}\left(A, A_{m}, K\right) \equiv 2^{\frac{1}{1+\alpha(\epsilon-1)+\gamma(1-\alpha-\beta)(\epsilon-1)}} \bar{L}\left(A, A_{m}, K\right)
$$

Condition (23) ensures that country $\mathrm{H}$ has a comparative advantage in producing good $d$ (i.e., $\left.\frac{p_{d}}{p_{n}}<A^{*}\right)$ so that only country $\mathrm{H}$ produces good $d$ and country $\mathrm{F}$ only produces and exports the numeraire good. Condition (24) ensures that country F consumes both numeraire good and downstream good $d$. Condition (25) guarantees that each agent in country $\mathrm{H}$, even the grass root, consumes a positive amount of numeraire good (i.e., $I_{g}>p_{n}^{\epsilon} p_{d}^{1-\epsilon}$ ). We also assume the following is true:

$$
(\epsilon-3)(1-\alpha-\beta)+1 \leq 0
$$

under which condition (25) automatically implies $L>\overline{\bar{L}}\left(A, A_{m}, K\right)$, ensuring that country $\mathrm{H}$ produces a positive amount of numeraire good in equilibrium.

In this free-trade equilibrium, we must have

$$
\begin{aligned}
& p_{n}=p_{n}^{*}=W=\frac{W^{*}}{A^{*}}, \\
& p_{d}=p_{d}^{*}=\frac{R^{\alpha} W^{\beta} p_{m}^{1-\alpha-\beta}}{A \alpha^{\alpha} \beta^{\beta}(1-\alpha-\beta)^{1-\alpha-\beta}} .
\end{aligned}
$$

Similar to the case of autarky, the capital market clearing condition determines the equilibrium rental price of capital $R$, which is given by

$$
R=p_{n} \cdot\left[A_{m}^{(1-\alpha-\beta)} A\right]^{\frac{(\epsilon-1)}{1+\alpha(\epsilon-1)+\gamma(1-\alpha-\beta)(\epsilon-1)}}\left(\frac{K}{2 \varkappa}\right)^{\frac{-1}{1+\alpha(\epsilon-1)+\gamma(1-\alpha-\beta)(\epsilon-1)}}
$$

Observe that $R$ is still given by (16) except that $K$ is replaced by $\frac{K}{2}$. To understand why, first notice that the demand functions for good $d$ are identical in the two countries $\left(D_{d}=D_{d}^{*}=\left(\frac{p_{n}}{p_{d}}\right)^{\epsilon}\right.$, due to the lack of income effect implied by the quasi-linear utility function), so the monopolist SOE charges the same markup as in the autarky case (10). As the world total demand for good $d$ doubles the domestic demand in country $\mathrm{H}$, the demand for the intermediate good is also scaled up 
(recall that good $d$ is produced only in country $\mathrm{H}$ ). Labor is abundant in country $\mathrm{H}$ but only half of the capital endowment is used to serve domestic demand for good $d$, thus the fact that all the technologies are constant returns to scale implies that in equilibrium $K$ is replaced by $\frac{K}{2}$ in formula (16). Similarly, (10) and (28) jointly yield

$$
p_{m}=p_{n} \cdot \frac{\mu}{A_{m} \gamma^{\gamma}(1-\gamma)^{1-\gamma}}\left[A_{m}^{(1-\alpha-\beta)} A\right]^{\frac{(\epsilon-1) \gamma}{1+\alpha(\epsilon-1)+\gamma(1-\alpha-\beta)(\epsilon-1)}}\left(\frac{K}{2 \varkappa}\right)^{\frac{-\gamma}{1+\alpha(\epsilon-1)+\gamma(1-\alpha-\beta)(\epsilon-1)}},
$$

The same is true for the price of downstream good $d$ (recall (18)):

$$
p_{d}=p_{n} \cdot\left\{\frac{\left[\frac{\mu}{\gamma^{\gamma}(1-\gamma)^{1-\gamma}}\right]^{1-\alpha-\beta}}{\alpha^{\alpha} \beta^{\beta}(1-\alpha-\beta)^{1-\alpha-\beta}}\right\}\left[A_{m}^{(1-\alpha-\beta)} A\right]^{\frac{-1}{1+\alpha(\epsilon-1)+\gamma(1-\alpha-\beta)(\epsilon-1)}}\left(\frac{K}{2 \varkappa}\right)^{\frac{-[\alpha+\gamma(1-\alpha-\beta)]}{1+\alpha(\epsilon-1)+\gamma(1-\alpha-\beta)(\epsilon-1)}}
$$

Lemma 3 Suppose (23) -(25) and (27) are true. In the free trade equilibrium, country H's upstream profit, total GDP, and labor income share are given by

$$
\begin{aligned}
\Pi_{m} & =\frac{(1-\alpha-\beta)(\mu-1)}{(1-\gamma)(1-\alpha-\beta)+\beta \mu} \overline{\bar{L}}\left(A, A_{m}, K\right) p_{n} . \\
Y & =\left[L+\frac{\alpha \mu+(1-\alpha-\beta)(\gamma+\mu-1)}{(1-\gamma)(1-\alpha-\beta)+\beta \mu} \overline{\bar{L}}\left(A, A_{m}, K\right)\right] p_{n} \\
\theta_{L} & =\frac{L}{L+\frac{\alpha \mu+(1-\alpha-\beta)(\gamma+\mu-1)}{(1-\gamma)(1-\alpha-\beta)+\beta \mu} \overline{\bar{L}}\left(A, A_{m}, K\right)},
\end{aligned}
$$

where $\overline{\bar{L}}\left(A, A_{m}, K\right)$ is given by (26).

Proof: See the appendix.

When compared with the autarky equilibrium summarized in Lemma 2, the only difference is that now $\bar{L}\left(A, A_{m}, K\right)$ is replaced by $\overline{\bar{L}}\left(A, A_{m}, K\right)$ in those formulas, reflecting the fact that now the total demand for and hence the production of the downstream good $d$ is scaled up due to international trade. Openness to trade boosts industrialization, absorbing more labor away from the numeraire sector into the industrial sector, and, therefore, the upstream profit and the total GDP both change with the industrial employment. The comparative static results are also similar to those in Proposition $1 .^{28}$

\footnotetext{
${ }^{28}$ Observe that the foreign productivity $A^{*}$ and foreign labor endowment $L^{*}$ are absent in the above formula under the given assumptions. There are two reasons. First, the foreign total wealth $A^{*} L^{*} p_{n}$ is large enough that it has no impact on the export demand on good $d$ due to the quasi-linear utility function. Second, country $\mathrm{H}$ has strict
} 
Proposition 3 Suppose (23) -(25) and (27) are true. The monopoly profit of the upstream SOE and the GDP in country $H$ are larger in the free trade equilibrium than in the autarky, but the labor income share in total GDP is smaller in the trade equilibrium.

The intuition for Proposition 3 is as follows. Country $\mathrm{H}$ has comparative advantage in producing the downstream good $d$, so international trade raises the aggregate demand for good $d$, which in turn enhances the total demand for the intermediate good monopolized by the upstream SOE in country H. As a result, the total SOE profit in country H becomes larger than in the autarky. The total GDP is also larger, partly because the total profit is larger and partly because the rental price of capital (hence the capital income) is larger than in the autarky. Since both $R K$ and $\Pi_{m}$ increase while the labor income $W L$ remains unchanged, country H's labor income share in total GDP is smaller in the trade equilibrium than in autarky.

The labor abundance condition (25) is crucial. It ensures that the wage is sufficiently low in country $\mathrm{H}$ so that good $d$ produced by country $\mathrm{H}$ is still competitive in the international market even though the intermediate good is charged at a monopolistic price. Put differently, country H's comparative advantage in good $d$ crucially depends on its labor abundance. Also, condition (25) ensures that the equilibrium wage in country $\mathrm{H}$ remains unchanged even after openness. Without this condition, the equilibrium wage in country $\mathrm{H}$ may become larger in the trade equilibrium than in autarky, so that the labor income share may become larger than that in the current trade equilibrium. Later, we will examine what happens when condition (25) is not true.

This simple benchmark model of open economy formalizes an important and novel mechanism for how the high profitability of the SOEs in China crucially depends on international trade in the past ten years, especially after China's accession to WTO in 2001. The membership of WTO facilitates China's export to the rest of the world, which tremendously increases the aggregate demand for the upstream goods and services monopolized by SOEs in China and hence SOEs' profit rises. In our model, trade also leads to an expansion in the total GDP by boosting industrialization, which is consistent with China's reality. Our model shows that international trade can further lower the labor income share in a labor-abundant country like China. The key reason is again the invariant wage implied by the large pool of labor in the agriculture sector while the total GDP comparative advantage in good $d$ in the current equilibrium (i.e., $\frac{p_{d}}{p_{n}}<A^{*}$ ). Hence, given the numeraire, $A^{*}$ does not appear in any expressions of the equilibrium outcome except for the foreign wage. Later, we will explore the equilibrium properties when (23) -(25) and (27) are no longer all satisfied. 
increases substantially. ${ }^{29}$

An immediate implication from Proposition 3 is that the upstream SOE can benefit from the export promotion policies for the goods and services produced in the downstream industries, as they stimulate foreign demand. Such export-facilitating policies include tariff reductions on imported inputs, tax reduction and loan subsidies, establishment of free-trade zones or processing trade zones, etc. It may help explain why the Chinese government (or the elite group) would have incentives to adopt various export-oriented trade policies. As long as foreign demand is sufficiently elastic to price, the total profit gain by the upstream SOE may well exceed the subsidy cost. If we push the logic a step further, it may also help us better understand the current account surplus in China: the Chinese government (the elite group) would have incentives to make loans to US because it enables US consumers to import more from China and ultimately benefits the upstream SOE most. This is particularly true given that China's domestic demand for good $d$ is indeed weak in reality, as partly captured by the quasi-linear utility function.

\section{Extension: Sustainability of China's State Capitalism}

Is this development model of state capitalism sustainable? Can the upstream SOE always make huge profit as the economy develops? Would the labor income share in total GDP continue to fall? In this section, we address these important issues by extending our benchmark open-economy model developed in Section 3.2. We consider three specific scenarios. First, the domestic wage rises endogenously after sufficient industrialization. Second, there exists a third country effectively competing with country $\mathrm{H}$ for the market of country F. Third, country F changes exogenously. ${ }^{30}$

\subsection{Wage Increase}

Suppose $K$ becomes sufficiently large (due to capital accumulation), or when the productivity $A$ or $A_{m}$ gets big enough (due to technological progress), then condition (25) no longer holds.

\footnotetext{
${ }^{29}$ If the upstream monopoly is abolished so that the world achieves the social optimality, the new equilibrium factor prices and the formula in Lemma 3 remain valid except that $\mu$ should be replaced by 1 , just as in the autarky case. The comparative static results are also similar to Proposition 2.

${ }^{30} \mathrm{~A}$ full-blown answer to these questions requires an explicit dynamic framework, which is easy to developed, but the key insights can be obtained in the static model via comparative statics.
} 
Specifically, suppose condition (25) is replaced by the following:

$$
L<\overline{\bar{L}}\left(A, A_{m}, K\right)
$$

which guarantees that country $\mathrm{H}$ no longer produces the numeraire good.

First, we consider the case when capital $K$ (or equivalently, $A$ or $A_{m}$ ) in country $\mathrm{H}$ is moderately high. More precisely, $K$ is sufficiently big that (30) is satisfied, but $K$ is also small enough such that the following is satisfied:

$$
A^{*} L^{*}>\frac{\mu}{2[(1-\gamma)(1-\alpha-\beta)+\beta \mu]} L^{\frac{[(1-\gamma)(1-\alpha-\beta)+\beta](\epsilon-1)}{\epsilon}}\left[\overline{\bar{L}}\left(A, A_{m}, K\right)\right]^{\frac{1+\alpha(\epsilon-1)+\gamma(1-\alpha-\beta)(\epsilon-1)}{\epsilon}}
$$

We have the following result: $:^{31}$

Proposition 4 Suppose (30) and (31) are true. Under some auxiliary conditions, we have the following free trade equilibrium. Country $H$ specializes in producing good $d$, and country $F$ specializes in producing the numeraire good; both countries consume both the numeraire and good d. The total GDP in country $H$ is given by

$$
Y=B \cdot\left(A_{m}^{1-\alpha-\beta} A\right)^{\frac{\epsilon-1}{\epsilon}} K^{\frac{\alpha(\epsilon-1)+\gamma(1-\alpha-\beta)(\epsilon-1)}{\epsilon}} L^{\frac{(\epsilon-1)\{\gamma \beta+(1-\alpha)(1-\gamma)\}}{\epsilon}} p_{n}
$$

where $B$ is a constant ${ }^{32}$, and the factor income shares in GDP are all constant:

$$
\begin{aligned}
\frac{W L}{Y} & =\frac{(1-\gamma)(1-\alpha-\beta)+\beta \mu}{\mu} \\
\frac{R K}{Y} & =\frac{\gamma(1-\alpha-\beta)+\alpha \mu}{\mu} \\
\frac{\Pi_{m}}{Y} & =\frac{(\mu-1)(1-\alpha-\beta)}{\mu} .
\end{aligned}
$$

\footnotetext{
${ }^{31}$ To highlight the key intuition and to simplify the analysis, in this section we do not emphasize the effect of the domestic income inequality in country $\mathrm{H}$ on the trade equilibrium. We can assume that the wealth is redistributed via a non-distorting taxation and transfer (for example, in a lump-sum fashion) among the agents in country $\mathrm{H}$ such that everyone ends up with identical wealth (and consumption). In the next section we will explicitly discuss the impact of income inequality.

$$
{ }^{32} B \equiv\left[\frac{(1-\gamma)(1-\alpha-\beta)+\beta \mu}{\gamma(1-\alpha-\beta)+\alpha \mu}+1+\frac{\frac{\mu-1}{\mu}(1-\alpha-\beta)}{\varkappa\left(\frac{\left[\frac{\mu}{\gamma \gamma(1-\gamma)^{1-\gamma}}\right]^{1-\alpha-\beta}}{\alpha^{\alpha} \beta(1-\alpha-\beta)^{1-\alpha-\beta}}\right)^{\epsilon-1}}\right] \frac{\left[\frac{\gamma(1-\alpha-\beta)+\alpha \mu}{(1-\gamma)(1-\alpha-\beta)+\beta \mu}\right]^{\frac{(\epsilon-1)\{\gamma \beta+(1-\alpha)(1-\gamma)\}}{\epsilon}}}{(2 \varkappa)^{-\frac{1}{\epsilon}}} .
$$
}


Proof: See the Appendix.

Condition (31) guarantees that country $\mathrm{F}$ also consumes the numeraire good in equilibrium. (32) and (33) also jointly determine the wage in country $\mathrm{H}$, which now depends on the domestic factor endowment and productivities. This is different from the benchmark model in the previous section. More specifically, $\frac{\partial W}{\partial L}<0, \frac{\partial W}{\partial A}>0, \frac{\partial W}{\partial A_{m}}>0$, and $\frac{\partial W}{\partial K}>0$. That is, the wage will increase as the economy develops after all the labor in the numeraire sector is absorbed out. (33) states that the labor income share in total GDP will be a constant, independent of the domestic factor endowment or productivity. Combined with the previous results in the benchmark model, this proposition indicates that, as the economy develops, the labor income share first declines and then stays constant after all the labor moves into the industrial sector. Proposition 4 also implies that the upstream SOE profit continues to get larger when the domestic productivity or factor endowment increases $\left(\frac{\partial \Pi_{m}}{\partial A}>0, \frac{\partial \Pi_{m}}{\partial A_{m}}>0, \frac{\partial \Pi_{m}}{\partial L}>0, \frac{\partial \Pi_{m}}{\partial K}>0\right)$, but its share in total GDP is constant. Once the upstream monopoly is abolished, the labor income share becomes $(1-\gamma)(1-\alpha-\beta)+\beta$ (obtained from (33) by substituting $\mu=1$ into it), larger than that in the current equilibrium. Moreover, $\Pi_{m}$ would be zero and capital income share $\frac{R K}{Y}$ would become $\gamma(1-\alpha-\beta)+\alpha$.

Next, we consider the case when $K$ (or equivalently, $A$ or $A_{m}$ ) becomes even larger so that condition (31) is violated. In that case, the price of good $d$ in country $\mathrm{H}$ becomes sufficiently low that country F no longer consumes the numeraire good. Alternatively speaking, country H becomes rich enough to consume all the numeraire goods in the world.

Proposition 5 Suppose (31) is not true. Under some auxiliary conditions, we have the following free trade equilibrium. Country $H$ specializes in producing good $d$ and country $F$ specializes in producing the numeraire good; country $H$ consumes both the numeraire and good d while country F only consumes good d. The total GDP in country $H$ is given by

$$
Y=\left[\frac{1}{(\widetilde{\mu}-\mu)(1-\alpha-\beta)(\epsilon-1)}+1\right] A^{*} L^{*} p_{n}
$$


and the factor income shares in GDP are:

$$
\begin{aligned}
\frac{W L}{Y} & =\beta+(1-\alpha-\beta) \frac{1-\gamma}{\widetilde{\mu}} \\
\frac{R K}{Y} & =\alpha+(1-\alpha-\beta) \frac{\gamma}{\widetilde{\mu}} \\
\frac{\Pi_{m}}{Y} & =(1-\alpha-\beta) \frac{\widetilde{\mu}-1}{\widetilde{\mu}}
\end{aligned}
$$

where $\widetilde{\mu}$, the markup, is uniquely determined by the following equation

$$
\left.\frac{[(\widetilde{\mu}-\mu)(1-\alpha-\beta)(\epsilon-1)]^{\frac{1}{\epsilon-1}}}{\widetilde{\mu}^{(1-\alpha-\beta)}}=\frac{\frac{\left(A^{*} L^{*}\right)^{\frac{\epsilon}{\epsilon-1}}}{\left[\beta+(1-\alpha-\beta) \frac{1-\gamma}{\widetilde{\mu}}\right]^{-1+\alpha+\gamma(1-\alpha-\beta)}} \cdot\left[\frac{1+(\widetilde{\mu}-\mu)(1-\alpha-\beta)(\epsilon-1)}{(\widetilde{\mu}-\mu)(1-\alpha-\beta)(\epsilon-1)}\right]}{\left.\left[\frac{([\alpha+(1-\alpha-\beta)}{\widetilde{\mu}}\right] \frac{L}{K}\right)^{\alpha+\gamma(1-\alpha-\beta)}}\right]^{-1} .
$$

Proof: See the Appendix.

In this new equilibrium, the predictions for several key variables are different from the previous equilibria.

First, (34) shows that the GDP of country H now depends explicitly on foreign variables ( $A^{*}$ and $L^{*}$ ). This is because now country $\mathrm{F}$ only consumes good $d$ and the foreign budget constraint is binding at the income level $A^{*} L^{*} p_{n}$. Second, notice that the external demand for good $d\left(D_{d}^{*}=\right.$ $\frac{A^{*} L^{*} p_{n}}{p_{d}}$ ) has unit price elasticity, so the new markup $\widetilde{\mu}$ is a weighted average of the optimal markup for the foreign market (infinity) and the optimal markup for the domestic market $(\mu)$; thus $\widetilde{\mu}>\mu$. In addition, (35) also implies the following:

$$
\frac{\partial \widetilde{\mu}}{\partial A^{*}}>0 ; \frac{\partial \widetilde{\mu}}{\partial L^{*}}>0 ; \frac{\partial \widetilde{\mu}}{\partial K}<0 ; \frac{\partial \widetilde{\mu}}{\partial L}<0 ; \frac{\partial \widetilde{\mu}}{\partial A}<0 ; \frac{\partial \widetilde{\mu}}{\partial A_{m}}<0
$$

which may help us understand why the ratio of profit to sales revenue of the SOEs $\left(\frac{\widetilde{\mu}-1}{\widetilde{\mu}}\right)$ can change. Third, the share of SOE profit in GDP in country $\mathrm{H}$ is larger than that in the previous equilibrium, but it decreases as country $\mathrm{H}$ develops (i.e., $K, A$ or $A_{m}$ increases) because $\widetilde{\mu}$ decreases. Fourth, the labor income share in country $\mathrm{H}$ is no longer a constant, but rather increases as country $\mathrm{H}$ develops because markup $\widetilde{\mu}$ is not a constant.

To summarize, the above two propositions show how an increase in capital stock or productivity in country $\mathrm{H}$ leads to different equilibria, in which predictions for key variables such as GDP, SOE 
profitability and labor income share are different.

So far, we have assumed that no unfavorable changes occur outside country H, and we will relax this assumption in the next two subsections.

\subsection{Export Competition}

Consider the complete specialization scenario characterized by Proposition 4 . The price of the downstream good is given by

$$
p_{d}=\Gamma(\mu) \cdot p_{n}
$$

where function $\Gamma(\cdot)$ is defined $\operatorname{as}^{33}$

$$
\begin{aligned}
\Gamma(\varpi) \equiv & \frac{2^{\frac{1}{\epsilon}}\left[\gamma^{\gamma}(1-\gamma)^{1-\gamma}\right]^{\frac{-(1-\alpha-\beta)}{\epsilon}}}{\left[\alpha^{\alpha} \beta^{\beta}(1-\alpha-\beta)^{1-\alpha-\beta}\right]^{\frac{1}{\epsilon}}}\left[A_{m}^{(1-\alpha-\beta)} A\right]^{\frac{-1}{\epsilon}} K^{\frac{-[\alpha+\gamma(1-\alpha-\beta)]}{\epsilon}} L^{-\frac{(1-\gamma)(1-\alpha-\beta)+\beta}{\epsilon}} \\
& \frac{[\gamma(1-\alpha-\beta)+\alpha \varpi]^{\alpha+\gamma(1-\alpha-\beta)}[(1-\gamma)(1-\alpha-\beta)+\beta \varpi]^{(1-\gamma)(1-\alpha-\beta)+\beta}}{\varpi^{\alpha+\beta}} .
\end{aligned}
$$

Now imagine there is a third country potentially competing with country $\mathrm{H}$ for the market of country F. Suppose this third country can produce good $d$ at $\operatorname{cost} T \cdot p_{n}$, where $T<A^{*}$ so that country F would import good $d$ from this country in the absence of country H. Obviously, the upstream SOE in country $\mathrm{H}$ now faces a limit pricing problem: It can still charge the original markup $\mu$ and monopolize the market for good $d$ in country $\mathrm{F}$ when $T>\Gamma(\mu)$. However, when the third country manages to lower $T$ (perhaps due to technological progress or policy subsidies) such that $T \in[\Gamma(1), \Gamma(\mu))$, then country $\mathrm{H}$ will have to set $p_{d}$ equal to $T \cdot p_{n}$ to remain competitive. This means that, given the downstream industry has already done its best, the upstream SOE has to lower its markup. Furthermore, when $T<\Gamma(1)$, the upstream SOE in country $\mathrm{H}$ has to improve its productivity $A_{m}$, otherwise this upstream SOE will strangle the downstream capitalist industry to "death".

The implication for China is that the monopoly rent of upstream SOEs would eventually decrease or even disappear if they fail to sufficiently improve productivities, because other developing countries such as Vietnam or Bangladesh may effectively compete with China. Eventually, the upstream SOE monopoly would strangle the downstream capitalist industries and undermine the

\footnotetext{
${ }^{33}$ It can be shown that $\Gamma^{\prime}(\varpi)>0$ for any $\varpi \in[1, \mu]$. This can be easily seen when no capital is needed for production in the model $(\alpha=\gamma=0)$ or when no labor is needed in the non-numeraire goods $(\beta=1-\gamma=0)$.
} 
growth potential of China. In addition, if China's population (labor force) shrinks sufficiently (for example, due to the fertility decision or aging problems), then rising labor cost would also increase $p_{d}($ see $(37))$ and reduce the SOE profit and the total output.

\subsection{Change in External Demand}

Trade openness facilitates the rent extraction by the upstream SOE as it enlarges the aggregate demand for the downstream goods and hence the demand for the upstream intermediate input. But what happens if foreign demand drops exogenously, for example, due to a global economic crisis? This can be modeled as an exogenous decrease in $L^{*}$ or $A^{*}$.

Recall that in the equilibrium regimes of the benchmark trade model and of Proportion 4, GDP, SOE profit, and labor income share of country $\mathrm{H}$ are all independent of $A^{*}$ and $L^{*}$, as the external demand is smaller than foreign income $A^{*} L^{*} p_{n}$. Now consider the equilibrium regime characterized by Proposition 5, which implies that a decline in $A^{*}$ (or $L^{*}$ ) leads to a strict decrease in both the monopoly profit $\Pi_{m}$ and GDP (i.e., $\frac{\partial \Pi_{m}}{\partial A^{*}}>0, \frac{\partial Y}{\partial A^{*}}>0 ; \frac{\partial \Pi_{m}}{\partial L^{*}}>0, \frac{\partial Y}{\partial L^{*}}>0$ ). In addition, the labor income share increases when $A^{*}$ (or $L^{*}$ ) declines, mainly because GDP drops, even though the wage decreases. To summarize, a decline in $A^{*}\left(\right.$ or $L^{*}$ ) would generally decrease the SOE profit and GDP in country $\mathrm{H}$, sometimes weakly, but the decrease is strict when country $\mathrm{H}$ is sufficiently developed (that is, $K$, or $A$, or $A_{m}$ becomes sufficiently large such that the conditions for Proposition 5 are satisfied).

The analysis suggests that a small change in external demand may lead to a large change in the upstream SOE profit due to the markup price effect. This is consistent with Figure 1: SOE profits increased disproportionately more than the non-state firms when export increased before 2007, but SOE profit also dropped more dramatically than non-SOEs when facing negative external demand shocks during the 2007-2008 episode, even though most upstream SOEs did not directly participate in trade.

\section{Emergence of China's State capitalism}

The benchmark model is designed to explain why China's SOEs have become more profitable than non-SOEs in the last decade since the vertical structure came into its full shape due to the massive privatization of downstream SOEs in the late 1990s. This section shows that the same analytical 
framework can be extended to explain the opposite pattern observed in the 1990s. Namely, private firms outperformed SOEs in terms of profitability before the vertical structure fully emerged. We also illustrate methodologically how this framework is flexible enough to address varieties of other relevant issues.

As Figure 1 shows, the profitability of SOEs was below that of non-SOEs in the early 1990s and the gap widened substantially between 1994 and 1998. SOEs experienced a sharp increase in profitability between 1998 and 2000, a period of massive privatization of downstream SOE and upstream SOE consolidation (the "three-year battle" mentioned in Section 2), and finally SOEs surpassed non-SOEs in profitability around 2000.

We argue that this phenomenon is due to the gradual liberalization of downstream industries in the 1990s, a process through which the vertical structure of today's state capitalism gradually emerged. As documented in Section 2, the market-oriented economic reform accelerated after 1992 and the openness to FDI and trade also drastically deepened. With the entry and expansion of the high-productivity non-SOEs, domestic or foreign, many SOEs had to rely on subsidies from the government or other SOEs to maintain operation. This drove down the average profitability of SOEs, although the country as a whole grew rapidly due to improved resource allocation from the low-productivity SOEs to the high-productivity non-SOEs, as formalized in Song et al. (2011). During the period of massive SOE privatization in the downstream industries in 1998-2000, most of those money-losing SOEs exited from competitive downstream industries and, therefore, the average profitability of SOEs started to rise. The vertical structure featured in today's state capitalism in China came into full shape around 2001, and the fortune of SOEs as a whole has been reversed since then. ${ }^{34}$

This emergence process of state capitalism can actually be formalized as follows. Suppose the downstream good $d$ is an aggregate of a continuum of differentiated goods:

$$
c_{d}=\left(\int_{0}^{1} c(i)^{\frac{\eta-1}{\eta}} d i\right)^{\frac{\eta}{\eta-1}}, \eta>1
$$

\footnotetext{
${ }^{34}$ Brandt, Tombe and Zhu (2010) empirically find, but have not yet formally explained, the following "V"-shaped pattern of distortions in China's TFP: it first decreased during 1985 and 1997 and then increased in the last decade. Our model can explain this non-monotonic pattern as follows. The distortion between state and non-state-controlled sectors declined as the SOEs gradually exited from the downstream industries during 1985-1997, and the distortion increased again in the last decade because the remaining SOEs monopolize the upstream industries and benefit disproportionately more from the trade liberalization than the downstream private sectors.
} 
where $c(i)$ is consumption of differentiated good $i, i \in[0,1]$, and the parameter $\eta$ represents the elasticity of substitution between the differentiated goods. The production functions for the differentiated goods are symmetric as in (2):

$$
F_{i}(k, l, m)=A k^{\alpha} l^{\beta} m^{1-\alpha-\beta}, \forall i \in[0,1]
$$

To fix the idea, first consider the same setting as the benchmark model of autarky except that now the downstream industries are partially liberalized. Let $\phi$ denote the fraction of downstream industries that have been already liberalized, where SOEs and non-SOEs are engaged in perfect competition and entry is free. However, the remaining $1-\phi$ fraction of the industries are regulated such that each of them is monopolized by one state firm. The production function for industry $i$ is still given by (39) for each $i \in[0,1]$, where $A=A_{p}$ if it is a private firm, and $A=A_{s}$ if it is a state firm. We assume $A_{s}<A_{p}$. We have $\phi=0$ before the downstream liberalization and $\phi=1$ when the vertical structure is fully developed (assumed in the previous sections).

Without government subsidies, SOEs will be completely driven out by competitive private firms in those liberalized industries. However, in the regulated industries, the SOEs are delegated to managers who cannot collude, so they are engaged in monopolistic competition. We can prove that, if the following is true:

$$
\frac{A_{p}}{A_{s}}>\left(\frac{\eta-1}{\eta}\right)\left[\frac{\eta-1}{\eta}+\frac{\mu}{\eta(\mu-1)(1-\alpha-\beta)}\right]^{\frac{1}{\eta-1}},
$$

the total profit of SOEs (and GDP) is maximized when the downstream industries are fully liberalized $(\phi=1)$. See the appendix for proof. This can be intuitively explained as follows. The low productivity of a monopolist SOE in the downstream has two negative effects on the total SOE profit. One is that the profit earned from that monopolized industry is small. The other is that the induced demand for the upstream intermediate good from this particular industry is also small. When some downstream industries are liberalized, SOEs in those industries lose profit. On the other hand, those liberalized industries will have a larger demand for upstream input than before and hence increase the upstream SOE profit. In addition, the profit of the remaining monopolist SOEs in the downstream will be reduced even further due to the cross-industry substitution effect. It turns out that when $\frac{A_{p}}{A_{s}}$ is sufficiently large, the net effect is such that the larger the fraction of 
downstream industries that are liberalized, the more profit the upstream industry can earn due to the larger induced demand for the intermediate good, which dominates the monopoly profit loss in all the downstream industries due to liberalization. Thus the profit-maximizing $\phi$ should be one (full liberalization of the downstream industries).

Now consider the case when some downstream SOEs are subsidized by the government to keep operating and compete with private firms in the same liberalized industries. This indeed occurred in China. To break even, an SOE in the liberalized industry needs a subsidy equal to $\frac{R^{\alpha} W^{\beta} p_{m}^{1-\alpha-\beta}}{\alpha^{\alpha} \beta^{\beta}(1-\alpha-\beta)^{1-\alpha-\beta}}\left(\frac{1}{A_{s}}-\frac{1}{A_{p}}\right)$ for each unit of output produced by this SOE. The more this SOE produces, the more subsidy it needs. In particular, it hurts the total SOE profits when the subsidy comes from other profitable SOEs such as upstream firms. This helps explain why in reality the aggregate SOE profitability was indeed lower than non-SOEs during the gradual reforms in the 1990s.

\section{More Discussion}

In this section, we briefly address several remaining issues within our framework.

\subsection{Vertical Structure and Imperfect Competition in the Downstream}

For simplicity, the downstream private industry is assumed to be perfectly competitive with free entry in the benchmark model in Section 3, so downstream private firms have zero profit. However, this simplification is not important for the main result - the vertical structure enables the upstream monopolist SOE to extract rents from the downstream private firms. To see this, imagine that the downstream industry now consists of a continuum of sub-industries as specified in (38) in Section 5 and that the vertical structure has emerged fully in the sense that no SOEs exist in the downstream $(\phi=1)$. Suppose each sub-industry is monopolized by one distinct private firm (without free entry). Thus all these firms are engaged in monopolistic competition and have positive profits.

Let $\Pi_{d}$ denote the total downstream profit. It can be easily shown that $\frac{\partial \Pi_{m}}{\partial A_{p}}>0$ and $\frac{\partial \Pi_{d}}{\partial A_{m}}>0$, 
suggesting that the "complementarity" between upstream and downstream firms still exists. ${ }^{35}$

Again, we emphasize that the vertical structure is crucial for our theory. It explains why lowproductivity SOEs may become profitable when high-productivity non-SOEs are allowed to enter and operate while the total GDP also increases at the same time. When combining this vertical structure and trade openness, we can also explain why the SOEs' profitability closely co-moves with the export GDP ratio even though upstream SOEs do not directly participate in trade. In contrast, if the economic structure is horizontal instead of vertical, then we cannot simultaneously explain all the features observed in Figure 1.

Counterfactually, one may wonder from a theoretical point of view whether the reverse vertical structure also works for SOEs, that is, the downstream industry is monopolized by SOE whereas the upstream industry is liberalized and open for private entry and free competition. First, in practice, members of WTO are required to liberalize the tradable sectors and allow for free entry by foreign investors, so administrative monopoly over those tradable goods is politically hard to implement. Second, low-productivity SOEs in the downstream may not be competitive enough to export even if the upstream intermediate inputs are cheap. In fact, under the vertical structure we study, although the upstream intermediate input is charged with a monopoly markup, the highproductivity downstream private firms can take advantage of cheap labor to partially substitute the expensive intermediate input, so the final good is still internationally competitive enough. Such substitution is not possible when the vertical structure is reversed. Third, a significant proportion of upstream industries are non-tradables, so aggregate productivity increase due to downstream liberalization is typically more significant than upstream liberalization, if only one part can be liberalized.

\footnotetext{
${ }^{35}$ More precisely, when $L$ is sufficiently large, the following can be obtained in autarky:$$
\Pi_{m}=\frac{(\eta-1)(1-\alpha-\beta)(\mu-1)}{\mu \eta} p_{d}^{* 1-\epsilon} ; \Pi_{d}=\frac{1}{\eta-1} p_{d}^{*-\epsilon}
$$$$
\text { where } p_{d}^{*}=\left[\frac{\eta}{\eta-1}\right]^{1+\epsilon[\alpha+\gamma(1-\alpha-\beta)]}\left(\frac{\mu}{\gamma(1-\alpha-\beta)+\alpha \mu}\right)^{\alpha+\gamma(1-\alpha-\beta)} \text {. }
$$$$
\left[\frac{\mu^{1-\alpha-\beta}}{\left[A_{m} \gamma^{\gamma}(1-\gamma)^{1-\gamma}\right]^{1-\alpha-\beta} A_{p} \alpha^{\alpha} \beta^{\beta}(1-\alpha-\beta)^{1-\alpha-\beta}}\right]^{1+(\epsilon-1)[\alpha+\gamma(1-\alpha-\beta)]} K^{-\frac{\alpha+\gamma(1-\alpha-\beta)}{1+(\epsilon-1)[\alpha+\gamma(1-\alpha-\beta)]}}
$$ 


\subsection{Income Distribution and Domestic Demand}

For simplicity, we have assumed that both the elite class and grass roots are rich enough to consume numeraire goods in the benchmark model. The sustainability analysis also circumvents the issue of household income distribution. However, our model enables us to offer a non-trivial analysis on the causes and consequences of income inequality.

The non-homothetic utility function, (1), implies that household income inequality would affect the aggregate consumption demand for the downstream good even when holding the aggregate income fixed. More precisely, at any given price, the domestic aggregate demand for the downstream good is fully determined by the aggregate income of the poor households who only consume the downstream good and the fraction of households who are rich enough to also consume a positive amount of numeraire good. The aggregate demand for the downstream good can be depressed if the income distribution deteriorates such that a larger fraction of total wealth is concentrated in a decreasing fraction of rich households, because the demand for the downstream good does not increase with income when the income exceeds a certain threshold, as seen in (4).

Our previous analysis shows that, as domestic productivity increases and/or capital accumulates, the labor income share in GDP typically declines while the capital income share and the SOE profit typically increase. International trade lowers the labor income share even further. All these suggest that income tends to concentrate in the hands of the elite group, so the domestic consumption demand for the industrial good (downstream good in the model) tends be more and more depressed from a dynamic point of view. On the other hand, the depressed aggregate demand for the industrial product deters industrialization and GDP expansion. Therefore, foreign demand becomes even more important for China's structural change (industrialization) and economic growth. Our model may help us understand why both the SOE profit and the GDP growth rate declined in China when the external demand plunged in the recent global recession.

\subsection{Domestic Labor Market Integration}

In our model, free mobility of labor ensures equal wage across different sectors as well as smooth industrialization. In reality, however, institutional barriers to labor migration exist, impeding labor

supply for the expanding sectors. In China, the requirement of a residence certificate, also known as hukou, has been an important obstacle to rural-urban migration. It results in a dual domestic 
labor market with important implications for upstream SOE profit.

Now we show explicitly why domestic labor market integration is important for the upstream SOE to extract more monopoly rents in an open economy. Consider the same environment as in the benchmark trade model except that the labor market in country $\mathrm{H}$ is dual. More precisely, suppose there exists an upper limit fraction, $\omega$, of total labor that is allowed to work in the industrial sector (living in urban areas) where $\omega \in(0,1)$. To make the analysis nontrivial, we assume $\omega$ is

sufficiently small such that $\omega L<\overline{\bar{L}}\left(A, A_{m}, K\right)$, which makes the equilibrium wage $W$ higher in the industrial sector than in the non-industrial sector (equal to $p_{n}$ ). It can be shown that, in the trade equilibrium, as $\omega$ increases (i.e., less restriction on labor mobility), the monopoly profit $\Pi_{m}$, the GDP $Y$, and the labor income all increase (see the proof in the Appendix). The intuition is the following. A reduction in labor market frictions lowers the labor cost in the industrial sector and hence the price of good $d$, which in turn increases the total demand for downstream good $d$ and thus enlarges the induced demand for the upstream input $m$. This would ultimately lead to a higher upstream monopoly profit. Naturally, GDP and the total labor income both increase.

Our analysis shows how domestic labor market integration ultimately helps the monopoly rent extraction of the upstream SOE. It also helps us understand from a new angle why China has gradually relaxed labor market restrictions including the hukou system in recent years.

\subsection{Subsidies and Taxes}

One may argue that the recent higher profitability of SOEs relative to non-SOEs is because SOEs receive more subsidies or pay less tax. First of all, this argument is logically complementary to our theory because our explanation holds independent of government subsidies or differential tax rates. Second, if subsidy or tax is the key reason, then it remains unclear why such good performance of SOEs was not observed in China in the earlier periods, especially given that both the scope and magnitude of subsidies for SOEs were much bigger in the 1980s or before the economic reform started in the late 1970s (see Lin, Cai and Li $(1998,1999)$ ). Further, the persistently outstanding performance of SOEs, which still account for China's $40 \%$ of total fixed investment and $80 \%$ of stock market value, would require substantial government support. Then it remains unclear why the whole economy can still grow so fast in spite of such severe resource misallocation.

Third, there seems no compelling empirical evidence that SOEs pay a lower effective tax rate or receive more direct subsidies than non-SOEs. Table 4 reports the data related to the tax and 
subsidies of industrial enterprises in China. Column (2) shows that share of total taxes paid by SOEs is about $50 \%$ in recent years. In comparison, columns (3) and (4) show that the share of the value added and profits from SOEs in the industrial sector is below $34 \%$ and $27 \%$, respectively. These results suggest that, if anything, SOEs pay much higher effective tax rates than non-SOEs. In other words, if government provides more subsidies to SOEs than to non-SOEs, those subsidies are unlikely in the form of lower taxes. Direct subsidies to SOEs, as shown in column (5), are decreasing over time and are relatively small both in absolute magnitude and as a percentage of GDP, SOE value-added, or SOE gross profits.

Fourth, it is possible that the Chinese government indirectly subsidizes SOEs with preferential access to large amounts of low-interest loans through financial intermediaries, which are largely state controlled. However, it is not obvious why the Chinese government would subsidize SOEs while simultaneously imposing much higher effective tax rates on SOEs. Also, even if such indirect subsidies exist, it is difficult to accurately differentiate and clarify the causality. As argued earlier, even without government intervention, the financial market (with frictions) itself would still favor SOEs over non-SOEs if the former are more profitable in the first place (in the spirit of Kiyotaki and Moore (1997) and Bernanke and Gertler (1989)).

To clarify, our model allows for different capital intensities for upstream and downstream industries (measured by $\gamma$ and $\alpha$, respectively). It can be shown that the profit-to-capital ratio in the upstream could be lower than that in the downstream when $\gamma$ is sufficiently larger than $\alpha$ in our framework. In other words, it is theoretically possible to have unequal profit-to-capital ratios across different firms even when factor markets are perfect.

\subsection{Causes of Monopoly and Industrial Distribution of Large Firms}

We want to emphasize that, although some of the upstream industries are prone to be natural monopolies, it is still the administrative monopoly that causes high profitability in most upstream industries, as partly revealed by the empirical evidences documented in Section 2. Natural monopoly alone does not permanently shield an inefficient incumbent firm from being replaced, as it is always exposed to potential competition from new entrants or existing players within the sector, especially if the monopoly profit is persistently much higher than other industries or if the inefficiency of the incumbent is enormous. Non-SOEs would have entered the high-profit upstream industries if allowed. Besides, natural monopoly does not necessarily imply that firms in such industries should 
be state-owned or should be more profitable under government regulations.

As documented earlier, a distinctive feature of China's economy is that the largest firms (and also those with highest profit margins) are highly skewed toward state ownership and are also highly concentrated in upstream industries (see Table 2). This is truly exceptional from a global perspective. For example, among the thirty-five French companies on the list of Fortune Global 500 in 2011, eleven involve state ownership with only four having more than $50 \%$ state-owned shares. Only six companies on the list are from the upstream non-financial industries such as power generation, oil and energy, materials, and telecommunications with three having state-owned shares. Among the 133 American counterparts, only four companies involve government ownership. The non-financial upstream industries account for less than $20 \%$ of the firms on this list and none of these large firms in those industries have state ownership.

These systematic differences between the state capitalism in China and the liberal capitalism in Europe and North America suggest at least the following. First, upstream industries with natural monopoly are not necessarily state-owned, and natural monopoly itself does not necessarily imply high profitability. Second, the most profitable firms are not necessarily in the upstream industries. In short, natural monopoly is neither a necessary nor a sufficient condition to generate the pattern of relative performance of SOEs and non-SOEs in China during the last two decades. Governmental forces are presumably crucial in explaining why China's SOEs are so profitable and so highly concentrated in upstream industries.

Notice that, according to our theory, once the downstream industries are fully liberalized, the high profitability of the upstream firm is mainly due to its monopoly position, not necessarily to state ownership itself. If the monopoly position is obtained by a non-SOE such as a politically connected private firm, our analysis still applies.

\section{Implications for Other Countries}

The motivating facts and several important features in the model are mainly based on China's experience. Nevertheless, our model is not only relevant for China. The general logic may also help us think about related issues in other economies, especially in emerging markets or transitional economies.

Take Vietnam, for instance. It is a transitional socialist economy that has been growing fast 
since it began to follow China by gradually liberalizing some downstream industries and actively participating in international trade. But the vertical structure has not fully emerged yet in Vietnam, as its SOE reform is still at a stage similar to China's in the 1990s. Our analysis may alert Vietnam to the potential downside of China's state capitalism.

India is another fast-growing emerging economy, with the second largest population in the world. However, the magnitudes of its manufacturing exports and the scale of FDI inflows are much smaller than those of China (See Bosworth and Collins (2008), Wang (2009), and the literature therein). Thus its total demand for the downstream products and services largely depends on domestic markets, so the induced demand for upstream goods and services (such as electricity, oils, transportations, raw materials) is relatively small. Accordingly, our model implies that those upstream industries would not be as profitable as in China even if they are also monopolized by profit-maximizing firms. In addition, our sustainability analysis in Section 4 suggests that insufficient participation in international trade makes both upstream and downstream industries, tradable or non-tradable, less disciplined by external market forces, and therefore may hurt the efficiency in those industries. ${ }^{36}$

Russia's state capitalism is different from China's. In Russia, upstream industries such as natural gas and oils are largely owned by the state but controlled by powerful oligarchs (Shleifer and Triesman (1999) and Myerson and Braguinsky (2007)). Russia has a relatively small population and high labor cost, which partly explains why the downstream manufacturing sector has no comparative advantage relative to China or Vietnam. Policy hurdles could be another important reason. For example, Russia is still not a member of WTO. The underdevelopment of the downstream industries further compels the upstream oligarchs to directly sell most of the natural gas and oils abroad at the international price, which in turn has important implications for domestic industrialization, growth sustainability, and income distribution. ${ }^{37}$ Similar analysis may be also applicable for other resource-abundant countries such as Brazil, Australia, and Mid-East OPEC members.

\footnotetext{
${ }^{36}$ For political economy reasons, the Indian government regulates upstream industries by setting prices lower than their production cost (such as electricity), so these key intermediate inputs and services are often under-supplied and unstable, which chokes off the manufacturing development, export and FDI inflows (Bardhan (2010)). This retards India's industrialization, urbanization, and participation in globalization.

${ }^{37}$ By regulation, private firms in China are not allowed to import certain key upstream inputs (such as oil) directly from abroad. Instead, these inputs have to be purchased from upstream SOEs (such as Sinopec Group or China National Petroleum) that monopolize the domestic supply, even though these inputs are technically tradable.
} 
In short, our analytical framework may prove useful in stimulating us to think further about a wide array of important issues, not just for China, but for many other countries.

\section{Conclusion}

We provide a simple model of China's state capitalism that highlights a vertical structure featured in the recent Chinese economy, namely, the upstream key industries are controlled by the state via SOE monopoly, whereas downstream industries are largely liberalized and operating under capitalism. We show that this vertical structure, when combined with trade openness and labor abundance, can explain the puzzling fact that SOEs have achieved an unprecedented high profitability, dwarfing the performance of non-SOEs, in the last decade, while the economy as a whole has still attained a high growth rate since China's accession to WTO in 2001. Our theory points to the incompleteness of the market-oriented reforms as the fundamental cause for the recent unusual prosperity of China's SOEs. We also demonstrate how our framework can explain the persistently low and declining labor income share in China's GDP in the past two decades and why SOEs as a whole were outperformed by non-SOEs in the 1990s before this vertical structure of state capitalism had fully emerged.

This paper adopts a positive and qualitative approach, and it represents only a first step toward the deeper understanding of state capitalism in countries like China. Several directions seem particularly appealing for future research. First, what are the quantitative implications of our model, especially when extended to an explicit dynamic framework? ${ }^{38}$ Second, how can we better understand the political-economy aspects of such a model of state capitalism? Third, given the institutional features illuminated in our model, what procedures should be taken to ensure sustainable growth? We believe that a deep understanding of state capitalism is of fundamental importance to both China and the world economy at large.

\footnotetext{
${ }^{38}$ Wang (2011) develops a two-country dynamic general-equilibrium model with infinite industries of different capital intensities to show how international trade and dynamic trade policies may affect industrialization, the structural change of industries from labor-intensive to capital-intensive ones within the modern sector, and the aggregate growth rate.
} 


\section{References:}

Acemoglu, D., 2008. Introduction to Modern Economic Growth, Princeton University Press.

Acemoglu, D. and V. Guerrieri., 2008. Capital Deepening and Nonbalanced Economic Growth. Journal of Political Economy 116: 467-498.

Allen, F., J. Qian, and M. Qian, 2005. Law, Finance, and Economic Growth in China. Journal of Financial Economics, 77: 57-116.

Antras, P., D. Chor, T. Fally and R. Hillberry. 2012. Measuring the Upstreamness of Production and Trade Flows, American Economic Review P\&P, 102: 412-416.

Bai, C., and Z., Qian, 2009. Determinants of Labor Income Share---Evidence from China's Provincial Data, Working Paper, NIFS, Tsinghua University.

-----, 2010. Factor Income Distribution: The Story behind the Statistics, Working Paper, NIFS, Tsinghua University.

Bai, C., Y. Du, Z. Tao, S. Tong, 2004. Local Protectionism and Regional Specialization: Evidence from China's Industries. Journal of International Economics 63, 397--417.

Bardan, P., 2010. Awakening Giants, Feet of Clay: Assessing the Economic Rise of China and India. Princeton University Press.

Bernanke, B., and M. Gertler,1989. Agency Costs, Net Worth, and Business Fluctuations, American Economic Review 79: 14-31

Binns, P., 1986. State Capitalism, Marxism and the Modern World, Education for Socialists No.1.

Bosworth, B., and S. Collins. 2008. Accounting for Growth: Comparing China and India, Journal of Economic Perspectives, 22: 45--66.

Brandt, L., C. Hsieh, and X. Zhu, 2008. Growth and Structural Transformation in China. In China's Great Economic Transformation, ed. L. Brandt, and T, Rawski, 683--728. New York: Cambridge University Press.

Brandt, L., T. Tombe, and X. Zhu, 2010. Factor Market Distortions Across Time, Space and Sectors in China, University of Toronto, working paper.

Brandt, L., and X. Zhu, 2010. Accounting for China's Growth, IZA Discussion Paper.

Bremmer, I., 2010. The End of the Free Market: Who Wins the War Between States and Corporations? Portfolio Hardcover.

Bruno, M., 1972. Market Distortions and Gradual Reform, Review of Economic Studies 39: 373383.

Buera, F. and J. Kaboski. 2012. The Rise of the Service Economy, American Economic Review 102: $2540--2569$

Burstein, A., and J. Vogel. 2011. Factor Prices and International Trade: A Unifying Perspective, NBER Working Paper No. 16904.

Cao, S., and J. Liu, 2011. Productivity Growth and Ownership Change in China: 1998-2007, working paper.

Cao, Y., Y. Qian, and B. Weingast, 1999. From Federalism, Chinese Style to Privatization, Chinese Style, Economics of Transition 7, 103--31.

Dean, J., A. Browne, and S. Oster, 2010. `State Capitalism' Sparks a Global Backlash, Wall Street Journal, November 16, 2010.

Dollar, D., and S. Wei, 2007. Das (Wasted) Kapital: Firm Ownership and Investment Efficiency in China, NBER working paper No.13103.

Dooley, M., D. Folkerts-Landau, and P. Garber. 2007. Direct Investment, Rising Real Wages, and the Absorption of Excess Labor in the Periphery. In G7 Current Account Imbalances: Sustainability and Adjustment, ed. R. Clarida, 103-26. Chicago: University of Chicago.

Feenstra, R., 2004. Advanced International Trade: Theory and Evidence, Princeton University Press.

Green, S., \& G. Liu, (Eds.) 2005. Exit the Dragon? Privatization and State Control in China. Oxford: Blackwell Publishing. 
Gollin, D., 2002. Getting Income Shares Right. Journal of Political Economy 110: 458-474.

Groves, T., Y. Hong, J. McMillan and B. Naughton, 1994. Autonomy and Incentives in Chinese State Enterprises, Quarterly Journal of Economics 109, 183-209.

Harrison, A., 2002. Has Globalization Eroded Labor's Share? Some Cross-Country Evidence, UC Berkeley working paper.

Herrendorf, B., R. Rogerson and A. Valentinyi, 2011. Growth and Structural Transformation, in Handbook of Economic Growth, forthcoming.

Hsieh, C.. and P. Klenow, 2009. Misallocation and Manufacturing TFP in China and India. Quarterly Journal of Economics 124: 1403-48.

Jaumotte, F., and I. Tytell, 2007. How Has The Globalization of Labor Affected the Labor Share in Advanced Countries?, IMF working paper.

Karabarbounis, L., and B. Neiman. 2012. Declining Labor Shares and the Global Rise of Corporate Savings, University of Chicago working paper

Kiyotaki, N., J. Moore, 1997. Credit Cycles, Journal of Political Economy 105: 211--248,

Kongsamut, P., S, Rebelo, and D. Xie. 2001. Beyond Balanced Growth. Review of Economic Studies 68: 869-882

Lawrence L., Y. Qian and G. Roland, 2000. Reform without Losers: An Interpretation of China's Dual-Track Approach to Transition, Journal of Political Economy 108: 120-143.

Lewis, A. 1954. Economic Development with Unlimited Supplies of Labor. Manchester School, 22: 139--91.

Li, S., S. Li, and W. Zhang, 2000. The Road to Capitalism: Competition and Institutional Change in China, Journal of Comparative Economics 28, 269-92.

Li, Wei, 1997. The Impact of Economic Reform on the Performance of Chinese State Enterprises, 1980-1989" Journal of Political Economy 105, 1080-1106.

Lin, J., F. Cai, and Z. Li. 1998. Competition, Policy Burdens, and State-owned Enterprise Reform. American Economic Review 88, 422-27.

-----, 1999. The China Miracle: Development Strategy and Economic Reform (2nd edition). Shanghai People's Publishing House and Shanghai Sanlian Shudian.

Liu, Q., and A. Siu, 2011. Institutions and Corporate Investment: Evidence from InvestmentImplied Return on Capital in China. Journal of Financial and Quantitative Analysis 46, 1831-1863.

Mastuyama, K., 2008. Structural Change, in L. Blume and S. Durlauf, eds., The New Palgrave Dictionary of Economics, 2nd Edition, Palgrave Macmillan, 2008.

-----, 2009. Structural Change in an Interdependent World: A Global View of Manufacturing Decline, Journal of the European Economic Association 7: 478-486.

McMillan, M., and D. Rodrik. 2011. Globalization, Structural Change, and Productivity Growth, Harvard University working paper

Myerson, R., and S. Braguinsky, 2007. A Macroeconomic Model of Russian Transition: the Role of Oligarchic Property Rights, Economics of Transition 15: 77-107.

Murphy, K., A. Shleifer and R. Vishny, 1992. The Transition to a Market Economy: Pitfalls of Partial Reform, Quarterly Journal of Economics 107, 889-906.

Ngai, R., and C. Passarides. 2007. Structural Change in a Multi-Sector Model of Growth. American Economic Review 97: 429-443

Naughton, B., 2007. The Chinese Economy: Transitions and Growth. Cambridge: The MIT Press

Qian, Y., 1996. Enterprise Reform in China: Agency Problems and Political Control, Economics of Transition 4, 427-447.

Restuccia, D., D. Yang, and X. Zhu, 2008. Agriculture and aggregate productivity: A quantitative cross-country analysis, Journal of Monetary Economics 55: 234-250.

Roland, G., 2000. Transtion and Economics: Politics, Markets and Firms, MIT Press. 
Sachs, J., and W. Woo, 2000. Understanding China's Economic Performance. Journal of Policy Reform 4: 1-50.

Shleifer, A., and D. Treisman. 1999. Without a Map: Political Tactics and Economic Reform in Russia, Cambridge: The MIT Press.

Shleifer, Andrei and R. Vishny, 1994, "Politic s of Market Socialism", Journal of Economic Perspectives, Spring 1994.

Song, Z., K. Storesletten, and F. Zilibotti. 2011. Growing Like China. American Economic Review 101: 196--233.

Sun, Q., and W. Ton. 2003. China Share Issue Privatization: the Extent of its Success, Journal of Financial Economics 70, 183--222

Szamosszegi, A., and C. Kyle. 2011. An Analysis of State-owned Enterprises and State Capitalism in China, US-China Economic and Security Review Commission.

Ventura, J., 1997. Growth and Interdependence. Quarterly Journal of Economics 112: 57--84.

Vollrath, D., 2009. How Important Are Dual Economy Effects for Aggregate Productivity? Journal of Development Economics 88, 325-334.

Wang, Y., 2009. Fiscal Decentralization, Endogenous Policies, and Foreign Direct Investment: Theory and Evidence from China and India, University of Chicago PhD Dissertation (Chapter 1).

----, 2011. Industrial Dynamics, International Trade, and Economic Growth, HKUST working paper.

World Bank, 2012. China 2030. The World Bank Press.

$\mathrm{Xu}, \mathrm{C} ., 2011$. The Fundamental Institutions of China's Reforms and Development, Journal of Economic Litera ture 49: 1076-1151.

Yi, K., 2003. Can Vertical Specialization Explain the Growth of World Trade? Journal of Political Economy 111, 52-102.

-----, and J. Zhang 2011. Structural Change in an Open Economy, Federal Reserve Bank of Minneapolis Staff Report 456.

Young, A., 2000. The Razor's Edge: Distortions and Incremental Reform in the People's Republic of China. Quarterly Journal of Economics 115: 1091-1135. 


\section{$9 \quad$ Appendix (for online publication)}

\subsection{Proof of Lemma 3}

First, we prove why (23) -(25) are needed. To ensure the trade pattern in equilibrium as described earlier, we require that

$$
\frac{p_{d}}{p_{n}}<A^{*}
$$

or equivalently

$$
\frac{1}{A \alpha^{\alpha} \beta^{\beta}(1-\alpha-\beta)^{1-\alpha-\beta}}\left(\frac{\mu}{A_{m} \gamma^{\gamma}(1-\gamma)^{1-\gamma}}\right)^{1-\alpha-\beta}\left(\frac{K}{2 b}\right)^{\frac{-[\alpha+\gamma(1-\alpha-\beta)]}{1+\alpha(\epsilon-1)+\gamma(1-\alpha-\beta)(\epsilon-1)}}<A^{*} .
$$

The positive production of the numeraire good in country $\mathrm{H}$ requires $L>\overline{\bar{L}}$, where

$$
\overline{\bar{L}} \equiv 2^{\frac{1}{1+\alpha(\epsilon-1)+\gamma(1-\alpha-\beta)(\epsilon-1)}} \bar{L}\left(A, A_{m}, K\right)
$$

which is the total labor employed in the non-numeraire sectors in country $\mathrm{H}$ in the trade equilibrium. On the other hand, the positive consumption of the numeraire good in country F requires

$$
D_{n}^{*}=A^{*} L^{*}-\frac{p_{d} D_{d}^{*}}{W}>0
$$

or equivalently

$$
A^{*} L^{*}-\left(A \alpha^{\alpha} \beta^{\beta}(1-\alpha-\beta)^{1-\alpha-\beta}\left(\frac{A_{m} \gamma^{\gamma}(1-\gamma)^{1-\gamma}}{\mu}\right)^{1-\alpha-\beta}\left(\frac{K}{2 b}\right)^{\frac{[\alpha+\gamma(1-\alpha-\beta)]}{1+\alpha(\epsilon-1)+\gamma(1-\alpha-\beta)(\epsilon-1)}}\right)^{\epsilon-1}>0
$$

The individual consumption in country $\mathrm{H}$ is given by 


$$
\begin{aligned}
c_{n}^{e}= & L+\left(\frac{K}{2 b}\right)^{\frac{-1}{1+\alpha(\epsilon-1)+\gamma(1-\alpha-\beta)(\epsilon-1)}} \cdot K+\frac{\left[\frac{1}{A \alpha^{\alpha} \beta^{\beta}(1-\alpha-\beta)^{1-\alpha-\beta}}\right]^{1-\epsilon}}{\left[\frac{\mu}{A_{m} \gamma^{\gamma}(1-\gamma)^{1-\gamma}}\right]^{(1-\alpha-\beta)(\epsilon-1)}} \\
& \cdot\left(\frac{K}{2 b}\right)^{\frac{\alpha(\epsilon-1)+\gamma(1-\alpha-\beta)(\epsilon-1)}{1+\alpha(\epsilon-1)+\gamma(1-\alpha-\beta)(\epsilon-1)}} \cdot\left[\frac{1}{\theta} \frac{2(1-\alpha-\beta)}{(1-\alpha-\beta)(\epsilon-1)+1}-1\right], \\
c_{n}^{g}= & L+\left(\frac{K}{2 b}\right)^{\frac{-1}{1+\alpha(\epsilon-1)+\gamma(1-\alpha-\beta)(\epsilon-1)}} \cdot K-\frac{\left[\frac{1}{A \alpha^{\alpha} \beta^{\beta}(1-\alpha-\beta)^{1-\alpha-\beta}}\right]^{1-\epsilon}}{\left[\frac{\mu}{A_{m} \gamma^{\gamma}(1-\gamma)^{1-\gamma}}\right]^{(1-\alpha-\beta)(\epsilon-1)}} \cdot \\
& \cdot\left(\frac{K}{2 b}\right)^{\frac{\alpha(\epsilon-1)+\gamma(1-\alpha-\beta)(\epsilon-1)}{1+\alpha(\epsilon-1)+\gamma(1-\alpha-\beta)(\epsilon-1)}}, \quad \\
c_{d}^{j}= & \left\{\frac{1}{A \alpha^{\alpha} \beta^{\beta}(1-\alpha-\beta)^{1-\alpha-\beta}}\left(\frac{\mu}{A_{m} \gamma^{\gamma}(1-\gamma)^{1-\gamma}}\right)^{1-\alpha-\beta}\left(\frac{K}{2 b}\right)^{\frac{-[\alpha+\gamma(1-\alpha-\beta)]}{1+\alpha(\epsilon-1)+\gamma(1-\alpha-\beta)(\epsilon-1)}}\right\}^{-\epsilon}, \\
\forall j \in & \{e, g\} .
\end{aligned}
$$

The aggregate consumption of the numeraire good in country $\mathrm{H}$ is

$$
\begin{aligned}
C_{n}= & L+\left(\frac{K}{2 b}\right)^{\frac{-1}{1+\alpha(\epsilon-1)+\gamma(1-\alpha-\beta)(\epsilon-1)}} \cdot K+\frac{\left[\frac{1}{A \alpha^{\alpha} \beta^{\beta}(1-\alpha-\beta)^{1-\alpha-\beta}}\right]^{1-\epsilon}}{\left[\frac{\mu}{A_{m} \gamma^{\gamma}(1-\gamma)^{1-\gamma}}\right]^{(1-\alpha-\beta)(\epsilon-1)}} \\
& \cdot\left(\frac{K}{2 b}\right)^{\frac{\alpha(\epsilon-1)+\gamma(1-\alpha-\beta)(\epsilon-1)}{1+\alpha(\epsilon-1)+\gamma(1-\alpha-\beta)(\epsilon-1)}}\left[\frac{2(1-\alpha-\beta)}{(1-\alpha-\beta)(\epsilon-1)+1}-1\right] .
\end{aligned}
$$

For completeness, the total (or individual) consumption in country $\mathrm{F}$ is given by $c_{n}^{*}=A^{*} L^{*}-$ $\left[\frac{1}{A \alpha^{\alpha} \beta^{\beta}(1-\alpha-\beta)^{1-\alpha-\beta}}\right]^{1-\epsilon}\left[\frac{\mu}{A_{m} \gamma^{\gamma}(1-\gamma)^{1-\gamma}}\right]^{(1-\alpha-\beta)(1-\epsilon)}\left(\frac{K}{2 b}\right)^{\frac{\alpha(\epsilon-1)+\gamma(1-\alpha-\beta)(\epsilon-1)}{1+\alpha(\epsilon-1)+\gamma(1-\alpha-\beta)(\epsilon-1)}}$ and $c_{d}^{*}=\left\{\frac{1}{A \alpha^{\alpha} \beta^{\beta}(1-\alpha-\beta)^{1-\alpha-\beta}}\left(\frac{\mu}{A_{m} \gamma^{\gamma}(1-\gamma)^{1-\gamma}}\right)^{1-\alpha-\beta}\left(\frac{K}{2 b}\right)^{\frac{-[\alpha+\gamma(1-\alpha-\beta)]}{1+\alpha(\epsilon-1)+\gamma(1-\alpha-\beta)(\epsilon-1)}}\right\}^{-\epsilon}$. Condition (24) guarantees that $c_{n}^{*}>0$. The total GDP in country $\mathrm{F}$ is $I^{*}=L^{*} W^{*}=L^{*} A^{*} W$.

To ensure that even the grass root in country $\mathrm{H}$ consumes a positive amount of numeraire good, we have

$$
\begin{aligned}
& R K+W L>p_{n}^{\epsilon} p_{d}^{1-\epsilon} \\
& \Leftrightarrow L>\left[p_{n} \cdot \frac{\left[A_{m}^{(1-\alpha-\beta)} A\right]^{\frac{-1}{1+\alpha(\epsilon-1)+\gamma(1-\alpha-\beta)(\epsilon-1)}}}{\alpha^{\alpha} \beta^{\beta}\left(\frac{1-\alpha-\beta}{\gamma^{\gamma}(1-\gamma)^{1-\gamma}}\right)^{1-\alpha-\beta}}\left(\frac{K}{2 \varkappa}\right)^{\frac{-[\alpha+\gamma(1-\alpha-\beta)]}{1+\alpha(\epsilon-1)+\gamma(1-\alpha-\beta)(\epsilon-1)}}\right]^{1-\epsilon} \\
& -\left[A_{m}^{(1-\alpha-\beta)} A\right]^{\frac{(\epsilon-1)}{1+\alpha(\epsilon-1)+\gamma(1-\alpha-\beta)(\epsilon-1)}}\left(\frac{K}{2 \varkappa}\right)^{\frac{-1}{1+\alpha(\epsilon-1)+\gamma(1-\alpha-\beta)(\epsilon-1)}} K \\
& \Leftrightarrow \quad L>\frac{\frac{\mu}{2}-\gamma(1-\alpha-\beta)-\alpha \mu}{(1-\gamma)(1-\alpha-\beta)+\beta \mu} \overline{\bar{L}}\left(A, A_{m}, K\right) .
\end{aligned}
$$


Therefore, the condition of $\frac{\frac{\mu}{2}-\gamma(1-\alpha-\beta)-\alpha \mu}{(1-\gamma)(1-\alpha-\beta)+\beta \mu} \geq 1$ means that $(1-\alpha-\beta)(\epsilon-3)+1 \leq 0$.

It is easy to confirm that

$$
\overline{\bar{L}}\left(A, A_{m}, K\right) \equiv 2^{\frac{1}{1+\alpha(\epsilon-1)+\gamma(1-\alpha-\beta)(\epsilon-1)}} \bar{L}\left(A, A_{m}, K\right)
$$

\subsection{Proof of Proposition 4}

Suppose that the SOE takes the wage as exogenously given. The labor market clearing condition in country $\mathrm{H}$ is

$$
\begin{aligned}
L & =\left(D_{d}+D_{d}^{*}\right) \cdot \frac{\partial p_{d}}{\partial W}+D_{m} \frac{\partial \frac{R^{\gamma} W^{1-\gamma}}{A_{m} \gamma^{\gamma}(1-\gamma)^{1-\gamma}}}{\partial W} \\
& =2 \frac{p_{n}^{\epsilon}}{W^{\epsilon}}\left[\frac{\left(\frac{R}{W}\right)^{\alpha+\gamma(1-\alpha-\beta)}\left(\frac{\tilde{\mu}}{A_{m} \gamma^{\gamma}(1-\gamma)^{1-\gamma}}\right){ }^{1-\alpha-\beta}}{A \alpha^{\alpha} \beta^{\beta}(1-\alpha-\beta)^{1-\alpha-\beta}}\right]^{1-\epsilon} \beta\left[1+\frac{(1-\gamma)(1-\alpha-\beta)}{\widetilde{\mu} \beta}\right],
\end{aligned}
$$

since $p_{m}=\frac{\widetilde{\mu} R^{\gamma} W^{1-\gamma}}{A_{m} \gamma^{\gamma}(1-\gamma)^{1-\gamma}}$. That is,

$$
L=2 \frac{p_{n}^{\epsilon}}{W^{\epsilon}}\left[\frac{\left(\frac{R}{W}\right)^{\alpha+\gamma(1-\alpha-\beta)}\left(\frac{\widetilde{\mu}}{A_{m} \gamma^{\gamma}(1-\gamma)^{1-\gamma}}\right)^{1-\alpha-\beta}}{A \alpha^{\alpha} \beta^{\beta}(1-\alpha-\beta)^{1-\alpha-\beta}}\right]^{1-\epsilon} \beta\left[1+\frac{(1-\gamma)(1-\alpha-\beta)}{\widetilde{\mu} \beta}\right]
$$

The capital labor market clearing condition in country $\mathrm{H}$ is $K=\left(D_{d}+D_{d}^{*}\right) \cdot \frac{\partial p_{d}}{\partial R}+D_{m} \frac{\partial \frac{R^{\gamma} W^{1-\gamma}}{A_{m} \gamma(1-\gamma)^{1-\gamma}}}{\partial R}$. From (14), we obtain $K=2 b\left(\frac{R}{W}\right)^{-[1+\alpha(\epsilon-1)+\gamma(1-\alpha-\beta)(\epsilon-1)]} \cdot\left(\frac{p_{n}}{W}\right)^{\epsilon}$, which, together with (40), yields $\frac{\mu^{(1-\alpha-\beta)(1-\epsilon)-1} \cdot[\gamma(1-\alpha-\beta)+\alpha \mu]}{\left[\widetilde{\mu}^{1-\alpha-\beta}\right]^{1-\epsilon}\left[\beta+\frac{(1-\gamma)(1-\alpha-\beta)}{\widetilde{\mu}}\right]}=\frac{K}{L} \frac{R}{W}$, where $b \equiv\left[A_{m}^{(1-\alpha-\beta)} A\right]^{\epsilon-1} \varkappa$.

When $\widetilde{\mu}=\mu$, the above equation becomes

$$
\frac{R}{W}=\frac{\gamma(1-\alpha-\beta)+\alpha \mu}{\beta \mu+(1-\gamma)(1-\alpha-\beta)} \frac{L}{K}
$$

Consequently,

$$
\begin{aligned}
W & =(2 b)^{\frac{1}{\epsilon}}\left[L \cdot \frac{\gamma(1-\alpha-\beta)+\alpha \mu}{(1-\gamma)(1-\alpha-\beta)+\beta \mu}\right]^{\frac{-[1+\alpha(\epsilon-1)+\gamma(1-\alpha-\beta)(\epsilon-1)]}{\epsilon}} K^{\frac{\alpha(\epsilon-1)+\gamma(1-\alpha-\beta)(\epsilon-1)}{\epsilon}} p_{n}, \\
R & =(2 b)^{\frac{1}{\epsilon}}\left[L \cdot \frac{\gamma(1-\alpha-\beta)+\alpha \mu}{(1-\gamma)(1-\alpha-\beta)+\beta \mu}\right]^{\frac{[1-\alpha-\gamma(1-\alpha-\beta)](\epsilon-1)}{\epsilon}} K^{\frac{\alpha(\epsilon-1)+\gamma(1-\alpha-\beta)(\epsilon-1)}{\epsilon}-1} p_{n}, \\
W^{*} & =A^{*} p_{n}
\end{aligned}
$$




$$
\begin{aligned}
& p_{m}=(2 b)^{\frac{1}{\epsilon}} \frac{\mu K^{\frac{\alpha(\epsilon-1)+\gamma(1-\alpha-\beta)(\epsilon-1)}{\epsilon}-\gamma}}{A_{m} \gamma^{\gamma}(1-\gamma)^{1-\gamma}}\left[L \cdot \frac{\gamma(1-\alpha-\beta)+\alpha \mu}{(1-\gamma)(1-\alpha-\beta)+\beta \mu}\right]^{\frac{(\epsilon-1)\{\gamma \beta-(1-\gamma) \alpha\}-(1-\gamma)}{\epsilon}} p_{n}, \\
& p_{d}=\frac{(2 b)^{\frac{1}{\epsilon}}\left[\frac{\mu}{A_{m} \gamma^{\gamma}(1-\gamma)^{1-\gamma}}\right]^{1-\alpha-\beta}}{A \alpha^{\alpha} \beta^{\beta}(1-\alpha-\beta)^{1-\alpha-\beta}} K^{\frac{-[\alpha+\gamma(1-\alpha-\beta)]}{\epsilon}}\left[L \cdot \frac{\gamma(1-\alpha-\beta)+\alpha \mu}{(1-\gamma)(1-\alpha-\beta)+\beta \mu}\right]^{-\frac{(1-\gamma)(1-\alpha-\beta)+\beta}{\epsilon}} p_{n}, \\
& D_{d}=D_{d}^{*}=(2 b)^{-1} K^{\alpha+\gamma(1-\alpha-\beta)} \frac{\left[L \cdot \frac{\gamma(1-\alpha-\beta)+\alpha \mu}{(1-\gamma)(1-\alpha-\beta)+\beta \mu}\right]^{(1-\gamma)(1-\alpha-\beta)+\beta}}{\left(\frac{\left[\frac{\mu}{\gamma^{\gamma}(1-\gamma)^{1-\gamma}}\right]^{1-\alpha-\beta}}{A_{m}^{1-\alpha-\beta} A \alpha^{\alpha} \beta^{\beta}(1-\alpha-\beta)^{1-\alpha-\beta}}\right)^{\epsilon}} \\
& D_{m}=(b)^{-1} K^{\gamma} \frac{\left[L \cdot \frac{\gamma(1-\alpha-\beta)+\alpha \mu}{(1-\gamma)(1-\alpha-\beta)+\beta \mu}\right]^{(1-\gamma)}}{\left(\frac{\left[\frac{\mu}{A_{m} \gamma(1-\gamma)^{1-\gamma}}\right]^{1-\alpha-\beta}}{A \alpha^{\alpha} \beta^{\beta}(1-\alpha-\beta)^{1-\alpha-\beta}}\right)^{\epsilon-1}} \frac{A_{m} \gamma^{\gamma}(1-\gamma)^{1-\gamma}(1-\alpha-\beta)}{\mu}, \\
& \Pi_{m}=D_{m} \frac{\mu-1}{\mu} p_{m} \\
& =\frac{\mu-1}{\mu} \frac{\left[A_{m}^{(1-\alpha-\beta)} A\right]^{\frac{\epsilon-1}{\epsilon}}(\varkappa)^{-1} \cdot K^{\frac{\alpha(\epsilon-1)+\gamma(1-\alpha-\beta)(\epsilon-1)}{\epsilon}}}{\frac{(2 \varkappa)^{-\frac{1}{\epsilon}}}{1-\alpha-\beta}\left[L \cdot \frac{\gamma(1-\alpha-\beta)+\alpha \mu}{(1-\gamma)(1-\alpha-\beta)+\beta \mu}\right]^{\frac{(1-\epsilon)\{\gamma \beta+(1-\alpha)(1-\gamma)\}}{\epsilon}}}\left(\frac{\left[\frac{\mu}{\gamma^{\gamma}(1-\gamma)^{1-\gamma}}\right] 1-\alpha-\beta}{\alpha^{\alpha} \beta^{\beta}(1-\alpha-\beta)^{1-\alpha-\beta}}\right)^{1-\epsilon} p_{n}, \\
& G D P=W L+R K+\Pi_{m} \\
& =\left[\frac{(1-\gamma)(1-\alpha-\beta)+\beta \mu}{\gamma(1-\alpha-\beta)+\alpha \mu}+1+\frac{\frac{\mu-1}{\mu}(b)^{-1}}{(1-\alpha-\beta)^{-1}}\left(\frac{\left[\frac{\mu}{A_{m} \gamma^{\gamma}(1-\gamma)^{1-\gamma}}\right]^{1-\alpha-\beta}}{A \alpha^{\alpha} \beta^{\beta}(1-\alpha-\beta)^{1-\alpha-\beta}}\right)^{1-\epsilon}\right] \\
& \cdot K^{\frac{\alpha(\epsilon-1)+\gamma(1-\alpha-\beta)(\epsilon-1)}{\epsilon}}\left[L \cdot \frac{\gamma(1-\alpha-\beta)+\alpha \mu}{(1-\gamma)(1-\alpha-\beta)+\beta \mu}\right]^{\frac{(\epsilon-1)\{\gamma \beta+(1-\alpha)(1-\gamma)\}}{\epsilon}}(2 b)^{\frac{1}{\epsilon}} p_{n} .
\end{aligned}
$$

It is easy to obtain $\frac{W L}{G D P}, \frac{R K}{G D P}$ and $\frac{\Pi_{m}}{G D P}$.

To ensure positive consumption of the numeraire good in country $\mathrm{H}$, we require

$$
G D P>D_{d} p_{d}
$$


which is true if and only if

$$
\frac{(1-\alpha-\beta)+(\beta+\alpha) \mu}{\gamma(1-\alpha-\beta)+\alpha \mu}>(\varkappa)^{-1}\left(\frac{\left[\frac{\mu}{\gamma^{\gamma}(1-\gamma)^{1-\gamma}}\right]{ }^{1-\alpha-\beta}}{\alpha^{\alpha} \beta^{\beta}(1-\alpha-\beta)^{1-\alpha-\beta}}\right)^{1-\epsilon}\left[\frac{1}{2}-\frac{\mu-1}{\mu}(1-\alpha-\beta)\right] .
$$

The above equation must always hold whenever

$$
(1-\alpha-\beta)(\epsilon-3)+1 \leq 0
$$

because $\frac{1}{2}-\frac{\mu-1}{\mu}(1-\alpha-\beta) \leq 0$. If $(1-\alpha-\beta)(\epsilon-3)+1>0$, then (42) holds if and only if

$$
\begin{aligned}
(1-\alpha-\beta)+(\beta+\alpha) \mu> & \left(\frac{\left[\alpha^{\alpha} \beta^{\beta}(1-\alpha-\beta)^{1-\alpha-\beta}\right]^{(-1+\epsilon) 2} \mu^{2(1-\alpha-\beta)(1-\epsilon)-1}}{\left[\gamma^{\gamma}(1-\gamma)^{1-\gamma}\right]^{2(1-\alpha-\beta)(1-\epsilon)}}\right)^{-1} \\
& {\left[\frac{1}{2}-\frac{\mu-1}{\mu}(1-\alpha-\beta)\right] }
\end{aligned}
$$

We also need to ensure that

$$
W^{*} L^{*}>D_{d}^{*} p_{d}
$$

so that country $\mathrm{F}$ also consumes the numeraire. The above condition is reduced to

$$
A^{*} L^{*}>\left[A_{m}^{(1-\alpha-\beta)} A\right]^{\frac{\epsilon-1}{\epsilon}}(2 \varkappa)^{\frac{1}{\epsilon}-1} K^{[\alpha+\gamma(1-\alpha-\beta)] \frac{\epsilon-1}{\epsilon}} \frac{\left[L \cdot \frac{\gamma(1-\alpha-\beta)+\alpha \mu}{(1-\gamma)(1-\alpha-\beta)+\beta \mu}\right]^{[(1-\gamma)(1-\alpha-\beta)+\beta] \frac{\epsilon-1}{\epsilon}}}{\left(\frac{\left[\frac{\mu}{\gamma \gamma(1-\gamma)^{1-\gamma}}\right]^{1-\alpha-\beta}}{\alpha^{\alpha} \beta^{\beta}(1-\alpha-\beta)^{1-\alpha-\beta}}\right)^{\epsilon-1}} .
$$

To ensure that country $\mathrm{H}$ does not produce the numeraire good, we must require $p_{n}<W$, which can be shown equivalent to $L<\overline{\bar{L}}\left(A, A_{m}, K\right)$. To ensure country $\mathrm{F}$ does not produce the differentiated good, we must require

$$
W^{*}>p_{d}
$$

or equivalently

$$
A^{*}>(2 \varkappa)^{\frac{1}{\epsilon}}\left[A_{m}^{(1-\alpha-\beta)} A\right]^{\frac{-1}{\epsilon}} \frac{\frac{\left[\frac{\mu}{\gamma^{\gamma}(1-\gamma)^{1-\gamma}}\right]^{1-\alpha-\beta}}{\alpha^{\alpha} \beta^{\beta}(1-\alpha-\beta)^{1-\alpha-\beta}} K^{\frac{-[\alpha+\gamma(1-\alpha-\beta)]}{\epsilon}}}{\left[L \cdot \frac{\gamma(1-\alpha-\beta)+\alpha \mu}{(1-\gamma)(1-\alpha-\beta)+\beta \mu}\right]^{\frac{(1-\gamma)(1-\alpha-\beta)+\beta}{\epsilon}}} .
$$




\subsection{Proof of Proposition 5}

Under the trade pattern, we have

$$
\begin{aligned}
p_{d} & =p_{d}^{*}=\frac{R^{\alpha} W^{\beta} p_{m}^{1-\alpha-\beta}}{A \alpha^{\alpha} \beta^{\beta}(1-\alpha-\beta)^{1-\alpha-\beta}}, \\
p_{n} & =p_{n}^{*}=\frac{W^{*}}{A^{*}} \\
D_{d}^{*} & =\frac{W^{*} L^{*}}{p_{d}^{*}} \\
G D P & =p_{n} A^{*} L^{*}+D_{d} p_{d} \\
A^{*} L^{*} & =\frac{[W L+R K]+\Pi_{m}}{p_{n}}-p_{n}^{\epsilon-1} p_{d}^{1-\epsilon} .
\end{aligned}
$$

Hence,

$$
\begin{aligned}
D_{m} & =\left(D_{d}+D_{d}^{*}\right) \frac{\partial p_{d}}{\partial p_{m}} \\
& =\left[\left(\frac{p_{n}}{p_{d}}\right)^{\epsilon}+\frac{W^{*} L^{*}}{p_{d}^{*}}\right] \frac{p_{d}}{p_{m}}(1-\alpha-\beta) \\
& =p_{n}^{\epsilon} \frac{p_{d}^{1-\epsilon}}{p_{m}}(1-\alpha-\beta)+\frac{W^{*} L^{*}}{p_{m}}(1-\alpha-\beta) .
\end{aligned}
$$

and

$$
\begin{aligned}
\Pi_{m} & =\max _{p_{m}} D_{m} \cdot\left[p_{m}-\frac{R^{\gamma} W^{1-\gamma}}{A_{m} \gamma^{\gamma}(1-\gamma)^{1-\gamma}}\right] \\
& =\max _{p_{m}}(1-\alpha-\beta)\left[p_{n}^{\epsilon} \frac{p_{d}^{1-\epsilon}}{p_{m}}+\frac{W^{*} L^{*}}{p_{m}}\right] \cdot\left[p_{m}-\frac{R^{\gamma} W^{1-\gamma}}{A_{m} \gamma^{\gamma}(1-\gamma)^{1-\gamma}}\right]
\end{aligned}
$$

The FOC is

$$
(1-\alpha-\beta)(\epsilon-1) B p_{m}^{(1-\alpha-\beta)(1-\epsilon)+1}-c[(1-\alpha-\beta)(\epsilon-1)+1] B p_{m}^{(1-\alpha-\beta)(1-\epsilon)}-W^{*} L^{*} c=0,
$$

and the SOC is

$$
[(1-\alpha-\beta)(1-\epsilon)+1] p_{m}+c[(1-\alpha-\beta)(\epsilon-1)+1]>0
$$


where

$$
B=p_{n}^{\epsilon}\left[\frac{R^{\alpha} W^{\beta}}{A \alpha^{\alpha} \beta^{\beta}(1-\alpha-\beta)^{1-\alpha-\beta}}\right]^{1-\epsilon}, c=\frac{R^{\gamma} W^{1-\gamma}}{A_{m} \gamma^{\gamma}(1-\gamma)^{1-\gamma}} .
$$

When $(1-\alpha-\beta)(1-\epsilon)+1>0$, the LHS of FOC is strictly increasing in $p_{m}$. So there exists a unique and positive solution for $p_{m}\left(B, c, W^{*} L^{*}\right)$. The second order condition is also satisfied. In addition,

$$
\frac{\partial p_{m}}{\partial B}<0 ; \frac{\partial p_{m}}{\partial c}>0 ; \frac{\partial p_{m}}{\partial\left(W^{*} L^{*}\right)}>0
$$

Without loss of generality, we denote the solution by

$$
p_{m}=\widetilde{\mu} \cdot c,
$$

where the price markup $\widetilde{\mu}$ is generally a function of $\left(B, c, W^{*} L^{*}\right)$. Obviously, $\widetilde{\mu}=\mu$ when $W^{*} L^{*}=0$, and $\widetilde{\mu}>\mu$ whenever $W^{*} L^{*}>0$, because the foreign demand is less elastic (unity elasticity). In fact,

$$
\begin{aligned}
\widetilde{\mu} & =\mu+\frac{W^{*} L^{*}}{(1-\alpha-\beta)(\epsilon-1) B(\widetilde{\mu} c)^{(1-\alpha-\beta)(1-\epsilon)}} \\
& \leq \mu+\frac{W^{*} L^{*}}{(1-\alpha-\beta)(\epsilon-1) p_{n}\left(A^{*}\right)^{(1-\epsilon)}} \\
& =\mu+\frac{A^{* \epsilon} L^{*}}{(1-\alpha-\beta)(\epsilon-1)} .
\end{aligned}
$$

Now we have the following equation:

$$
\frac{[(\widetilde{\mu}-\mu)(1-\alpha-\beta)(\epsilon-1)]^{\frac{1}{\epsilon-1}}}{\widetilde{\mu}^{(1-\alpha-\beta)}}=\frac{\frac{\left(A^{*} L^{*}\right)^{\frac{\epsilon}{\epsilon-1}}}{\left[\beta+(1-\alpha-\beta) \frac{1-\gamma}{\tilde{\mu}}\right]^{-1+\alpha+\gamma(1-\alpha-\beta)}} \cdot\left[\frac{1+(\widetilde{\mu}-\mu)(1-\alpha-\beta)(\epsilon-1)}{(\widetilde{\mu}-\mu)(1-\alpha-\beta)(\epsilon-1)}\right]}{\left[\frac{\left(\left[\alpha+(1-\alpha-\beta) \frac{\gamma}{\widetilde{\mu}}\right] \frac{L}{K}\right)^{\alpha+\gamma(1-\alpha-\beta)}}{A \alpha^{\alpha} \beta^{\beta}\left[A_{m} \gamma^{\gamma}(1-\gamma)^{1-\gamma}(1-\alpha-\beta)\right]^{1-\alpha-\beta} L}\right]^{-1}} .
$$

where RHS is decreasing in $\widetilde{\mu}$. LHS increases in $\widetilde{\mu}$ iff $\widetilde{\mu}<\mu\left[1+\frac{1}{(\epsilon-1)(1-\alpha-\beta)-1}\right]$. Thus $\widetilde{\mu}$ can be uniquely determined by (35) under the previous condition, which must be true when $\frac{(1-\alpha-\beta)(\epsilon-1)+1}{(\epsilon-1)(1-\alpha-\beta)-1}>A^{* \epsilon} L^{*}$ by using $(44)$. 


\subsection{Proof in Section 5}

Consider any industry $j$ that is monopolized by an SOE. This firm faces the following demand function $D(j)=\left(\frac{p_{n}}{P}\right)^{\epsilon}\left[\frac{p(j)}{P}\right]^{-\eta}$, where $p(i)$ denotes the market price of good $i \in[0,1]$ and the price index $P$ is defined as $P \equiv\left(\int_{0}^{1} p(i)^{1-\eta} d i\right)^{\frac{1}{1-\eta}}$. The aggregate price $P$ and $p_{n}$ are taken as given by the SOE, so it would choose $p(j)=\frac{\eta}{\eta-1} \frac{R^{\alpha} W^{\beta} p_{m}{ }^{1-\alpha-\beta}}{A_{s} \alpha^{\alpha} \beta^{\beta}(1-\alpha-\beta)^{1-\alpha-\beta}}$. On the other hand, for any liberalized industry $j^{\prime}$ perfect competition implies $p\left(j^{\prime}\right)=\frac{R^{\alpha} W^{\beta} p_{m}{ }^{1-\alpha-\beta}}{A_{p} \alpha^{\alpha} \beta^{\beta}(1-\alpha-\beta)^{1-\alpha-\beta}}$, so the aggregate price level

$$
\begin{aligned}
P & =\left(\int_{0}^{1} p(i)^{1-\eta} d i\right)^{\frac{1}{1-\eta}} \\
& =\left((1-\phi)\left[\frac{\eta}{\eta-1} \frac{1}{A_{s}}\right]^{1-\eta}+\phi\left[\frac{1}{A_{p}}\right]^{1-\eta}\right)^{\frac{1}{1-\eta}} \frac{R^{\alpha} W^{\beta} p_{m}^{1-\alpha-\beta}}{\alpha^{\alpha} \beta^{\beta}(1-\alpha-\beta)^{1-\alpha-\beta}}
\end{aligned}
$$

The induced demand for the intermediate good from the SOE monopolist in industry $j$ is

$$
D(j) \frac{(1-\alpha-\beta)}{p_{m}} \frac{p(j)}{\frac{\eta}{\eta-1}} .
$$

The total demand for the intermediate good is

$$
\begin{aligned}
& \phi \frac{(1-\alpha-\beta) p\left(j^{\prime}\right)}{p_{m}}\left(\frac{p_{n}}{P}\right)^{\epsilon}\left[\frac{p\left(j^{\prime}\right)}{P}\right]^{-\eta}+(1-\phi)\left(\frac{p_{n}}{P}\right)^{\epsilon}\left[\frac{p(j)}{P}\right]^{-\eta} \frac{(1-\alpha-\beta)}{p_{m}} \frac{p(j)}{\frac{\eta}{\eta-1}} \\
= & p_{n}^{\epsilon} \frac{(1-\alpha-\beta)}{p_{m}} \frac{\phi\left(\frac{1}{A_{p}}\right)^{1-\eta}+(1-\phi)\left[\frac{1}{A_{s}}\right]^{1-\eta}\left(\frac{\eta}{\eta-1}\right)^{-\eta}}{\left[(1-\phi)\left[\frac{\eta}{\eta-1} \frac{1}{A_{s}}\right]^{1-\eta}+\phi\left[\frac{1}{A_{p}}\right]^{1-\eta}\right]^{\frac{\epsilon-\eta}{1-\eta}}}\left[\frac{R^{\alpha} W^{\beta} p_{m}^{1-\alpha-\beta}}{\alpha^{\alpha} \beta^{\beta}(1-\alpha-\beta)^{1-\alpha-\beta}}\right]^{1-\epsilon},
\end{aligned}
$$

so the total profit of the upstream SOE is

$$
p_{n}^{\epsilon} \frac{(1-\alpha-\beta)}{p_{m}} \frac{\phi\left(\frac{1}{A_{p}}\right)^{1-\eta}+(1-\phi)\left[\frac{1}{A_{s}}\right]^{1-\eta}\left(\frac{\eta}{\eta-1}\right)^{-\eta}}{\left[(1-\phi)\left[\frac{\eta}{\eta-1} \frac{1}{A_{s}}\right]^{1-\eta}+\phi\left[\frac{1}{A_{p}}\right]^{1-\eta}\right]^{\frac{\epsilon-\eta}{1-\eta}}}\left[\frac{R^{\alpha} W^{\beta} p_{m}^{1-\alpha-\beta}}{\alpha^{\alpha} \beta^{\beta}(1-\alpha-\beta)^{1-\alpha-\beta}}\right]^{1-\epsilon}\left[\frac{\mu-1}{\mu} p_{m}\right],
$$


and the total downstream SOE profit is

$$
\begin{aligned}
& (1-\phi)\left(\frac{p_{n}}{P}\right)^{\epsilon}\left[\frac{p(j)}{P}\right]^{-\eta}\left(\frac{\eta}{\eta-1}-1\right) \frac{R^{\alpha} W^{\beta} p_{m}{ }^{1-\alpha-\beta}}{A_{s} \alpha^{\alpha} \beta^{\beta}(1-\alpha-\beta)^{1-\alpha-\beta}} \\
= & p_{n}^{\epsilon} \frac{(1-\phi)\left[\frac{\eta}{\eta-1} \frac{1}{A_{s}}\right]^{-\eta}\left(\frac{1}{\eta-1}\right) \frac{1}{A_{s}}}{\left((1-\phi)\left[\frac{\eta}{\eta-1} \frac{1}{A_{s}}\right]^{1-\eta}+\phi\left[\frac{1}{A_{p}}\right]^{1-\eta}\right)^{\frac{\epsilon-\eta}{1-\eta}}}\left[\frac{R^{\alpha} W^{\beta} p_{m}{ }^{1-\alpha-\beta}}{\alpha^{\alpha} \beta^{\beta}(1-\alpha-\beta)^{1-\alpha-\beta}}\right]^{1-\epsilon} .
\end{aligned}
$$

Therefore, the aggregate profit of SOE is

$$
\begin{aligned}
& {\left[\frac{(\mu-1)(1-\alpha-\beta)}{\mu} \frac{\phi\left(\frac{1}{A_{p}}\right)^{1-\eta}+(1-\phi)\left[\frac{1}{A_{s}}\right]^{1-\eta}\left(\frac{\eta}{\eta-1}\right)^{-\eta}}{\left[(1-\phi)\left[\frac{\eta}{\eta-1} \frac{1}{A_{s}}\right]^{1-\eta}+\phi\left[\frac{1}{A_{p}}\right]^{1-\eta}\right]^{\frac{\epsilon-\eta}{1-\eta}}}+\frac{(1-\phi)\left[\frac{\eta}{\eta-1} \frac{1}{A_{s}}\right]^{-\eta}\left(\frac{1}{\eta-1}\right) \frac{1}{A_{s}}}{\left((1-\phi)\left[\frac{\eta}{\eta-1} \frac{1}{A_{s}}\right]^{1-\eta}+\phi\left[\frac{1}{A_{p}}\right]^{1-\eta}\right)^{\frac{\epsilon-\eta}{1-\eta}}}\right]} \\
& \cdot p_{n}^{\epsilon}\left[\frac{R^{\alpha} W^{\beta} p_{m}^{1-\alpha-\beta}}{\alpha^{\alpha} \beta^{\beta}(1-\alpha-\beta)^{1-\alpha-\beta}}\right]^{1-\epsilon} .
\end{aligned}
$$

which is maximized when $\phi=1$ if $\frac{A_{p}}{A_{s}}>\left(\frac{\eta-1}{\eta}\right)\left[\frac{\eta-1}{\eta}+\frac{\mu}{\eta(\mu-1)(1-\alpha-\beta)}\right]^{\frac{1}{\eta-1}}$ given all the factor prices $(R$ and $W)$ and optimal price choice of upstream intermediate input $p_{m}$. In other words, imagine each of the downstream and upstream SOEs is run by a different profit-maximizing manager (agent) non-cooperatively while a common principle tries to maximize the aggregate profit of all the SOEs in the whole economy by choosing $\phi$. Suppose this common principle takes all the factor prices and all the agents' micro decisions (including $p_{m}$ ) as exogenous, then it would choose to liberalize all the downstream industries $(\phi=1)$.

\subsection{Proof in Section 6.2}

In order to understand the equilibrium under labor market frictions (i.e, $\omega L<\overline{\bar{L}}\left(A, A_{m}, K\right)$ and $\left.L>\overline{\bar{L}}\left(A, A_{m}, K\right)\right)$, we consider the equilibrium in Proposition 4 as a benchmark where $L<$ $\overline{\bar{L}}\left(A, A_{m}, K\right)$. In that equilibrium, country $\mathrm{H}$ consumes a positive amount of numeraire good and, in particular, the equilibrium prices, the SOE profit, and the total GDP in country H are functions of the total labor in the non-numeraire sectors.

Now we consider the trade equilibrium under labor market frictions in which the maximum amount of labor endowment that can be employed in the industrial sector is $\omega L<\overline{\bar{L}}\left(A, A_{m}, K\right)$ 
and the labor endowment $(1-\omega) L$ can only be used to produce the numeraire good. Imagine that each agent in country $\mathrm{H}$ is originally endowed with $\omega L$ units of urban labor and now has additional $(1-\omega) L$ units of rural labor. First, we can show that the trade equilibrium under labor market frictions is similar to the one in Proposition 4, that is, equilibrium prices are completely determined by urban labor $\omega L$, unrelated to rural labor $(1-\omega) L$. More specifically, to obtain the trade equilibrium prices, we only need to replace $L$ in Proposition 4 with $\omega L$ and the wage for the rural labour is $W_{r}=p_{n}<W$. That is, the only difference in the new equilibrium is that country $\mathrm{H}$ uses the labor endowment $(1-\omega) L$ to produce numeraire goods, which are completely consumed domestically; the rural labor does not affect the trade equilibrium prices and hence the equilibrium consumption in country F.

Second, we conduct comparative statics with respect to $\omega$. We have $\frac{\partial R}{\partial \omega}>0, \frac{\partial W}{\partial \omega}<0$ and $\frac{\partial \Pi_{m}}{\partial \omega}>0$, by noting that an increase in $\omega$ is equivalent to an increase in $L$ in Proposition 4 . The total labor income is $(\omega L) W+[(1-\omega) L] p_{n}$, where the first (second) term represents the urban (rural) labor income, and the total GDP is $Y=(\omega L) W+K R+\Pi_{m}+[(1-\omega) L] p_{n}$. Considering $p_{n}<W$, we have that $\frac{\partial Y}{\partial \omega}>0$. The labor income share is $\theta_{L}=\frac{(\omega L) W+[(1-\omega) L] p_{n}}{(\omega L) W+K R+\Pi_{m}+[(1-\omega) L] p_{n}}$. Based on Proposition 4, the labor income share in the industrial sector, the term $\frac{(\omega L) W}{(\omega L) W+K R+\Pi_{m}}$, is constant (in $\omega L)$. By noting that $\theta_{L}$ is obtained by adding $[(1-\omega) L] p_{n}$ on both the numerator and the denominator of the term, we have that $\theta_{L}$ is decreasing in $\omega$. 


\section{Table 1. Chinese Exports by Enterprise Ownership}

Exports are in billions of US dollars. The data are from China Custom. Some years of data are missing.

\begin{tabular}{lrrrc}
\hline & Total Exports & \multicolumn{2}{c}{ Exports by Ownership } & \% of export \\
Year & & SOEs & non-SOEs & from SOEs \\
\cline { 2 - 5 } 1994 & 121.01 & 84.94 & 36.06 & 70.20 \\
1995 & 148.78 & 99.25 & 49.53 & 66.71 \\
1996 & 151.05 & 86.04 & 65.01 & 56.96 \\
1997 & 182.79 & 102.74 & 80.05 & 56.21 \\
1998 & 183.81 & 96.85 & 86.96 & 52.69 \\
2000 & 249.20 & 116.45 & 132.76 & 46.73 \\
2002 & 325.60 & 122.85 & 202.75 & 37.73 \\
2004 & 593.33 & 153.58 & 439.75 & 25.88 \\
2006 & 968.94 & 191.33 & 777.60 & 19.75 \\
2008 & 1430.69 & 257.48 & 1173.21 & 18.00 \\
\hline
\end{tabular}


Table 2. Chinese firms in 2011 Fortune Global 500

\begin{tabular}{|c|c|c|c|c|}
\hline Company Name & Fortune Rank & $\begin{array}{l}\text { Revenues } \\
\text { (\$millions) }\end{array}$ & Headquarter & Industry \\
\hline Sinopec Group & 5 & 273422 & Beijing & Oil and Refinery \\
\hline China National Petroleum & 6 & 240192 & Beijing & Oil and Refinery \\
\hline State Grid & 7 & 226294 & Beijing & Electricity Power \\
\hline Industrial \& Commercial Bank of Chin a & 77 & 80501 & Beijing & Banking \\
\hline China Mobile Communications & 87 & 76673 & Beijing & Telecom \\
\hline China Railway Group & 95 & 69973 & Beijing & Construction and Infrastructure \\
\hline China Railway Construction & 105 & 67414 & Beijing & Construction and Infrastructure \\
\hline China Construction Bank & 108 & 67081 & Beijing & Banking \\
\hline China Life Insurance & 113 & 64635 & Beijing & Insurance \\
\hline Agricultural Bank of China & 127 & 60536 & Beijing & Banking \\
\hline Bank of China & 132 & 59212 & Beijing & Banking \\
\hline Dongfeng Motor & 145 & 55748 & Wuhan & Automobile \\
\hline China State Construction Engineering & 147 & 54721 & Beijing & Construction and Infrastructure \\
\hline China Southern Power Grid & 149 & 54449 & Guangzhou & Electricity Power \\
\hline Shan ghai Automotive & 151 & 54257 & Shan ghai & Automobile \\
\hline China National Offshore Oil & 162 & 52408 & Beijing & Oil and Refinery \\
\hline Sinochem Group & 168 & 49537 & Beijing & Material: Chemical \\
\hline China FAW Group & 197 & 43434 & Changchun & Automobile \\
\hline China Communications Construction & 211 & 40414 & Beijing & Construction and Infrastructure \\
\hline Baosteel Group & 212 & 40327 & Shanghai & Material: Metal \\
\hline CITIC Group & 221 & 38985 & Beijing & Financial \\
\hline China Telecommunications & 222 & 38469 & Beijing & Telecom \\
\hline China South Industries Group & 227 & 37996 & Beijing & Defense \\
\hline China Minmetals & 229 & 37555 & Beijing & Material: Metal \\
\hline China North Industries Group & 250 & 35629 & Beijing & Defense \\
\hline China Huaneng Group & 276 & 33681 & Beijing & Electricity Power \\
\hline HeBei Iron \& Steel Group & 279 & 33549 & Shijiazhuang & Material: Metal \\
\hline People's Insurance Co. of China & 289 & 32579 & Beijing & Insurance \\
\hline Shenhua Group & 293 & 32446 & Beijing & Energy \\
\hline China Metallurgical Group & 297 & 32076 & Beijing & Construction and Infrastructure \\
\hline Aviation Industry Corp. of China & 311 & 31006 & Beijing & Aerospace \\
\hline Shou gan g Group & 326 & 29181 & Beijing & Material: Metal \\
\hline Ping An Insurance & 328 & 28927 & Shenzhen & Insurance \\
\hline Aluminum Corp. of China & 331 & 28871 & Beijing & Material: Metal \\
\hline Wuhan Iron \& Steel & 341 & 28170 & Wuhan & Material: Metal \\
\hline China Post Group & 343 & 28094 & Beijing & Postal \\
\hline Huawei Technologies & 352 & 27356 & Shenzhen & Telecom Equipment \\
\hline Sinosteel & 354 & 27266 & Beijing & Material: Metal \\
\hline $\mathrm{COFCO}$ & 366 & 26469 & Beijing & Agriculture Trading and Processing \\
\hline Jiangsu Shagang Group & 367 & 26388 & Zhangjiagang & Material: Metal \\
\hline China United Network Communications & 371 & 26025 & Shanghai & Telecom \\
\hline China Datang & 375 & 25915 & Beijing & Electricity Power \\
\hline Bank of Communications & 398 & 24264 & Shanghai & Banking \\
\hline China Ocean Shipping & 399 & 24250 & Beijing & Shipping \\
\hline China Guodian & 405 & 24016 & Beijing & Electricity Power \\
\hline China Electronics & 408 & 23761 & Beijing & Electronics \\
\hline China Railway Materials Commercial & 430 & 22631 & Beijing & Material: Railway \\
\hline China National Aviation Fuel Group & 431 & 22630 & Beijing & Oil and Refinery \\
\hline Sinomach & 435 & 22487 & Beijing & Machinery \\
\hline Henan Coal \& Chemical & 446 & 21715 & Zhengzhou & Energy \\
\hline Lenovo Group & 450 & 21594 & Beijing & Computer \\
\hline Jizhong Energy Group & 458 & 21255 & Xingtai & Energy \\
\hline China Shipbuilding Industry & 463 & 21055 & Beijing & Ship Building \\
\hline China Pacific Insurance (Group) & 467 & 20878 & Shan ghai & Insurance \\
\hline ChemChina & 475 & 20715 & Beijing & Material: Chemical \\
\hline Zhejiang Materials Industry Group & 484 & 20001 & Hangzhou & Material: Metal \\
\hline China National Building Material Group & 485 & 19996 & Beijing & Material: Construction \\
\hline
\end{tabular}


Table 3. Descriptive Statistics on Industrial SOEs

Table 3 present the descriptive statistics on SOEs in the industrial sector. The data are from CEIC and National Bureau of Statistics.

\begin{tabular}{|c|c|c|c|c|c|c|c|c|c|c|c|c|}
\hline Year & $\begin{array}{l}\% \text { of } \\
\text { Work } \\
\text { Force }\end{array}$ & $\begin{array}{c}\% \text { of } \\
\text { Net } \\
\text { Output }\end{array}$ & $\begin{array}{l}\% \text { of } \\
\text { Sales } \\
\end{array}$ & $\begin{array}{l}\text { Gross } \\
\text { Profits } \\
\text { (Billion } \\
\text { Yuan) } \\
\end{array}$ & $\begin{array}{c}\text { Total } \\
\text { Losses } \\
\text { (Billion } \\
\text { Yuan) } \\
\end{array}$ & $\begin{array}{c}\text { Gross } \\
\text { Profit to } \\
\text { Assets } \\
(\%)\end{array}$ & $\begin{array}{c}\% \text { of } \\
\text { Loss } \\
\text { Making } \\
\text { SOEs } \\
\end{array}$ & $\begin{array}{c}\text { Debt to } \\
\text { Equity } \\
\text { Ratio } \\
\end{array}$ & $\begin{array}{c}\text { SOE } \\
\text { Layoffs } \\
\text { (Million) }\end{array}$ & $\begin{array}{c}\text { Total } \\
\text { Nu mber } \\
\text { of SOEs }\end{array}$ & $\begin{array}{c}\text { Average } \\
\text { Assets } \\
\text { (Million } \\
\text { Yuan) } \\
\end{array}$ & $\begin{array}{l}\text { Profits } \\
\text { to Sales } \\
(\%) \\
\end{array}$ \\
\hline 1978 & 72.1 & & & 51 & 4.2 & 15.5 & & & & & & \\
\hline 1979 & 70.7 & & & 56 & 3.6 & 16.1 & & & & & & \\
\hline 1980 & 70.0 & 81.5 & 80.9 & 59 & 3.4 & 16.0 & & & & & & 16.3 \\
\hline 1981 & 70.0 & 78.9 & & 58 & 4.6 & 15.0 & & & & 62065 & 6 & \\
\hline 1982 & 70.0 & 78.3 & & 60 & 4.8 & 14.4 & & & & 63063 & 7 & \\
\hline 1983 & 69.8 & & & 64 & 3.2 & 14.4 & & & & & & \\
\hline 1984 & 68.7 & 77.3 & & 71 & 2.7 & 14.9 & & & & & & \\
\hline 1985 & 68.7 & 74.5 & 73.0 & 74 & 3.2 & 13.2 & 9.6 & & & 70342 & 8 & 12.6 \\
\hline 1986 & 68.4 & 73.1 & 72.8 & 69 & 5.4 & 10.6 & 13.1 & & & 70511 & 9 & 10.4 \\
\hline 1987 & 68.4 & 72.5 & 71.5 & 79 & 6.1 & 10.6 & 13.0 & & & 72803 & 10 & 10.0 \\
\hline 1988 & 68.7 & 71.2 & 69.2 & 89 & 8.2 & 10.4 & 10.9 & & & 72494 & 12 & 9.1 \\
\hline 1989 & 68.6 & 70.6 & 69.1 & 74 & 18.0 & 7.2 & 16.0 & & & 73501 & 14 & 6.7 \\
\hline 1990 & 68.4 & 70.1 & 68.8 & 39 & 34.9 & 3.2 & 27.6 & & & 74775 & 16 & 3.3 \\
\hline 1991 & 68.3 & 67.9 & 66.7 & 40 & 36.7 & 2.9 & 25.8 & & & 75248 & 19 & 2.9 \\
\hline 1992 & 68.3 & 65.0 & 63.6 & 54 & 36.9 & 3.3 & 23.4 & & & 74066 & 22 & 3.2 \\
\hline 1993 & 67.9 & 56.7 & 58.7 & 82 & 45.3 & 2.5 & 28.8 & 2.07 & & 80586 & 40 & 3.6 \\
\hline 1994 & 66.4 & 53.8 & 51.7 & 83 & 48.3 & 2.2 & 30.9 & 2.11 & & 79731 & 48 & 3.8 \\
\hline 1995 & 66.5 & 53.8 & 48.8 & 67 & 64.0 & 1.4 & & 1.92 & & 87905 & 54 & 2.5 \\
\hline 1996 & 66.3 & 48.5 & 46.3 & 41 & 79.1 & 0.8 & 33.6 & 1.87 & & 86982 & 61 & 1.5 \\
\hline 1997 & 65.0 & 46.4 & 43.5 & 43 & 83.1 & 0.7 & 38.2 & 1.89 & & 74388 & 79 & 1.5 \\
\hline 1998 & 57.3 & 57.0 & 51.8 & 53 & 115.1 & 0.7 & 40.6 & 1.80 & 5.9 & 64737 & 116 & 1.6 \\
\hline 1999 & 54.5 & 56.3 & 50.9 & 100 & 96.7 & 1.2 & 39.2 & 1.63 & 6.5 & 61301 & 131 & 2.8 \\
\hline 2000 & 51.1 & 54.3 & 49.6 & 241 & 70.4 & 2.9 & 34.1 & 1.57 & 6.6 & 53489 & 157 & 5.7 \\
\hline 2001 & 21.5 & 51.7 & 46.9 & 239 & 75.2 & 2.7 & 36.0 & 1.46 & 5.2 & 46767 & 188 & 5.4 \\
\hline 2002 & 41.5 & 48.3 & 43.1 & 263 & 66.9 & 3.0 & 36.1 & 1.46 & 4.1 & 41125 & 217 & 5.5 \\
\hline 2003 & 36.3 & 44.9 & 40.0 & 384 & 68.0 & 4.1 & 35.2 & 1.46 & 2.6 & 34280 & 276 & 6.6 \\
\hline 2004 & 32.2 & 42.4 & 35.4 & 545 & 83.7 & 5.0 & 37.4 & 1.31 & 1.5 & 35597 & 308 & 7.6 \\
\hline 2005 & 26.8 & 37.7 & 34.0 & 652 & 107.2 & 5.5 & 35.5 & 1.32 & 0.6 & 27477 & 428 & 7.6 \\
\hline 2006 & 24.1 & 35.8 & 31.9 & 849 & 117.6 & 6.3 & 31.9 & 1.30 & & 24961 & 541 & 8.4 \\
\hline 2007 & 22.2 & 34.2 & 30.2 & 1080 & 89.1 & 6.8 & 25.8 & 1.30 & & 20680 & 765 & 8.8 \\
\hline 2008 & & & 29.1 & 906 & 343.5 & 4.8 & 27.4 & 1.44 & & 21313 & 886 & 6.1 \\
\hline
\end{tabular}


Table 4. Taxes and Subsidies for Industrial Enterprises

Table 4 reports the value added taxes payable and other business taxes and charges, value added, profit, and subsidy of industrial SOE and SHEs and other industrial enterprises. The data are from China Finance Yearbook and CEIC.

\begin{tabular}{|c|c|c|c|c|c|c|c|c|c|c|c|}
\hline Year & $\begin{array}{c}\text { GDP } \\
\text { (Billion } \\
\text { RMB) }\end{array}$ & $\begin{array}{c}\text { Taxes } \\
\text { from } \\
\text { SOEs } \\
(\%)\end{array}$ & $\begin{array}{c}\text { Value- } \\
\text { Added } \\
\text { from } \\
\text { SOEs } \\
(\%)\end{array}$ & $\begin{array}{c}\text { Profits } \\
\text { from } \\
\text { SOEs } \\
(\%)\end{array}$ & $\begin{array}{c}\text { SOE } \\
\text { Taxes } \\
\text { (Billion } \\
\text { Yuan) }\end{array}$ & $\begin{array}{c}\text { SOE } \\
\text { Value } \\
\text { Added } \\
\text { (Billion } \\
\text { Yuan) }\end{array}$ & $\begin{array}{c}\text { SOE } \\
\text { Profits } \\
\text { (Billion } \\
\text { Yuan) }\end{array}$ & $\begin{array}{c}\text { Subsidy } \\
\text { to SOEs } \\
\text { (billion } \\
\text { RMB) }\end{array}$ & $\begin{array}{c}\text { Subsidy } \\
\text { to SOEs } \\
\text { / GDP } \\
(\%)\end{array}$ & $\begin{array}{l}\text { SOE Pro fit } \\
\text { / Gov't } \\
\text { Revenue } \\
(\%)\end{array}$ & $\begin{array}{c}\text { SOE Taxes } \\
\text { / Gov't } \\
\text { Revenue } \\
(\%)\end{array}$ \\
\hline & (1) & (2) & (3) & (4) & (7) & (8) & (9) & (5) & (6) & (10) & (11) \\
\hline 1978 & 365 & 89.0 & & 84.9 & 28 & & 51 & & & 44.9 & 24.9 \\
\hline 1979 & 406 & 88.8 & & 86.0 & 30 & & 56 & & & 49.1 & 26.3 \\
\hline 1980 & 455 & 87.7 & 81.5 & 84.6 & 32 & 130 & 59 & & & 50.5 & 27.7 \\
\hline 1981 & 489 & 86.2 & 78.9 & 85.0 & 34 & 132 & 58 & & & 49.3 & 29.2 \\
\hline 1982 & 532 & 85.6 & 78.3 & 84.9 & 37 & 137 & 60 & & & 49.3 & 30.9 \\
\hline 1983 & 596 & 84.5 & & 83.0 & 39 & & 64 & & & 46.9 & 28.7 \\
\hline 1984 & 721 & 83.6 & 77.3 & 82.8 & 45 & 173 & 71 & & & 43.0 & 27.2 \\
\hline 1985 & 902 & 81.9 & 74.5 & 79.4 & 60 & 204 & 74 & -51 & -5.62 & 36.8 & 29.7 \\
\hline 1986 & 1028 & 82.7 & 73.1 & 78.6 & 65 & 218 & 69 & -32 & -3.16 & 32.5 & 30.7 \\
\hline 1987 & 1206 & 81.8 & 72.5 & 78.3 & 73 & 253 & 79 & -38 & -3.12 & 35.8 & 33.1 \\
\hline 1988 & 1504 & 80.4 & 71.2 & 75.0 & 88 & 306 & 89 & -45 & -2.97 & 37.8 & 37.5 \\
\hline 1989 & 1699 & 80.8 & 70.6 & 74.3 & 103 & 346 & 74 & -60 & -3.52 & 27.9 & 38.7 \\
\hline 1990 & 1867 & 80.4 & 70.1 & 69.3 & 111 & 357 & 39 & -58 & -3.10 & 13.2 & 38.0 \\
\hline 1991 & 2178 & 79.2 & 67.9 & 62.6 & 126 & 402 & 40 & -51 & -2.34 & 12.8 & 40.0 \\
\hline 1992 & 2692 & 77.1 & 65.0 & 55.0 & 141 & 484 & 54 & -44 & -1.65 & 15.4 & 40.4 \\
\hline 1993 & 3533 & 70.5 & 56.7 & 51.0 & 164 & 728 & 82 & -41 & -1.16 & 18.8 & 37.7 \\
\hline 1994 & 4820 & 65.2 & 53.8 & 46.1 & 205 & 790 & 83 & -37 & -0.76 & 15.9 & 39.2 \\
\hline 1995 & 6079 & 64.7 & 53.8 & 40.7 & 221 & 831 & 67 & -33 & -0.54 & 10.7 & 35.4 \\
\hline 1996 & 7118 & 63.6 & 48.5 & 27.7 & 232 & 874 & 41 & -34 & -0.47 & 5.6 & 31.4 \\
\hline 1997 & 7897 & 61.4 & 46.4 & 25.1 & 248 & 919 & 43 & -37 & -0.47 & 4.9 & 28.7 \\
\hline 1998 & 8440 & 70.0 & 57.0 & 36.0 & 285 & 1108 & 53 & -33 & -0.40 & 5.3 & 28.8 \\
\hline 1999 & 8968 & 69.8 & 56.3 & 43.6 & 308 & 1213 & 100 & -29 & -0.32 & 8.7 & 26.9 \\
\hline 2000 & 9921 & 67.8 & 54.3 & 54.8 & 347 & 1378 & 241 & -28 & -0.28 & 18.0 & 25.9 \\
\hline 2001 & 10966 & 65.7 & 51.7 & 50.5 & 366 & 1465 & 239 & -30 & -0.27 & 14.6 & 22.3 \\
\hline 2002 & 12033 & 63.8 & 48.3 & 45.5 & 398 & 1594 & 263 & -26 & -0.22 & 13.9 & 21.1 \\
\hline 2003 & 13582 & 61.2 & 44.9 & 46.0 & 462 & 1884 & 384 & -23 & -0.17 & 17.7 & 21.3 \\
\hline 2004 & 15988 & 31.3 & 42.4 & 45.7 & 299 & 2321 & 545 & -22 & -0.14 & 20.7 & 11.3 \\
\hline 2005 & 18494 & 54.0 & 37.7 & 44.0 & 622 & 2718 & 652 & -19 & -0.10 & 20.6 & 19.7 \\
\hline 2006 & 21631 & 52.2 & 35.8 & 43.5 & 754 & 3259 & 849 & -18 & -0.08 & 21.9 & 19.5 \\
\hline 2007 & 26581 & 49.9 & 34.2 & 39.8 & 919 & 3997 & 1080 & -28 & -0.10 & 21.0 & 17.9 \\
\hline 2008 & 31405 & 44.4 & & 29.7 & 1065 & & 906 & -16 & -0.05 & 14.8 & 17.4 \\
\hline
\end{tabular}




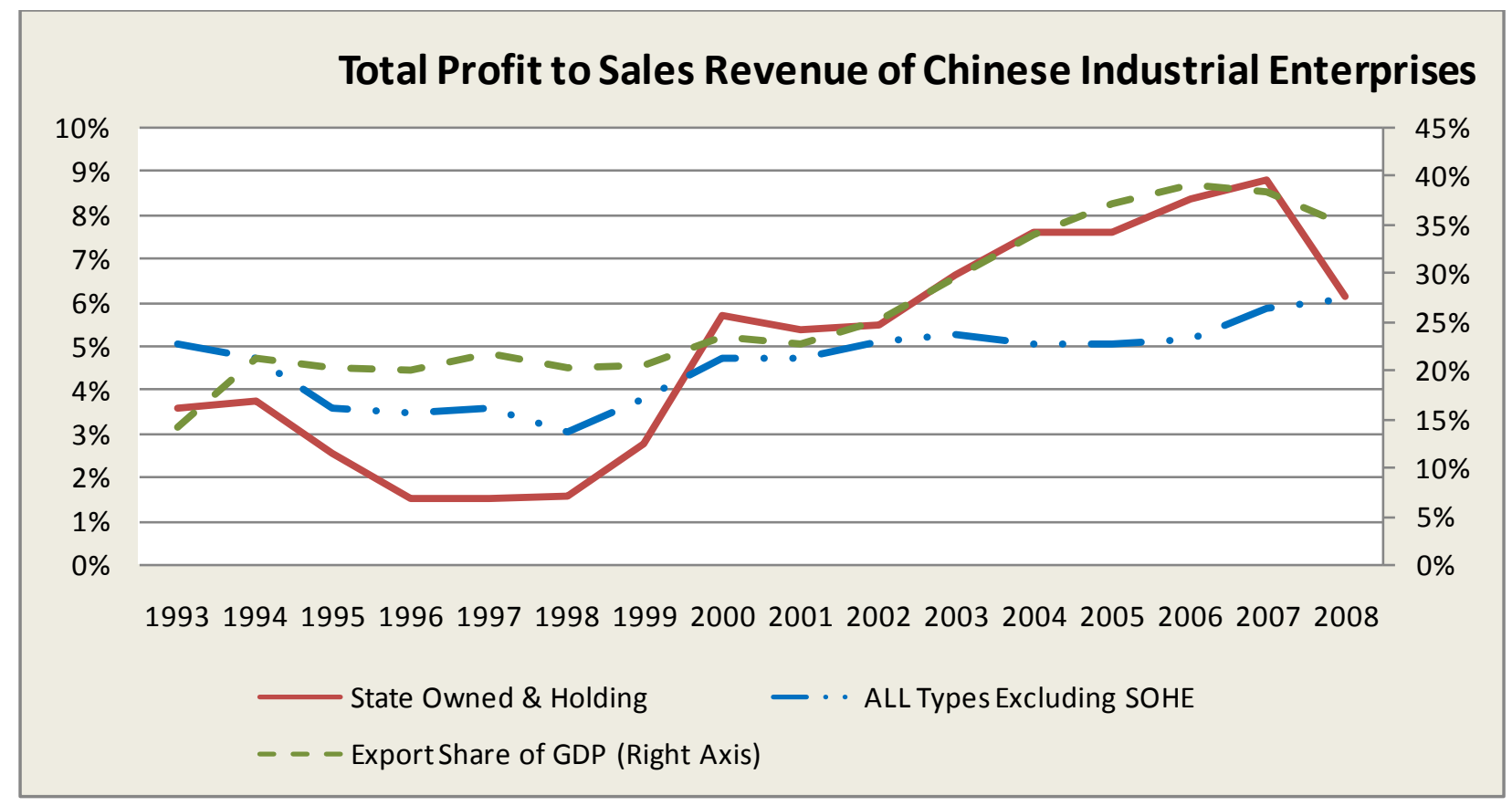

Figure 1: Total profit to sales revenues of Chinese enterprises in the industrial sector. We use CEIC (Table CN.BF: Industrial Financial Data: By Enterprise Type) to obtain Total profit to Sales Revenue. In this table, CEIC categorizes industrial enterprises into: state owned \& holding, priv ate, HMT \& foreign, collective owned, shareholding corporations, foreign funded, and Hong Kong, Macau \& Taiwan funded. We divide all the industrial enterprises into state owned \& holding and the rest. The right axis shows the ratio of export to GDP, also obtained fro $\mathrm{m}$ CEIC. 


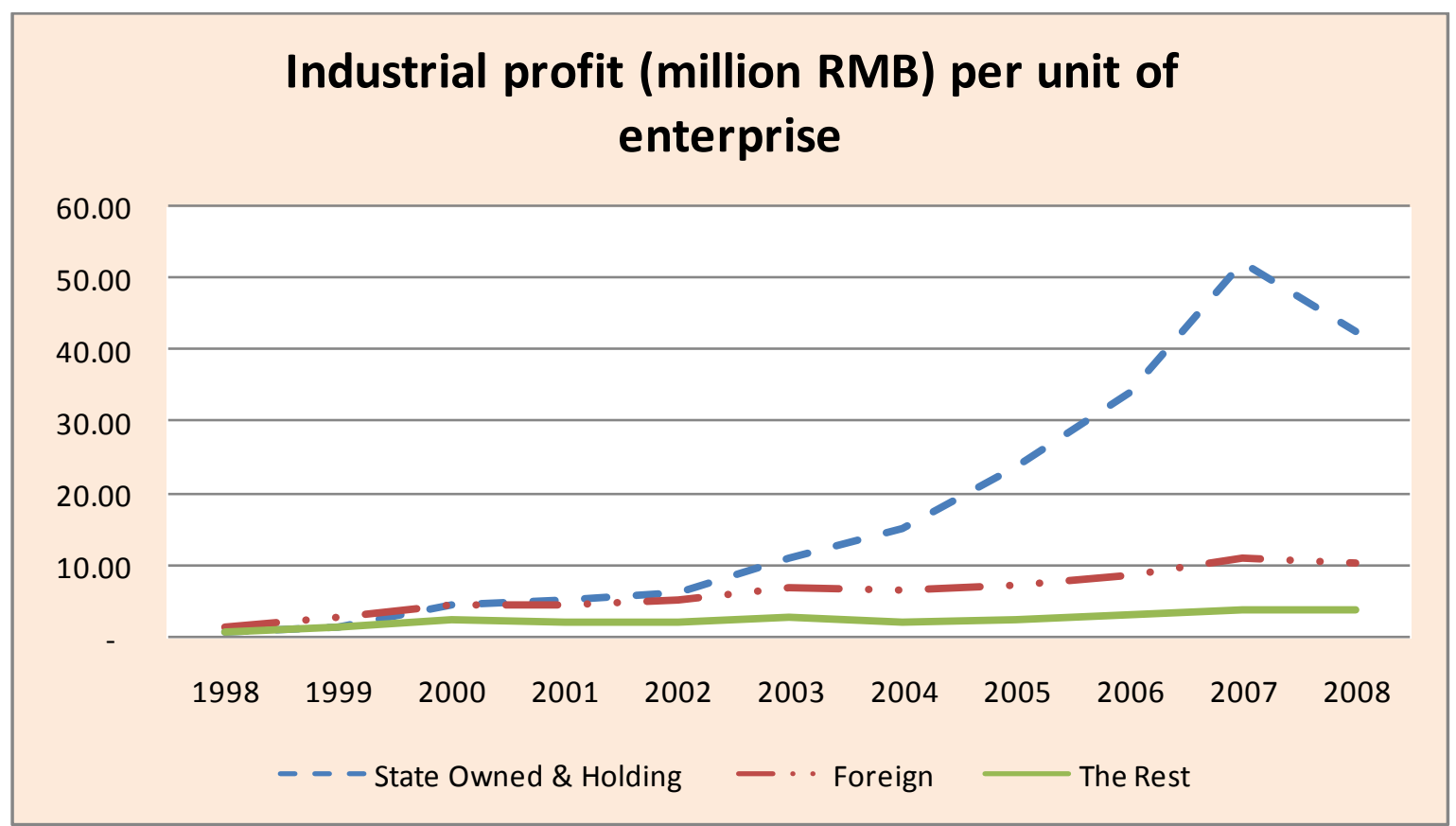

Figure 2a: Average profit per industrial enterprise for 1998-2008

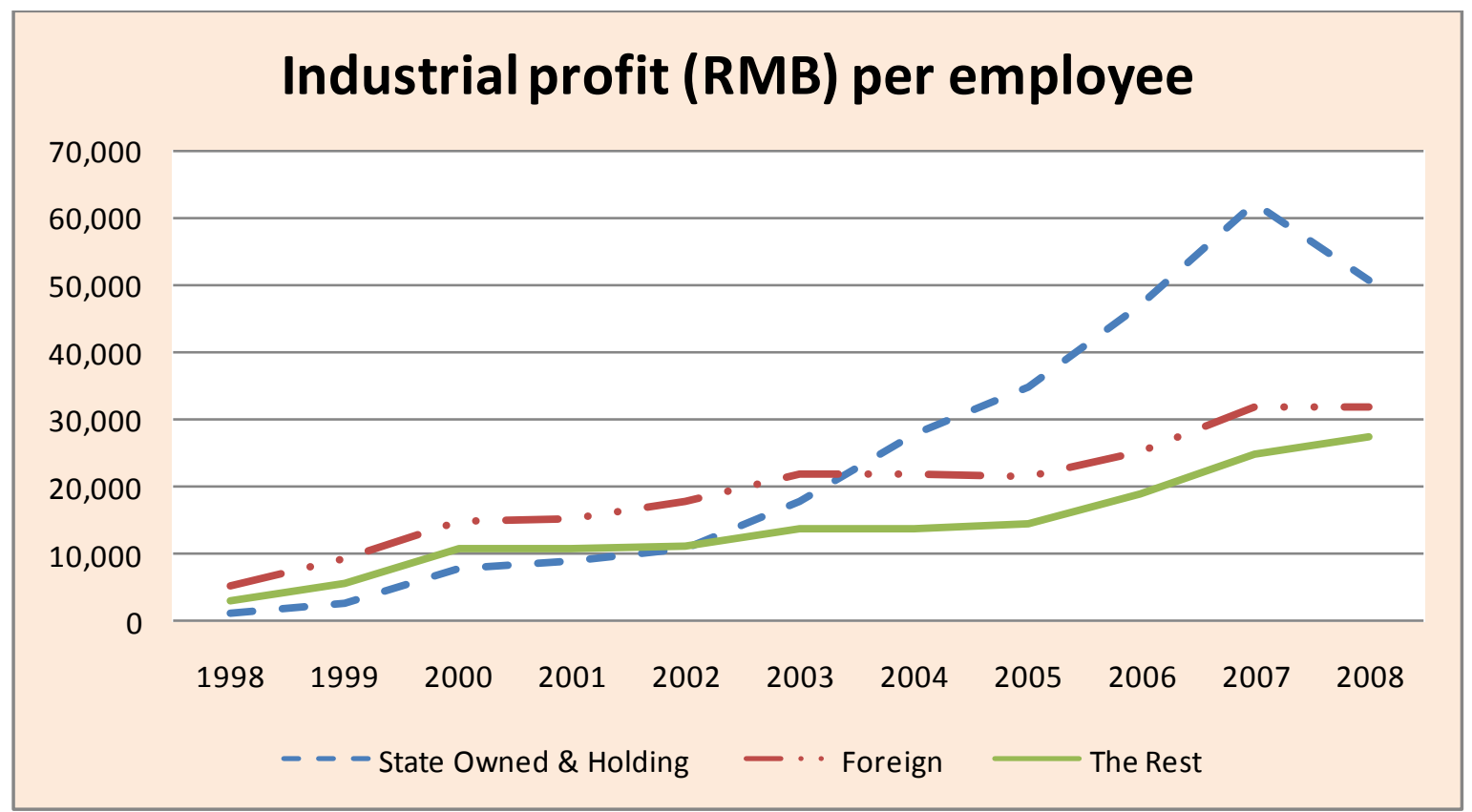

Figure 2b: Average profit per employee for 1998-2008

Figure 2: Industrial profit by enterprises of different owne rship structure for the industrial sector. Figure $2 \mathrm{a}$ and $2 \mathrm{~b}$ reports respectively the total profit of industrial enterprises divided by the number of enterprises and the number of employees. It reports separately for three types of enterprises according to ownership structure. The data are from CEIC. 


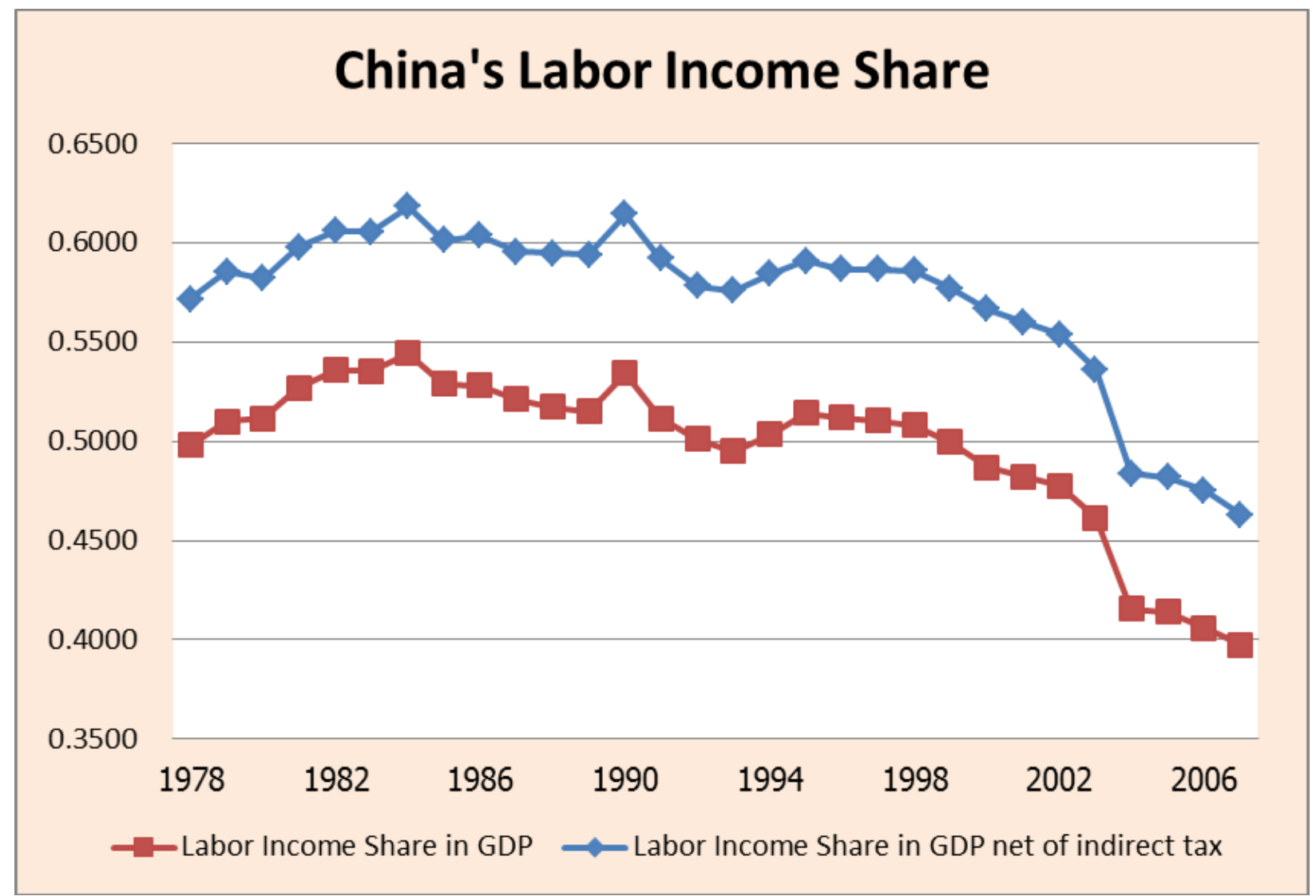

Figure 3: The shares of labor compensation in national income under different Definitions. We use the data from Bai and Qian (2010) to reproduce their Figure 2 here. 


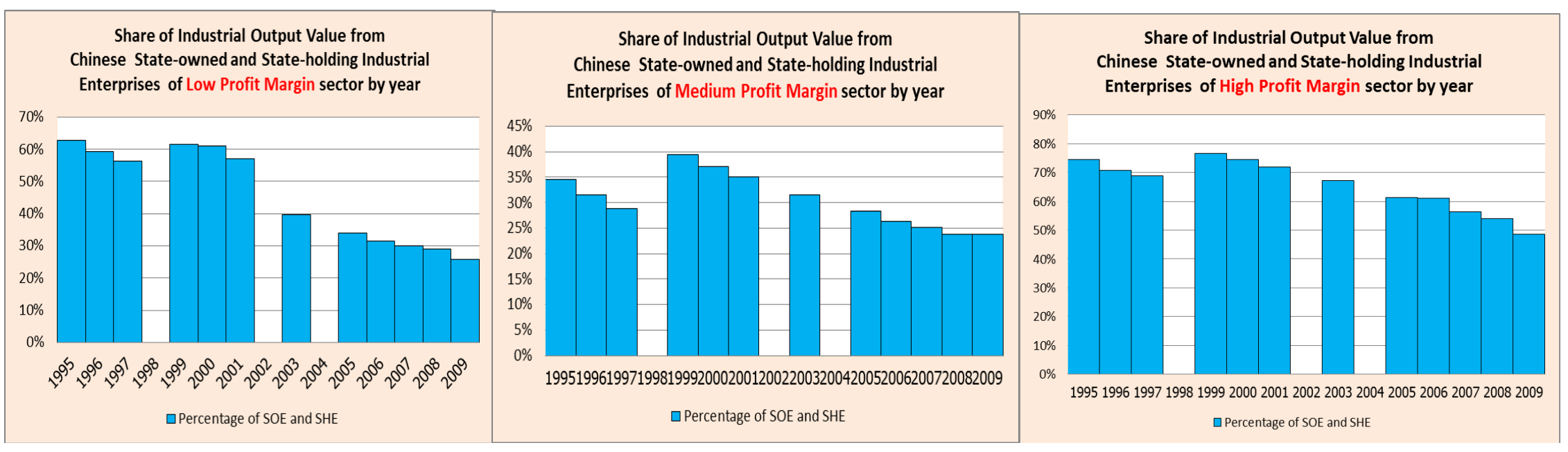

Figure 4: Share of industrial output value from state enterprises in the industrial sector. The criteria that we use to breakdown the share of the state enterprises' gross industrial output value (GIOV) is a measure of profit margin, ratio of profit to industrial cost (\%) from 1995-2008. Profits and costs data are from CEIC (Table CN.OE03 and 04). The low profit margin subsectors are those with less than or equal to 5\% profit margin, which include subsectors such as textiles and agriculture. The median profit subsectors are those with profit margin of 5\% - 10\%, which include subsectors such as mining and food. The high profit subsectors are those with greater than $10 \%$ profit margin, which include subsectors such as petrochemical, tobacco, and pharmaceuticals. The vertical axis is GIOV of the state enterprises as a percentage of total GIOV. GIOV of all enterprises is from CEIC (Table CN.BD03: Gross Industrial Output: By Industry). GIOV of the state enterprises is from National Bureau of Statistics (NBS) Yearbook because CEIC does not have this data. Also, GIOV of the state enterprises is missing from NBS yearbook for year 1998, 2002, and 2004. Note also that in the table "Main Indicators by Industrial Se ctor of State portion", NBS has changed the definition of the state enterprises back and forth. NBS uses "state-owned industrial enterprises" in 1995-1997; "state-owned and state holding industrial enterprises" in 1999-2003 and 2005-2008. 


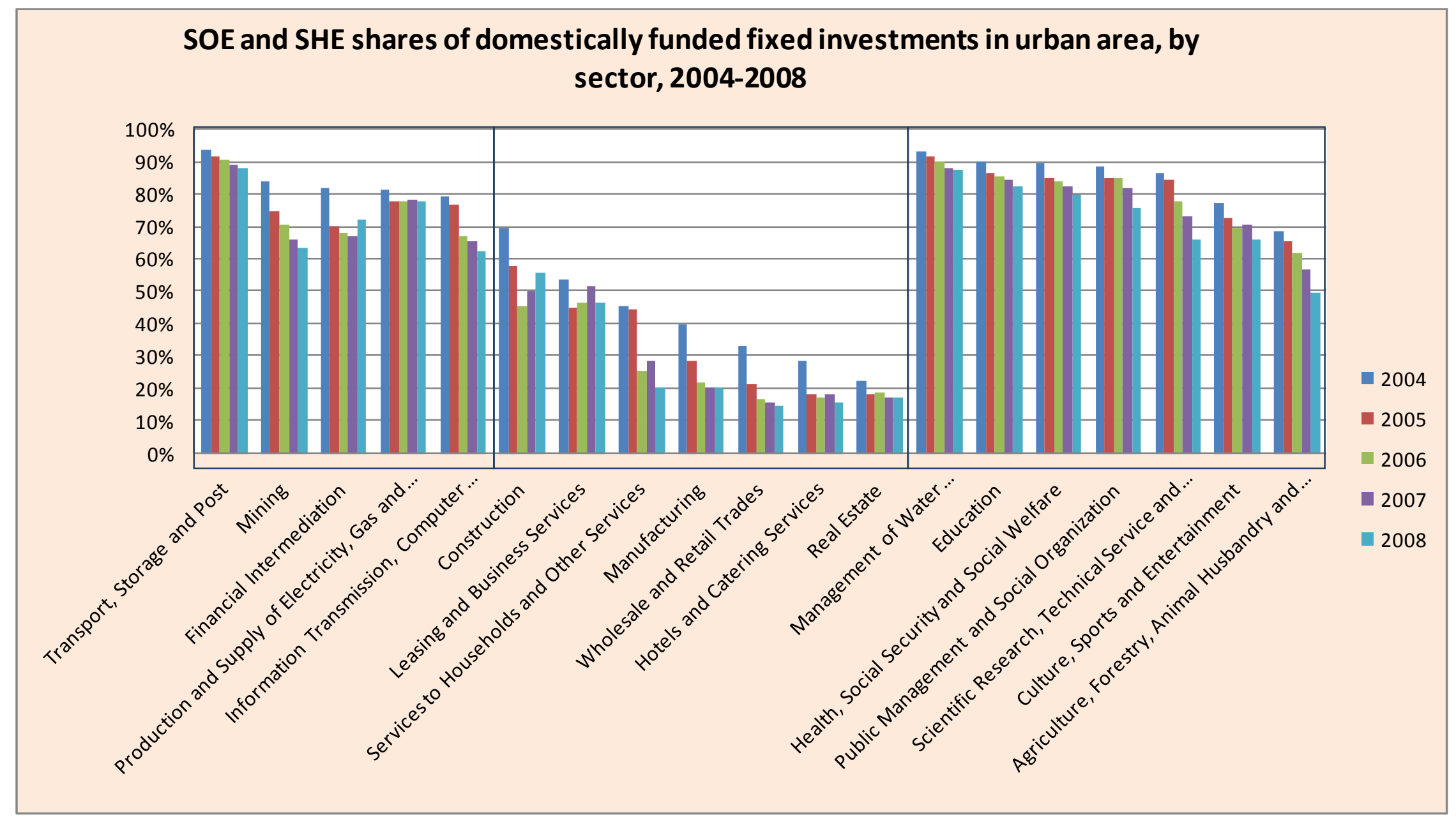

Figure 5: Investments in fixed assets in urban a rea by ownership for all sectors. The data are from the following tables of National Bureau of Statistics (NBS) of China: Investment in Urban Area by Sector, Source of Funds, Jurisdiction of Management and Reg istration Status. Note that NBS has changed the column title of state related ownership over time. NBS uses "state-owned and state-controlled" in Table 6-14 of 2004;"state-owned and stateholding" in Table 6-14 of 2005; "state-holding" in Table 6-14 of 2006; and "state-holding" in Table 5-14 of 2007-2008. Before Year 2004, data for the state enterprises is not available. 


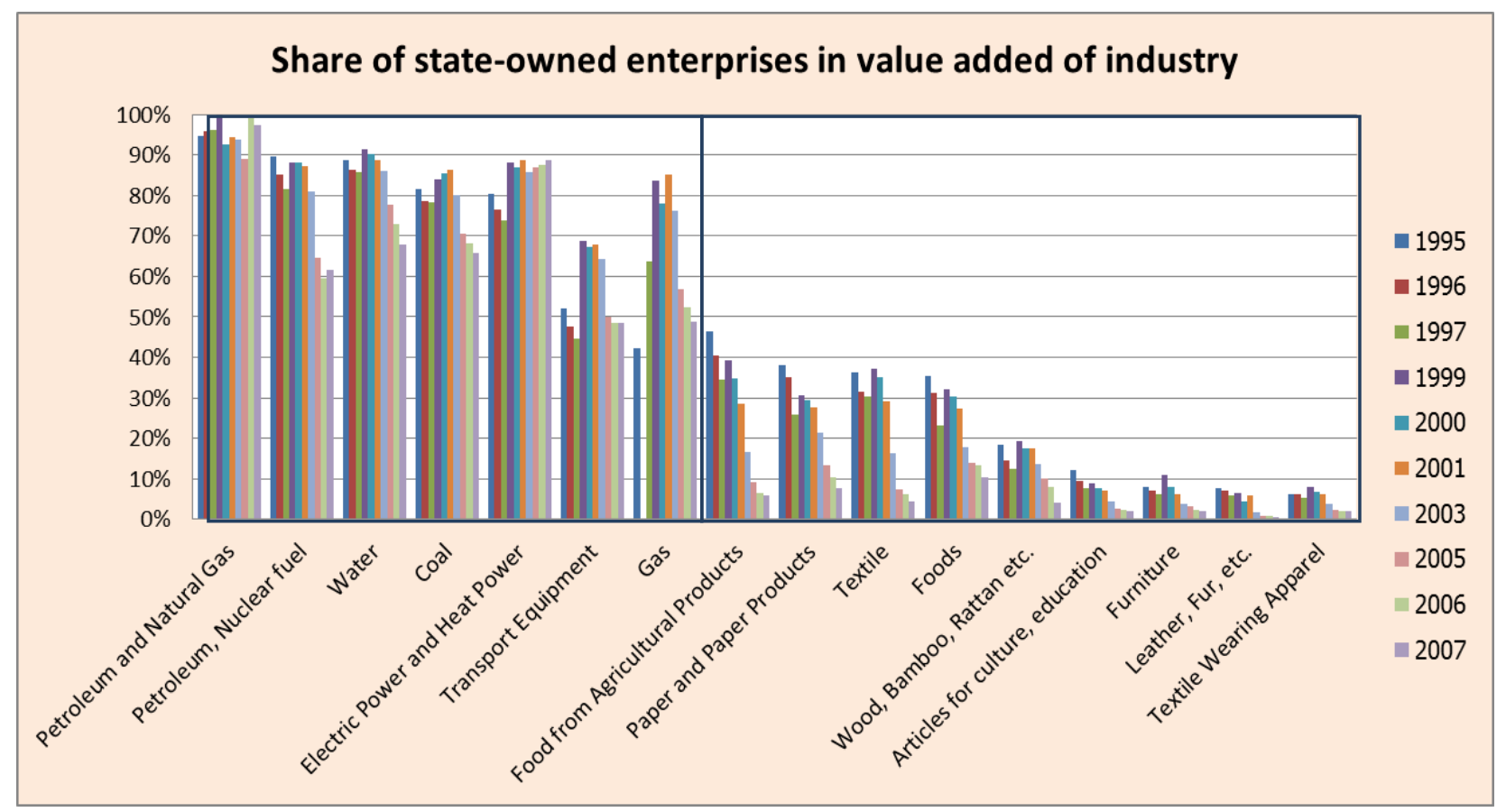

Figure 6a: Share of state ente rprises in indus trial value-added.

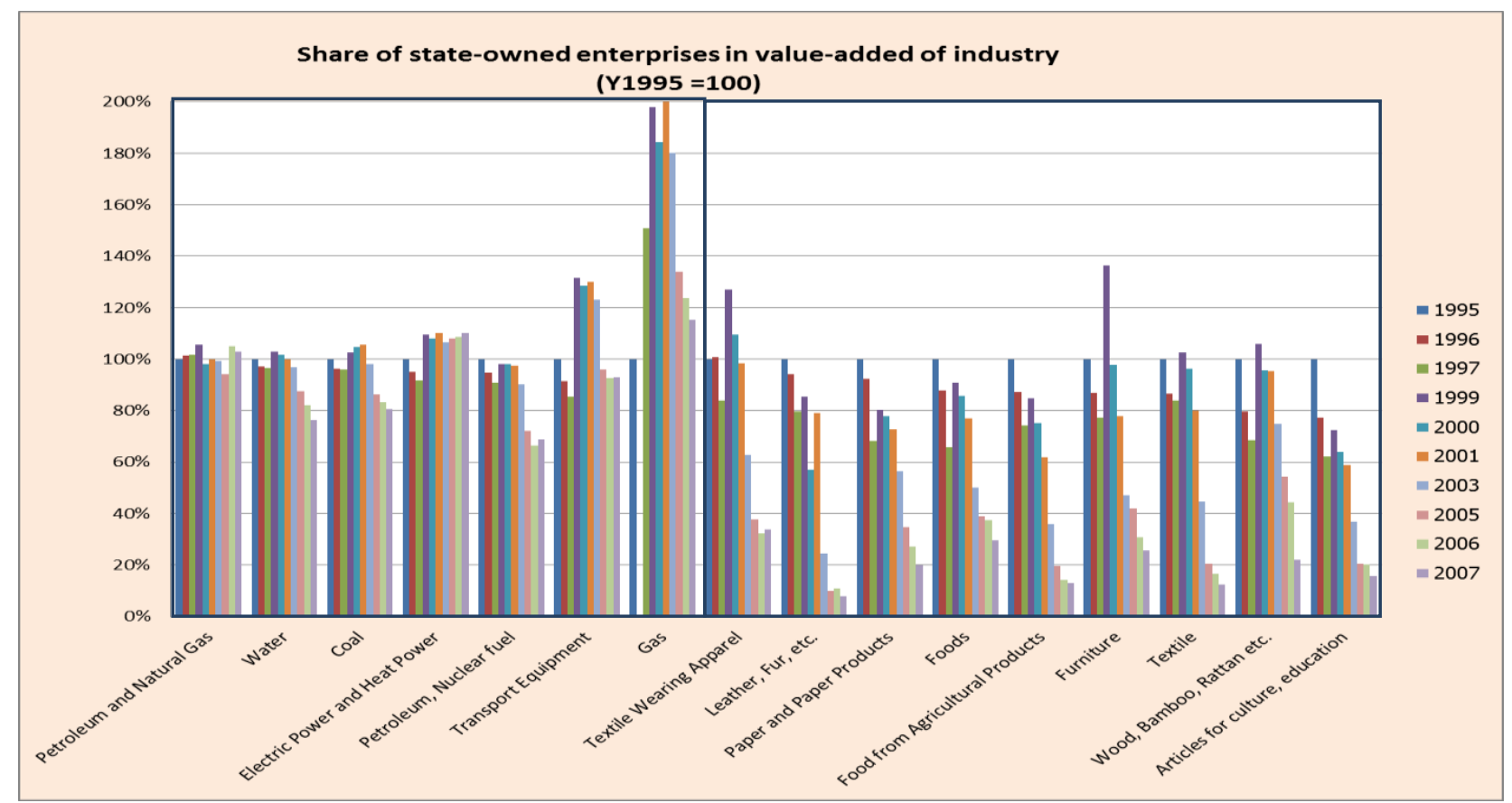

Figure 6b: Share of state enterprises in value-added as a percentage of its 1995 value.

Figure 6: Share of state enterprises in industrial value added of the industrial sector. The data are from National Bureau of Statistics (NBS) of China, Table 14-2, and Table 14-6. Note that NBS has changed the title of state related enterprises over time. NBS uses "state-owned industrial enterprises" in 1995-1997; "state-owned and state-holding" in 1999-2003 and 2005-2007. The data are missing in 1998, 2002, and 2004. 